\title{
JCS/JHFS 2021 Guideline Focused Update on Diagnosis and Treatment of Acute and Chronic Heart Failure
}

\author{
Hiroyuki Tsutsui; Tomomi Ide; Hiroshi Ito; Yasuki Kihara; Koichiro Kinugawa; \\ Shintaro Kinugawa; Miyuki Makaya; Toyoaki Murohara; Koichi Node; Yoshihiko Saito; \\ Yasushi Sakata; Wataru Shimizu; Kazuhiro Yamamoto; Yasuko Bando; Yu-ki Iwasaki; \\ Yoshiharu Kinugasa; Isamu Mizote; Hitoshi Nakagawa; Shogo Oishi; Akiko Okada; \\ Atsushi Tanaka; Takashi Akasaka; Minoru Ono; Takeshi Kimura; Shun Kosaka; \\ Masami Kosuge; Shin-ichi Momomura on behalf of the Japanese Circulation Society and \\ the Japanese Heart Failure Society Joint Working Group
}

\section{Table of Contents}

\section{Preamble}

I. Definition and Classification.

1. Definition of Heart Failure

2. Classification of Heart Failure by LVEF on

Examination.....

3. Classification of Heart Failure Based on

Time-Dependent Changes in LVEF ...

II. Basic Principles for the Treatment of Heart

Failure

1. Treatment Algorithms for Heart Failure

III. Pharmacologic Therapy .

1. If Channel Blocker or HCN Channel Blocker; Ivabradine.

2. ARNI: Sacubitril/Valsartan

3. SGLT2 Inhibitors

4. Newer Drugs...

5. Therapeutic Drugs for HFrEF

IV. Nonpharmacologic Therapy

1. Percutaneous Mitral Valve Repair System (MitraClip ${ }^{\circledR}$ )...

2. Transcatheter Aortic Valve Implantation

v. Comorbidities

1. Atrial Fibrillation
2253

2255

2255 2256 2257 2258 2259 2259 2259 2262 2263 2267 2268 2268 . 2269 2270 2270
2. Diabetes Mellitus

2273

VI. Surgical Treatment 2274

1. Mechanical Circulatory Support 2274

2. Catheter-Based Transaortic Microaxial Pumps

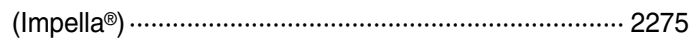

VII. Disease Management ……................................... 2275

1. Certified Heart Failure Educator ……............................. 2275

2. Disease Management Program ………………............. 2276

VIII. Palliative Care …………………........................... 2277

1. Symptoms and Treatment of End-Stage Heart Failure …............................................................ 2277

2. Additional Medical Fee for Palliative Care .................... 2277

3. Quality Evaluation Index of Palliative Care ................. 2278

4. Provision of Palliative Care for Heart Failure and Educational System …............................................ 2279

IX. Complementary Therapy …………………........ 2279

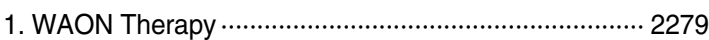

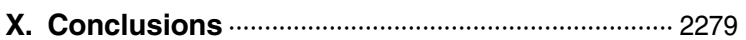

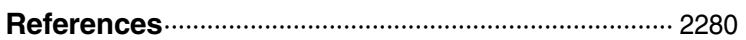

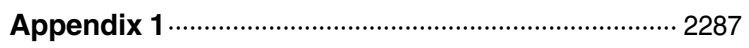

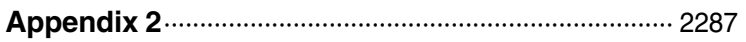

J-STAGE Advance Publication released online September 29, 2021

This document is an English version of the JCS/JHFS 2021 Guideline Focused Update on Diagnosis and Treatment of Acute and Chronic Heart Failure reported at the Japanese Circulation Society Joint Working Group published in 2021 (https://www.j-circ. or.jp/cms/wp-content/uploads/2021/03/JCS2021_Tsutsui.pdf).

Refer to Appendix 1 for the details of members.

Joint Working Groups: The Japanese Circulation Society; the Japanese Heart Failure Society; the Japanese Association for Thoracic Surgery; the Japanese Society of Hypertension; Japanese Society of Echocardiography; the Japanese Society for Cardiovascular Surgery; Japanese College of Cardiology; the Japanese Association of Cardiac Rehabilitation; the Japan Society of Ultrasonics in Medicine; the Japan Diabetes Society; Japanese Heart Rhythm Society; "the Study Group on Idiopathic Cardiomyopathy" supported by the Health and Labor Sciences Research Grant on Intractable Diseases; and "the Study Group on the Multi-center Observational Study of Dilated- phase Hypertrophic Cardiomyopathy", supported by the "Practical Research Project for Rare/ intractable Diseases by the Japan Agency for Medical Research and Development.

Mailing address: Guideline Committee of the Japanese Circulation Society, 6th Floor, Uchikanda Central Building, 1-18-13 Uchikanda, Chiyoda-ku, Tokyo 101-0047, Japan. E-mail: jcsGL@j-circ.or.jp

All rights are reserved to the Japanese Circulation Society. For permissions, please e-mail: cj@j-circ.or.jp

ISSN-1346-9843 


\section{Abbreviations}

\begin{tabular}{|l|l|}
\hline ACCF & American College of Cardiology Foundation \\
\hline ACE & angiotensin converting enzyme \\
\hline ADL & activities of daily livings \\
\hline AHA & American Heart Association \\
\hline AMPK & $\begin{array}{l}\text { adenosine monophosphate-activated protein } \\
\text { kinase }\end{array}$ \\
\hline ARB & angiotensin II receptor blocker \\
\hline ARNI & angiotensin receptor neprilysin inhibitor \\
\hline AS & aortic (valve) stenosis \\
\hline cGMP & cyclic guanosine monophosphate \\
\hline Cl & confidence interval \\
\hline CRT & cardiac resynchronization therapy \\
\hline CVOT & cardiovascular outcome trial \\
\hline DOAC & direct oral anticoagulant \\
\hline FDA U.S. & Food and Drug Administration \\
\hline GDMT & guideline-directed medical therapy \\
\hline HFmrEF & heart failure with mid-range ejection fraction \\
\hline HFpEF & heart failure with preserved ejection fraction \\
\hline HFrEF & heart failure with reduced ejection fraction \\
\hline HFrecEF & heart failure with recovered ejection fraction \\
\hline HFuncEF & heart failure with unchanged ejection fraction \\
\hline
\end{tabular}

\begin{tabular}{|l|l|}
\hline HFworEF & heart failure with worsened ejection fraction \\
\hline HR & hazard ratio \\
\hline IABP & intra-aortic balloon pump \\
\hline ICD & implantable cardioverter defibrillator \\
\hline LVAD & left ventricular assist device \\
\hline LVEF & left ventricular ejection fraction \\
\hline MRA & mineralocorticoid receptor antagonist \\
\hline NEP & neutral endopeptidase \\
\hline NT-proBNP & N-terminal pro-brain natriuretic peptide \\
\hline NYHA & New York Heart Association \\
\hline PDE & phosphodiesterase \\
\hline PT-INR & prothrombin time -international normalized ratio \\
\hline RCT & randomized controlled trial \\
\hline SAVR & surgical aortic valve replacement \\
\hline SGC & soluble guanylate cyclase \\
\hline SGLT2 & Sodium glucose cotransporter 2 \\
\hline T2DM & type 2 diabetes mellitus \\
\hline TAVI & transcatheter aortic valve implantation \\
\hline TAVR & transcatheter aortic valve replacement \\
\hline VAD & ventricular assist device \\
\hline
\end{tabular}

\section{Preamble}

In March 2018, the Japanese Circulation Society (JCS)/ Japanese Heart Failure Society (JHFS) jointly published the 2017 Guideline on Diagnosis and Treatment of Acute and Chronic Heart Failure. In this revised edition, a research group comprised of members recommended by 11 academic societies, including the JCS, JHFS, Japanese Association for Thoracic Surgery, Japanese Society of Hypertension, Japanese Society of Echocardiography, Japanese Society for Cardiovascular Surgery, Japanese College of Cardiology, Japanese Association of Cardiac Rehabilitation, Japan Society of Ultrasonics in Medicine, Japan Diabetes Society, and Japanese Heart Rhythm Society (JHRS), was organized. In addition, 2 study groups participated in this revision, the "Survey and research on idiopathic myopathy" of the Research Program on Rare and Intractable Diseases, Ministry of Health, Labour and Welfare, and "A Multicenter Registered Observational Study on the Dilated Phase of Hypertrophic Cardiomyopathy" of the Japan Agency for Medical Research and Development Practical Research Project for Rare/Intractable Diseases. Taking the latest guidelines of Western countries into considerations, we published the revised edition as the guidelines presenting standard treatment of acute and chronic heart failure by incorporating evidence and actual clinical experience in Japan.

The major change in this revised edition is the integration of the previous heart failure treatment guidelines, which were separated into acute heart failure and chronic heart failure. This change was based on the recognition that separate treatment guidelines into acute and chronic sections is not realistic because many patients with acute heart failure are acute exacerbation of chronic heart failure and the seamless management from the acute to chronic phase is necessary.

The main points of the 2017 revised edition are as follows:

1) The definition of heart failure was clarified and a definition easy to understand for the general public was newly described.

2) Heart failure, stage with progression of the risk, and treatment target were newly described.

3) Heart failure was classified based on the left ventricular ejection fraction (LVEF).

4) The heart failure diagnosis algorithm was newly presented.

5) Management concerning prevention of heart failure was newly added.

6) The heart failure treatment algorithm was newly presented.

7) The descriptions of the clinical state and treatment of comorbidities were expanded.

8) The flow chart of acute heart failure treatment based on the time course and clinical state was newly presented.

9) The treatment algorithm of severe heart failure with a ventricular assist device (VAD) was newly presented.

10) The description of palliative care was expanded.

After the publication of the revised edition, therapeutic drugs described in "Future Treatment" were approved and important evidence for pharmacologic therapy and nonpharmacologic therapy has been reported. These changes are related directly to routine clinical practice for heart failure and the contents were important and should 


\begin{tabular}{|c|l|}
\hline \multicolumn{2}{|c|}{ Table 1. Classes of Recommendation } \\
\hline Class I & $\begin{array}{l}\text { There is evidence and/or general agreement that a } \\
\text { given procedure or treatment is effective and/or useful }\end{array}$ \\
\hline Class Ila & $\begin{array}{l}\text { There is a high probability of efficacy/usefulness } \\
\text { based on evidence and opinion }\end{array}$ \\
\hline Class IIb & $\begin{array}{l}\text { Effectiveness/usefulness is not well-established } \\
\text { based on evidence and opinion }\end{array}$ \\
\hline $\begin{array}{c}\text { III } \\
\text { (No benefit) }\end{array}$ & $\begin{array}{l}\text { There is evidence or general agreement that the } \\
\text { procedure or treatment is not effective and/or useful }\end{array}$ \\
$\begin{array}{c}\text { III } \\
\text { (Harm) }\end{array}$ & $\begin{array}{l}\text { There is evidence and/or general agreement that the } \\
\text { procedure or treatment is harmful }\end{array}$ \\
\hline
\end{tabular}

\begin{tabular}{|c|c|}
\hline Grade A & $\begin{array}{l}\text { Strongly recommended and supported by strong } \\
\text { evidence }\end{array}$ \\
\hline Grade B & $\begin{array}{l}\text { Recommended with moderately strong supporting } \\
\text { evidence }\end{array}$ \\
\hline Grade C1 & $\begin{array}{l}\text { Recommended despite no strong supporting } \\
\text { evidence }\end{array}$ \\
\hline Grade C2 & $\begin{array}{l}\text { Not recommended because of the absence of strong } \\
\text { supporting evidence }\end{array}$ \\
\hline Grade D & $\begin{array}{l}\text { Not recommended as evidence indicates that the } \\
\text { treatment is ineffective or even harmful }\end{array}$ \\
\hline
\end{tabular}

(Adapted from MINDS Treatment Guidelines Selection Committee. Tsuguya Fukui et al., IGAKU-SHOIN Ltd. p.16. 2007.1)

be reflected in the guidelines. Therefore, it was decided to publish the JCS/JHFS 2021 Guideline Focused Update on Diagnosis and Treatment of Acute and Chronic Heart Failure without waiting for the next revision.

The main revised points included in this Focused Update are as follows:

1. General Principles: Proposal of a new LVEF-based classification and changes in the definition about heart failure with mid-range $\mathrm{EF}(\mathrm{HFmrEF})$ and heart failure with recovered EF (HFrecEF) (2017 edition, Chapter II; Focused Update, Chapter I). Based on the importance of time-dependent changes in LVEF, new classification of heart failure as $\mathrm{HFrecEF}$, heart failure with worsened EF (HFworEF), and heart failure with unchanged EF (HFuncEF) was presented.

2. Basic Principles for the Treatment of Heart Failure: Updated treatment algorithms for heart failure (2017 edition, Chapter V; Focused Update, Chapter II). Newer drugs including If channel blocker or HCN channel blocker, ivabradine, angiotensin receptor neprilysin inhibitor (ARNI), sacubitril and valsartan, and sodium glucose cotransporter 2 (SGLT2) inhibitor were included in the revised treatment algorithms.

3. Pharmacologic Therapy: Updated descriptions regarding If channel blockers (HCN channel blocker), ARNI, and SGLT2 inhibitors based on new clinical trials performed also in Japan such as J-SHIFT study and PARALLEL-HF study (2017 edition, Chapter VI; Focused Update, Chapter III). Updated descriptions regarding vericiguat based on VICTORIA and omecamtiv mecarbil based on GALACTIC-HF.

4. Nonpharmacologic Therapy: Updated statements based on the transcatheter aortic valve implantation

\begin{tabular}{|c|l|}
\hline \multicolumn{2}{|c|}{ Table 2. } \\
\hline Level A & $\begin{array}{l}\text { Demonstrated by multiple randomized clinical trials or } \\
\text { metaanalysis }\end{array}$ \\
\hline Level B & $\begin{array}{l}\text { Demonstrated by a single randomized clinical trial or } \\
\text { large nonrandomized studies }\end{array}$ \\
\hline Level C & $\begin{array}{l}\text { Consensus from expert opinion and/or small clinical } \\
\text { trials (including retrospective studies and case series) }\end{array}$ \\
\hline
\end{tabular}

\begin{tabular}{|c|c|}
\hline Table 4. & $\begin{array}{l}\text { Medical Information Network Distribution Service } \\
\text { Levels of Evidence (Levels of Evidence in the } \\
\text { Literature on Treatment) }\end{array}$ \\
\hline I & $\begin{array}{l}\text { Systematic review/meta-analysis of randomized } \\
\text { controlled trials }\end{array}$ \\
\hline II & One or more randomized controlled trials \\
\hline III & Nonrandomized controlled trials \\
\hline IVa & Analytical epidemiologic studies (cohort studies) \\
\hline $\mathrm{IVb}$ & $\begin{array}{l}\text { Analytical epidemiologic studies (case-control studies } \\
\text { and cross-sectional studies) }\end{array}$ \\
\hline $\mathrm{V}$ & Descriptive studies (case reports and case series) \\
\hline VI & $\begin{array}{l}\text { Not based on patient data, or based on opinions from a } \\
\text { specialist committee or individual specialists }\end{array}$ \\
\hline
\end{tabular}

(Adapted from MINDS Treatment Guidelines Selection Committee. Tsuguya Fukui et al., IGAKU-SHOIN Ltd. p.16. 2007.')

(TAVI) low-risk study, PARTER 3 study, and EVOLUT study and percutaneous mitral valve repair system and presentation of new tables (2017 edition, Chapter VII; Focused Update, Chapter IV).

5. Comorbidity: Atrial fibrillation. Updated statements based on the CASTLE-AF study and CABANA study (2017 edition, Chapter IX; Focused Update, Chapter V).

6. Comorbidity: Diabetes mellitus. Updated statements based on the DAPA-HF, EMPEROR-Reduced, and SOLOIST-WHF study and recent trials (2017 edition, Chapter IX; Focused Update, Chapter V).

7. Surgical Treatment: Updated statements regarding mechanical circulatory support including Impella ${ }^{\circledR}$ (2017 edition, Chapter XI; Focused Update, Chapter VI).

8. Disease Management: Addition of statements about certified heart failure educator newly established as a measure to develop human resources in "The Five-Year Plan for Overcoming Stroke and Cardiovascular Disease" formulated by the JCS and Japan Stroke Society in December 2016 (2017 edition, Chapter XII; Focused Update, Chapter VII).

9. Palliative Care: Updated statements regarding palliative care treatment (2017 edition, Chapter XIII; Focused Update, Chapter VIII).

10. Future Treatment: Updated descriptions about WAON therapy (2017 edition, Chapter XIV; Focused Update, Chapter IX).

Based on the results of clinical trials of pharmacologic and nonpharmacologic therapies for heart failure have been published in Japan and other countries in 2018 and, thereafter, focused major revisions were made to a part of the recommendation levels and contents of statements 
based on such accumulated new evidence in this update. In addition, regarding the recommendation class, class III was classified into cases without efficacy or usefulness (no benefit) and those with harm based on the clinical usefulness (Table 1). Level of Evidence (Table 2), the Medical Information Network Distribution Service (MINDS) Grades of Recommendation and MINDS Levels of Evidence were described together in this edition (Tables 3,4). The classification of recommendations and levels of evidence are described similarly to our previous heart failure guidelines using a style similar to those used in the American College of Cardiology (ACC)/American Heart Association (AHA) guidelines and the European Society of Cardiology (ESC) guidelines (Tables 1,2). In Japan, guidelines for cardiovascular diseases have extensively used a common style that is highly consistent with Western guidelines. In contrast, the Japan Council for Quality Health Care uses a different style in its MINDS to show grades of recommen- dations and levels of evidence as described in the "Minds Handbook for Clinical Practice Guideline Development 2007" (Tables 3,4). ${ }^{1}$ Accordingly, the present document shows classification of recommendations and level of evidence in the tables including both styles; class of recommendation, level of evidence, grade of recommendation (MINDS), and level of evidence (MINDS). The grade of recommendation is determined based on a comprehensive assessment of the level and quantity of evidence, variation of conclusion, size of effectiveness, applicability to the clinical setting, and evidence on harms and costs.

Important contents of the 2017 revised edition of the guidelines were partially overlapped in this focused update; however, overlapping was avoided as much as possible. To make the sections revised from the 2017 revised edition easy to understand, the chapter numbers in the 2017 revised edition were described together.

\section{Definition and Classification}

\section{Definition of Heart Failure}

Heart failure is defined as a clinical syndrome consisting of dyspnea, malaise, swelling, and/or decreased exercise capacity owing to the loss of compensation for cardiac pumping function owing to structural and/or functional abnormalities of the heart (Table 5).

Previously, acute heart failure was defined as a "clinical state in which the compensation mechanism of heart pump function rapidly collapses and induces ventricular enddiastolic pressure elevation and failure of perfusion to the main organs, resulting in acute appearance or aggravation of symptoms and signs." In contrast, chronic heart failure was distinguished by being defined as "the clinical state in which congestion of the pulmonary and/or systemic venous system and tissue hypoperfusion continue due to chronic heart pump ataxia and interfere with daily life." The distinction between acute and chronic heart failure relates to the efficacy of pharmacotherapies. However, this classification of acute and chronic heart failure became less important as the usefulness of early therapeutic intervention before the appearance of obvious symptoms and signs has been confirmed.

In the diagnosis of heart failure, patients should be examined first for symptoms, medical history, their family history, physical findings, electrocardiogram, and chest radiographic findings. Next, the concentration of brain natriuretic peptide (BNP) or N-terminal pro-brain natriuretic peptide (NT-proBNP) in the blood should be determined.

Heart failure is a disease condition where the heart is unable to fill with and eject enough blood for various reasons, such as epicardial, myocardial, or endocardial lesions; valvular disease; coronary arterial disease; aortic disease; arrhythmias; and endocrine disorders. However, left ventricular dysfunction is present in many cases with heart failure, and is the most important factor in determining monitoring and treatment strategies. Heart failure should thus be defined and classified according to left ventricular function.

In this edition, the JCS partially revised the left ventricular dysfunction-based heart failure classification table referring to the 2017 Guideline on Diagnosis and Treatment of Acute and Chronic Heart Failure (2017 revised edition). ${ }^{2}$ The previously used classification based on LVEF evaluated at the time of examination (Table 6) is essential for making decision on treatment strategy, so that this feature was not changed. However, we often encounter improvement and aggravation of LVEF with treatment and time course in patients with heart failure, that is, transition of the phenotype from that judged based on LVEF at the onset occurs with the course. Multiple clinical studies have demonstrated that changes in LVEF were related to the outcome. Because evaluation of the clinical state including the course may be also necessary from this viewpoint, it was decided to separately present classification based on timecourse changes in LVEF (Table 7). There is no clear rule on the interval to investigate changes in LVEF, but many study reports were based on LVEF evaluated at an interval of more than 1 month or 6 months to a few years on average. .,4 $^{3}$ Nonetheless for the purposes of the present document, LVEF at the time of clinical evaluation was used to determine the classification and treatment of heart failure.

\begin{tabular}{|l|l|}
\hline \multicolumn{2}{|l|}{ Table 5. Definition of Heart Failure } \\
\hline $\begin{array}{l}\text { Definition of heart failure in the } \\
\text { present guidelines }\end{array}$ & $\begin{array}{l}\text { Clinical syndrome consisting of dyspnea, fatigue, edema and/or decreased } \\
\text { exercise capacity owing to the loss of compensation for cardiac pumping function } \\
\text { caused by structural and/or functional abnormalities of the heart }\end{array}$ \\
\hline $\begin{array}{l}\text { Definition of heart failure for the } \\
\text { public (patient-friendly version) }\end{array}$ & $\begin{array}{l}\text { Heart failure is a heart disease that causes shortness of breath and swelling, gets } \\
\text { worse with time, and shortens life expectancy }\end{array}$ \\
\hline
\end{tabular}




\begin{tabular}{|l|c|l|}
\hline \multicolumn{1}{|c|}{ Table 6. Classification of Heart Failure by LVEF on Examination } \\
\hline $\begin{array}{l}\text { Heart failure with reduced } \\
\text { ejection fraction: HFrEF }\end{array}$ & LVEF & \multicolumn{1}{c|}{ Definition } \\
\hline $\begin{array}{l}\text { Heart failure with preserved } \\
\text { ejection fraction: HFpEF }\end{array}$ & $\geq 50 \%$ & $\begin{array}{l}\text { Left ventricular systolic dysfunction. In many clinical studies, patients } \\
\text { with a low LVEF despite standard medical treatment for heart failure } \\
\text { are enrolled as patients with HFrEF }\end{array}$ \\
\hline $\begin{array}{l}\text { Heart failure with midrange } \\
\text { ejection fraction: HFmrEF }\end{array}$ & $40 \%-<50 \%$ & $\begin{array}{l}\text { Left ventricular diastolic dysfunction. Other diseases that may cause } \\
\text { similar symptoms should be ruled out. No effective treatments have } \\
\text { been established }\end{array}$ \\
\hline
\end{tabular}

LVEF, left ventricular ejection fraction.

\begin{tabular}{|l|l|}
\hline \multicolumn{1}{|c|}{ Table 7. Classification of Heart Failure Based on Time-Dependent Changes in LVEF } \\
\hline \multicolumn{1}{|c|}{ Changes in phenotype } & \multicolumn{1}{c|}{ Definition } \\
\hline $\begin{array}{l}\text { Heart failure with recovered EF: } \\
\text { HFrecEF }\end{array}$ & $\begin{array}{l}\text { LVEF improved during the treatment course and the condition transitioned from } \\
\text { HFrEF to HFmrEF or HFpEF, or from HFmrEF to HFpEF. The outcome is } \\
\text { relatively favorable }\end{array}$ \\
\hline $\begin{array}{l}\text { Heart failure with worsened EF: } \\
\text { HFworEF }\end{array}$ & $\begin{array}{l}\text { LVEF decreased with the treatment course and the condition transitioned from } \\
\text { HFpEF to HFmrEF or HFrEF, or from HFmrEF to HFrEF. The outcome is poor }\end{array}$ \\
\hline $\begin{array}{l}\text { Heart failure with unchanged EF: } \\
\text { HFuncEF }\end{array}$ & No major change is observed in LVEF throughout the course \\
\hline
\end{tabular}

$\mathrm{HFmrEF}$, heart failure with midrange ejection fraction; $\mathrm{HFpEF}$, heart failure with preserved ejection fraction; HFrEF, heart failure with reduced ejection fraction; LVEF, left ventricular ejection fraction.

\section{Classification of Heart Failure by LVEF on Examination}

\subsection{Heart Failure With Reduced EF}

In many large-scale clinical studies in heart failure, heart failure with reduced $\mathrm{EF}$ (HFrEF) was defined as heart failure with a LVEF of $35 \%$ or less or less than $40 \%$ (Table 6). In the guidelines in Japan and Western countries, $40 \%$ or less or less than $40 \% \mathrm{LVEF}$ is adopted as a criterion of HFrEF.,25,6 In HFrEF, left ventricular dilatation is frequently observed and it is accompanied by not only left ventricular systolic dysfunction represented by reduced LVEF but also diastolic dysfunction. In Japan, previously, nonischemic etiology, such as dilated cardiomyopathy, accounted for a high percentage of the main causes of HFrEF, but the proportion of coronary artery disease has been gradually increasing. ${ }^{7}$

\subsection{Heart Failure With Preserved EF}

The standard concept of diagnosing heart failure with preserved EF (HFpEF) is consideration based on the following 3 points: (1) manifestation of clinical symptoms of heart failure, (2) normal or retention of LVEF, (3) the presence of left ventricular diastolic dysfunction. ${ }^{8}$ In the guidelines in Japan and Western countries, a $50 \%$ or higher LVEF is adopted as a standard value, and based on the results of previous epidemiologic surveys, HFpEF accounts for about one-half of patients with heart failure. ${ }^{9}$ Because it is not easy to diagnose diastolic dysfunction in routine practice and there is no established diagnostic criterion for $\mathrm{HFpEF}$, a comprehensive diagnostic method using multiple indices assessed on echocardiography has been proposed.10,11 Background factors strongly associated with $\mathrm{HFpEF}$ include advanced age, hypertension, atrial fibrillation, coronary artery disease, diabetes, and obesity. ${ }^{12}$ A simple screening tool, the $\mathrm{H}_{2}$ FPEF score, scoring obesity, hypertension requiring polypharmacy, atrial fibrillation, pulmonary hypertension, advanced age, and left atrial pressure elevation as variables has been proposed. ${ }^{13}$

\section{2.3 Heart Failure With Mid-Range EF}

The challenges of defining heart failure based on LVEF was verified by an epidemiologic survey performed in Japan. ${ }^{14}$ This intermediate range between HFpEF and HFrEF has both similarities and differences with each of these clinical entities. There are data positioned at intermediate between HFrEF and HFpEF in the age, sex ratio, and atrial fibrillation complication rate in patients belonging to the heart failure with midrange EF (HFmrEF) category, ${ }^{3,15,16}$ but it has been reported that the distribution of underlying heart diseases is similar to that of HFrEF and ischemic heart disease accounts for a high rate. ${ }^{17,18}$ The survival rate of patients with HFmrEF has not been correlated with LVEF in some studies, ,4,19,20 $^{2}$ whereas it was similar to that of patients with HFpEF and higher than that of patients with HFrEF in other studies, ${ }^{3,18}$ but it has been reported as a consistent result that the relationship between BNP/NT-proBNP and outcome is not affected by the LVEF., ${ }^{3,18,20}$ Regarding HFmrEF, an investigation of whether there is a population with a characteristic condition different from those of HFrEF and HFpEF or whether patients to be included in HFpEF and those to be included in $\mathrm{HFrEF}$ were mixed in the population without a unique characteristic of HFmrEF is awaited. Further studies are required to better understand and define HFmrEF. 


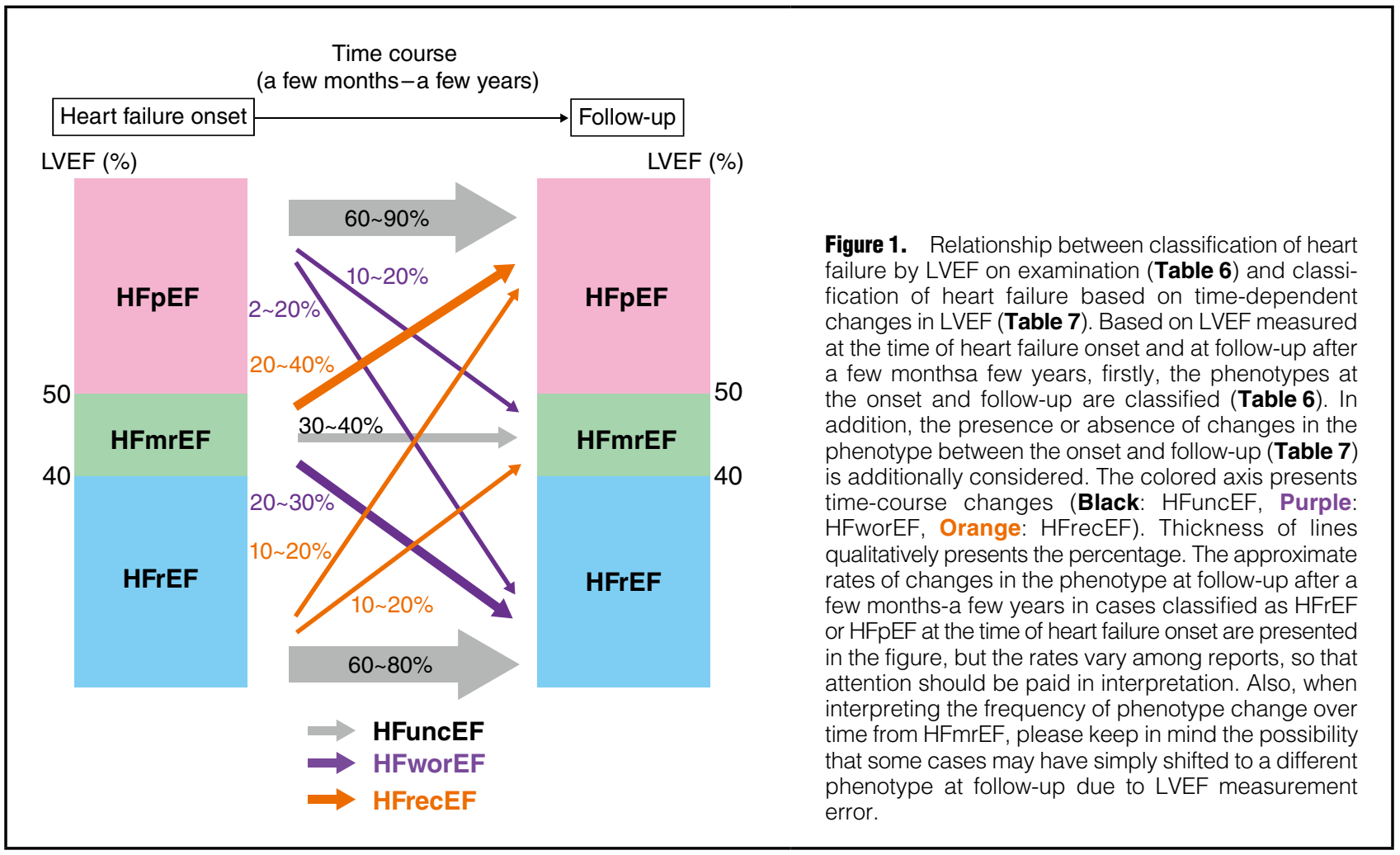

\section{Classification of Heart Failure Based on Time-Dependent Changes in LVEF}

\subsection{Heart Failure With Recovered EF}

In tachycardiainduced cardiomyopathy caused by tachycardiac atrial fibrillation, ischemic heart disease, and dilated cardiomyopathy, improvement of LVEF compared with that at onset of heart failure may be noted during the course owing to th effects of treatment (Table 7, Figure 1). According to previous clinical studies, approximately $20-40 \%$ of HFrEF cases transitioned to HFmrEF or HFpEF and about $20-40 \%$ of HFmrEF cases transitioned to $\mathrm{HFpEF}$, $^{\mathbf{3 , 4 2 1 , 2 2}}$ In the results of multiple studies, female, young age, and nonischemic heart disease were included in the clinical background of heart failure with recovered EF (HFrecEF). The outcome of patients with HFrecEF among patients classified as those with HFrEF at the time of heart failure onset has been reported to be relatively favorable., 3,423 In addition, it has been reported that patients with HFrecEF and patients with HFuncEF were mixed in patients judged as having $\mathrm{HFpEF}$ in follow-up and the outcome was more favorable in patients with HFpEF with HFrecEF than those with HFuncEF.4,23 However, it has been reported that suspension or dose reduction of pharmacologic therapy caused a re-decrease in LVEF and re-left ventricular dilatation in dilated cardiomyopathy patients in whom pharmacologic therapy improved LVEF, ${ }^{24}$ showing that the clinical state of HFrecEF does not mean the resolution of the disease and no need for drug administration.

The Universal Definition of Heart Failure based on a recent report of the Heart Failure Society of America, Heart Failure Association of the European Society of Cardiology, and JHFS defined heart failure with improved EF as heart failure with a baseline LVEF of less than $40 \%$, a greater than 10-point increase from baseline LVEF, and a second measurement of LVEF of greater than $40 \%$. It recommended the use of the improved terminology rather than recovered EF. Improved EF deserves a separate classification and should not be classified as HFmrEF or HFpEF, even after an improvement in the LVEF to $41-49 \%$ or to greater than $50 \%$, respectively, because discontinuing HFrEF therapy in this group leads to a poor outcome.

\subsection{Heart Failure With Worsened EF}

LVEF may aggravate during the course, such as transition of hypertrophic cardiomyopathy to the dilated phase and recurrence of ischemic events, and/or progression of remodeling in ischemic heart disease, such as old myocardial infarction.Most $\mathrm{HFpEF}$ cases remained $\mathrm{HFpEF}$ throughout the course in some reports, ${ }^{25}$ although $10-40 \%$ of HFpEF cases transitioned to HFmrEF or HFrEF and $20-30 \%$ of HFmrEF cases transitioned to HFrEF owing to LVEF reduction during the course in other reports., $\mathbf{3 , 2 2 , 2 6}$ heart failure with worsened EF (HFworEF) is defined as heart failure in which LVEF decreased with the treatment course and the condition transitioned from HFpEF to HFmrEF or HFrEF, or from HFmrEF to HFrEF. The outcome is poor. Male sex and ischemic heart disease are considered predictive factors of aggravation of LVEF. A decrease in the LVEF was not associated with the outcome in 1 study, ${ }^{25}$ but the outcome was poor in a patient group with reduction of LVEF in many studies. ${ }^{3,4}$ In addition, it has been reported that patients with HFworEF and those with HFuncEF were mixed in patients judged as having HFrEF in follow-up 
and the outcome was poorer in patients with HFworEF than HFuncEF. 4

\subsection{Heart Failure With Unchanged EF}

Heart failure with unchanged EF (HFuncEF) is defined as heart failure in which no major change is observed in LVEF throughout the course. Many patients with HFrEF and HFpEF at the time of heart failure onset remained the same phenotype throughout the follow-up period, whereas HFmrEF remained in only onethird of patients with HFmrEF. ${ }^{3,4}$ However, LVEF in HFmrEF is defined as a narrow range of $40-50 \%$. Considering the accuracy of echocardiography used in LVEF evaluation, the clinical state did not change at a considerable rate of patients with HFmrEF with transition to HFpEF or HFrEF accounting for two-thirds of cases, and the data may have appeared as if transition to the different phenotype of heart failure occurred simply owing to LVEF measurement error. ${ }^{27,28}$ In LVEF measurement, measurement errors are also large among the imaging diagnosis methods used. ${ }^{29}$ These LVEF measurement errors may be another limitation of extraction of the characteristics of HFmrEF.

\section{Basic Principles for the Treatment of Heart Failure}

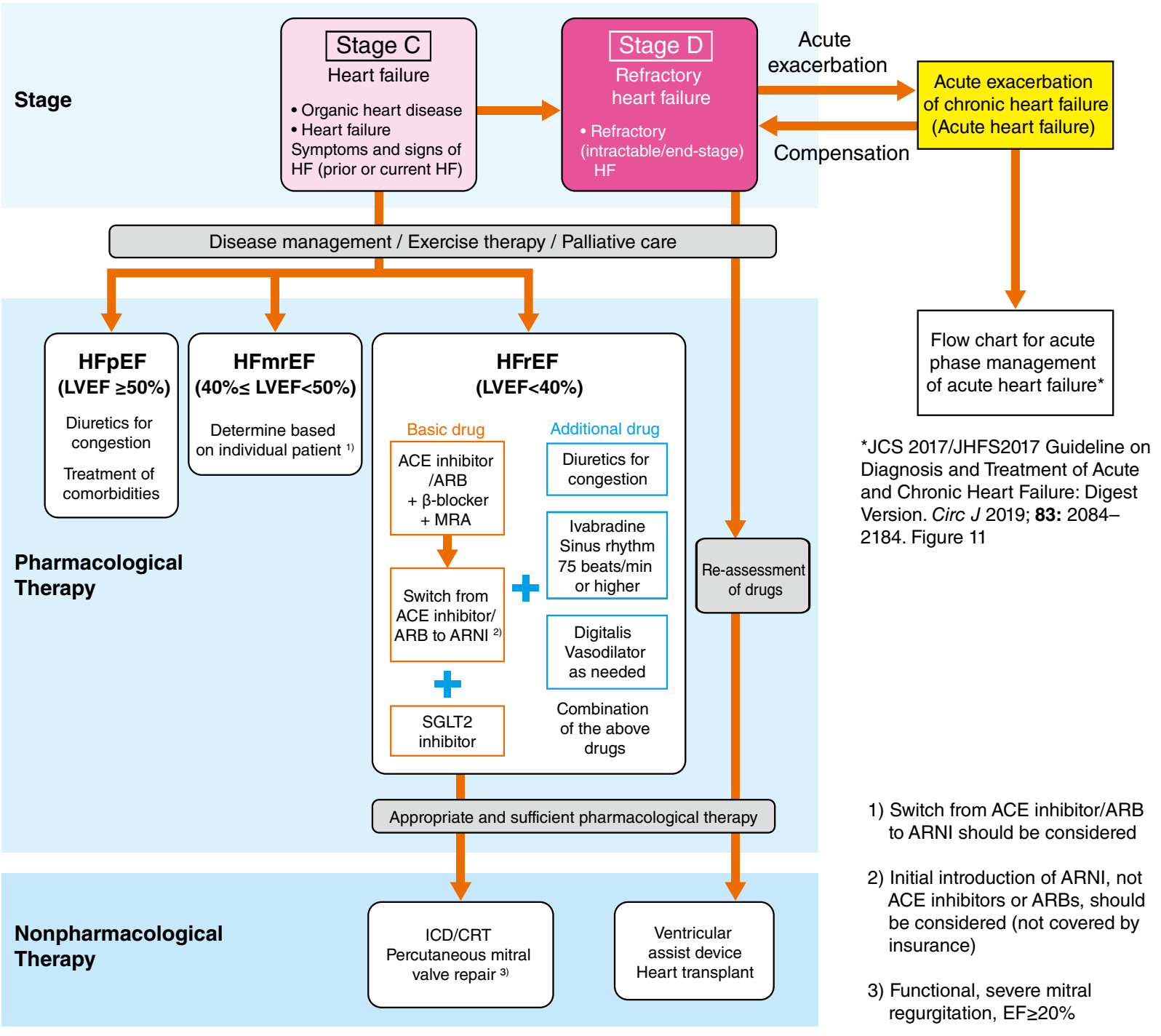

Figure 2. Treatment algorithm for heart failure. 


\section{Treatment Algorithms for Heart Failure}

Because abundant evidence of pharmacologic and nonpharmacologic therapies for heart failure, especially, HFrEF was reported after the publication of the JCS 2017/ JHFS 2017 Guideline on Diagnosis and Treatment of Acute and Chronic Heart Failure (2017 revised edition), the heart failure treatment algorithm was revised in this edition (Figure 2). The clinical course of heart failure is chronic and progressive in many cases, and the patients with established heart failure often have repeated episodes of acute exacerbation of heart failure. The repeated exacerbations gradually lead to more severe stage from stage $\mathrm{C}$ (heart failure stage) to stage D (refractory heart failure stage). In both stages, multidisciplinary disease management and exercise therapy are performed. This is the concept of cardiac rehabilitation for heart failure. In addition, palliative care is introduced early in stage $\mathrm{C}$, aiming at improvement of quality of life of overall patients with heart failure and support for decision-making in selection of treatment method.

Treatment for stage $\mathrm{C}$ disease includes the treatment both of chronic heart failure and of acute heart failure in acute exacerbation. Treatment for the chronic phase of stage $\mathrm{C}$ is selected corresponding with the LVEF. The most important point of $\mathrm{HFrEF}$ treatment is to use the maximum tolerable dose of angiotensin-converting enzyme (ACE) inhibitors or angiotensin II receptor blockers (ARBs) in conjunction with $\beta$-blockers, which have been shown to improve the clinical outcomes, from the first diagnosis. Pharmacologic therapy combining mineralocorticoid receptor antagonist (MRA) with these is regarded as the basic treatment for HFrEF. In patients with symptomatic HFrEF despite optimal basic treatment, replacement for ACE inhibitor or ARB by an ARNI is recommended to further reduce morbidity and mortality. Initial introduction of an ARNI - and not ACE inhibitors or ARBs - should be also considered. Furthermore, in patients with symptomatic HFrEF and with optimal basic treatment, SGLT2 inhibitors are also recommended regardless of the presence or absence of diabetes to further decrease the risk of exacerbation of heart failure or cardiovascular death. Diuretics are necessary to improve symptoms owing to congestion as a concomitant drug in many patients with heart failure, but there is no clear evidence for improvement of survival, and dose adjustment corresponding with organ congestion is important. In patients with symptomatic HFrEF and with a sinus rhythm and $75 \mathrm{bpm}$ heart rate or higher despite optimal basic treatment, ivabradine should be considered to decrease the risk of heart failure hospitalization or cardiovascular death. Cardiac resynchronization therapy is recommended according to its indication in patients with symptomatic despite the maximum and optimal pharmacologic therapy. The indication of implantable cardioverter defibrillator is decided from the viewpoint of primary and secondary prevention of sudden death. In symptomatic patients with HFrEF with a $20 \%$ or higher LVEF and with severe mitral valve insufficiency despite optimal basic medical treatment, percutaneous mitral valve repair should be considered. In patients with severe symptoms even at rest and with repeated hospitalization for worsening heart failure despite optimal treatment for stage C disease, treatment for stage $\mathrm{D}$ disease is selected.

\section{Pharmacologic Therapy}

Established guideline-directed medical therapy (GDMT) for chronic HFrEF include ACE inhibitors, ARBs, $\beta$-blockers, and MRA recommended in the JCS/JHFS 2017 Guideline on Diagnosis and Treatment of Acute and Chronic Heart Failure (Table 8) ${ }^{30-44}$ All of these drugs have been demonstrated in randomized controlled clinical trials to improve symptoms, decrease hospitalization, and prolong survival. After the publication of the JCS/JHFS 2017 Guideline on Diagnosis and Treatment of Acute and Chronic Heart Failure, more data have emerged to support the use of new medications including ivabradine, ARNI, and SGLT2 inhibitors in patients with HFrEF. In light of these developments, an update on these HFrEF therapies was deemed important.

\section{If Channel Blocker or HCN Channel Blocker; Ivabradine}

Ivabradine decreases the heart rate by inhibiting the $I_{\mathrm{f}}$ channel of sinoatrial node cells, and it is indicated only for patients with sinus rhythm (Table 9). It has no influence on cardiac contractility. The SHIFT study demonstrated that the treatment target of this drug in patients with HFrEF is solely decreasing the heart rate. ${ }^{45}$ This doubleblind randomized controlled study targeted patients with HFrEF with an LVEF of $35 \%$ or lower LVEF, even though treated with $\beta$-blockers and ACE inhibitors (or ARB) at the recommended or maximum dose and then MRA, sinus rhythm, and a resting heart rate of $70 \mathrm{bpm}$ or higher, who had a past medical history of admission for heart failure within a past 1 year. Ivabradine significantly decreased the hazard ratio (HR) of the composite end point: cardiovascular death and admission for aggravation of heart failure, to $0.82(95 \%$ confidence interval [CI] $0.75-0.90, \mathrm{P}<0.0001)$ in comparison with placebo. This difference was mainly due to a decrease in admission for heart failure (HR 0.74, 95\% CI $0.66-0.83, \mathrm{P}<0.0001)$. This study clarified that tachycardia higher than a certain level is a risk for patients with HFrEF with sinus rhythm and reduction of the heart rate is the treatment target. ${ }^{46}$ The indication of ivabradine in Western countries is symptomatic HFrEF with $35 \%$ or lower LVEF (New York Heart Association [NYHA] classification functional class II-III) in patients with sinus rhythm in whom the resting heart rate does not decrease to less than 70bpm, even though appropriate pharmacologic therapy is performed, such as $\beta$-blocker administration at the maximum dose or acceptable maximum dose for the patients and then ACE inhibitors (ARB) and MRA. In addition, the administration of ivabradine instead of $\beta$-blockers is approved for patients in whom it is difficult to administer $\beta$-blockers. In real-world evidence of ivabradine for patients with HFrEF, time-course improvement of the NYHA functional classification was observed. ${ }^{47}$ 
Furthermore, in a study in which exercise tolerance of patients with HFrEF was compared with that of patients treated with $\beta$-blockers, exercise tolerance was improved in ivabradine-treated patients compared with that in $\beta$-blocker-treated patients ${ }^{48}$ and this finding was considered to be due to the dominant negative effects of $\beta$-blockers that suppress the sympathetic nerve during exercise, limiting improvement of exercise tolerance, whereas ivabradine does not have this action. On meta-analysis, ivabradine did not decrease the mortality rate. ${ }^{49}$

The J-SHIFT study was performed similarly to the SHIFT study to confirm that ivabradine decreases deaths and admission for heart failure of Japanese patients with HFrEF. ${ }^{50}$ The criteria of the target patients were the same as those in the SHIFT study, including patients with sinus rhythm and a resting heart rate of $75 \mathrm{bpm}$ or higher. Although the ivabradineinduced changes were not signifi- cant on comparison with placebo, ivabradine tended to decrease the composite end point of cardiovascular death and admission for heart failure (HR $0.67,95 \%$ CI 0.40 $1.11, \mathrm{P}=0.1179)$. Because the tendency was consistent between the J-SHIFT study and SHIFT study, ivabradine was also approved in Japan.

Ivabradine is indicated for patients with $\mathrm{HFrEF}$ in Western countries, whereas the indication in Japan is "chronic heart failure with sinus rhythm and a resting heart rate at initiation of administration of $75 \mathrm{bpm}$ or higher limited to patients under the standard treatment including $\beta$-blockers for chronic heart failure." The package insert in Japan does not contain specific description about LVEF of indicated patients, but the following description in proviso should be considered: "Select indicated patients after sufficiently understanding the background (such as LVEF) of patients enrolled in the clinical study." There has been

\begin{tabular}{|c|c|c|c|c|c|c|}
\hline Drug class & Trial name & $\begin{array}{c}\text { Year } \\
\text { published }\end{array}$ & $\begin{array}{l}\text { Drug vs. } \\
\text { placebo }\end{array}$ & $\begin{array}{l}\text { Major inclusion } \\
\text { criteria }\end{array}$ & $\begin{array}{l}\text { Mean } \\
\text { follow-up } \\
\text { (years) }\end{array}$ & Primary end point \\
\hline \multicolumn{7}{|l|}{ HFrEF } \\
\hline ACEi & CONSENSUS ${ }^{30}$ & 1987 & Enalapril & $\begin{array}{l}\text { NYHA IV, cardiomegaly } \\
\text { on chest radiograph }\end{array}$ & 0.5 & $\begin{array}{l}\text { All-cause mortality reduced } \\
\text { by } 40 \% \text { at } 6 \text { months ( } 26 \% \\
\text { vs. } 44 \%, P=0.002 \text { ) and by } \\
31 \% \text { at } 12 \text { months ( } 52 \% \text { vs. } \\
36 \%, P=0.001)\end{array}$ \\
\hline ACEi & SOLVD-Treatment ${ }^{31}$ & 1991 & Enalapril & $\begin{array}{l}\text { LVEF } \leq 35 \% ; \text { NYHA I-IV } \\
\text { (90\% NYHA II-III) }\end{array}$ & 3.5 & $\begin{array}{l}\text { All-cause mortality reduced } \\
\text { by } 16 \%(35 \% \text { vs. } 40 \%) \\
(P=0.004)\end{array}$ \\
\hline ARB & Val-HeFT 32 & 2001 & Valsartan & $\begin{array}{l}\text { LVEF } \leq 40 \% \text {, NYHA II-IV, } \\
\text { with ACEi, LVID } 2.9 \mathrm{~cm} / \\
\text { BSA }\end{array}$ & 1.9 & $\begin{array}{l}\text { All-cause mortality did not } \\
\text { differ }(19.7 \% \text { vs. } 19.4 \% \text {, } \\
\mathrm{P}=0.80) \text { Combined end point } \\
\text { of allcause death, cardiac } \\
\text { arrest with resuscitation, HF } \\
\text { hospitalization, or i.v. } \\
\text { administration of inotropic or } \\
\text { vasodilator drugs for } \geq 4 \\
\text { hours without hospitalization } \\
\text { reduced by } 13 \% \text { ( } 29 \% \text { vs. } \\
32 \%, P=0.009)\end{array}$ \\
\hline ARB & CHARM-Alternative $^{33}$ & 2003 & Candesartan & $\begin{array}{l}\text { LVEF } \leq 40 \%, N Y H A ~ I I-I V, \\
\text { intolerant to ACEi }\end{array}$ & 2.8 & $\begin{array}{l}\text { Combined cardiovascular } \\
\text { mortality or HF hospitalization } \\
\text { reduced by } 23 \% \text { (33\% vs. } \\
40 \%, \mathrm{P}<0.001)\end{array}$ \\
\hline$\beta$-Blockers & CIBIS-II & 1999 & Bisoprolol & LVEF $\leq 35 \%$, NYHA III-IV & 1.3 & $\begin{array}{l}\text { All-cause mortality reduced } \\
\text { by } 34 \%(12 \% \text { vs. } 17 \%) \\
(P<0.001)\end{array}$ \\
\hline$\beta$-Blockers & MERIT-HF 35 & 1999 & $\begin{array}{l}\text { Metoprolol CR/ } \\
\text { XL }\end{array}$ & LVEF $\leq 40 \%$, NYHA II-IV & 1.0 & $\begin{array}{l}\text { All-cause mortality reduced } \\
\text { by } 34 \%(7 \% \text { vs. } 11 \%) \\
(P<0.001)\end{array}$ \\
\hline$\beta$-Blockers & COPERNICUS ${ }^{36}$ & 2001 & Carvedilol & LVEF $<25 \%$, NYHA IV & 0.9 & $\begin{array}{l}\text { All-cause mortality reduced } \\
\text { by } 35 \%(11 \% \text { vs. } 17 \%) \\
(\mathrm{P}<0.001)\end{array}$ \\
\hline MRA & RALES ${ }^{37}$ & 1999 & Spironolactone & $\begin{array}{l}\text { LVEF } \leq 35 \% \text {, NYHA III-IV } \\
\text { at enrolment and NYHA } \\
\text { IV within recent } 6 \text { months }\end{array}$ & 2.0 & $\begin{array}{l}\text { All-cause mortality reduced } \\
\text { by } 30 \%(35 \% \text { vs. } 46 \%) \\
(\mathrm{P}<0.001)\end{array}$ \\
\hline MRA & EMPHASIS-HF ${ }^{38}$ & 2011 & Eplerenone & $\begin{array}{l}\text { NYHA II, LVEF } \leq 30 \% \text { or } \\
\text { LVEF } 30-35 \% \text { with QRS } \\
>130 \mathrm{~ms} \text {, cardiovascular } \\
\text { hospitalization within } \\
\text { recent } 6 \text { months or BNP } \\
\geq 250 \mathrm{pg} / \mathrm{mL} \text { or NTproBNP } \\
\geq 500 \mathrm{pg} / \mathrm{mL} \text { in men and } \\
\geq 750 \mathrm{pg} / \mathrm{mL} \text { in women }\end{array}$ & 1.8 & $\begin{array}{l}\text { Combined cardiovascular } \\
\text { mortality or HF hospitalization } \\
\text { reduced by } 37 \% \text { ( } 18 \% \text { vs. } \\
26 \%, \mathrm{P}<0.001)\end{array}$ \\
\hline
\end{tabular}




\begin{tabular}{|c|c|c|c|c|c|c|}
\hline Drug class & Trial name & $\begin{array}{l}\text { Year } \\
\text { published }\end{array}$ & $\begin{array}{l}\text { Drug vs. } \\
\text { placebo }\end{array}$ & $\begin{array}{l}\text { Major inclusion } \\
\text { criteria }\end{array}$ & $\begin{array}{l}\text { Mean } \\
\text { follow-up } \\
\text { (years) }\end{array}$ & Primary end point \\
\hline \multicolumn{7}{|l|}{ HFpEF } \\
\hline $\mathrm{ACEi}$ & PEP-CHF 39 & 2006 & Perindopril & $\begin{array}{l}\text { LV wall motion index } \geq 1.4 \\
\text { (corresponding to LVEF } \\
\geq 40 \% \text { ), symptomatic HF } \\
\text { treated with diuretic, } \\
\text { diastolic dysfunction in } \\
\text { echocardiography, age } \\
\geq 70 \text { years old }\end{array}$ & 2.1 & $\begin{array}{l}\text { Combined all-cause mortality } \\
\text { or cardiovascular } \\
\text { hospitalization did not differ } \\
(36 \% \text { vs. } 37 \%, P=0.35)\end{array}$ \\
\hline ARB & CHARM-Preserved ${ }^{40}$ & 2003 & Candesartan & $\begin{array}{l}\text { LVEF }>40 \% \text {, NYHA II-IV, } \\
\text { history of cardiac } \\
\text { hospitalization }\end{array}$ & 3.0 & $\begin{array}{l}\text { Combined cardiovascular } \\
\text { mortality or HF hospitalization } \\
\text { tended to reduce by } 11 \% \\
(22 \% \text { vs. } 24 \% \text {, unadjusted } \\
\mathrm{P}=0.12 \text {, adjusted } \mathrm{P}=0.051)\end{array}$ \\
\hline ARB & I-PRESERVE ${ }^{41}$ & 2008 & Irbesartan & $\begin{array}{l}\text { LVEF } \geq 45 \% \text {, NYHA III-IV, } \\
\text { or NYHA II with HF } \\
\text { hospitalization within } \\
\text { recent } 6 \text { months, } \geq 60 \\
\text { years old }\end{array}$ & 4.1 & $\begin{array}{l}\text { Combined all-cause mortality } \\
\text { or HF hospitalization did not } \\
\text { differ ( } 24 \% \text { vs. } 25 \% \text {, } \\
\mathrm{P}=0.54) \text {. }\end{array}$ \\
\hline MRA & TOPCAT $^{42}$ & 2014 & Spironolactone & $\begin{array}{l}\text { LVEF } \geq 45 \%, \geq 1 \mathrm{HF} \text { sign, } \\
\geq 1 \mathrm{HF} \text { symptom, HF } \\
\text { hospitalization within } \\
\text { recent } 12 \text { months, or BNP } \\
\geq 100 \mathrm{pg} / \mathrm{mL} \text { or NTproBNP } \\
\geq 360 \mathrm{pg} / \mathrm{mL}, \geq 50 \text { years old }\end{array}$ & 3.3 & $\begin{array}{l}\text { Combined cardiovascular } \\
\text { death, aborted cardiac arrest, } \\
\text { or HF hospitalization did not } \\
\text { differ }(19 \% \text { vs. } 20 \%, P=0.14)\end{array}$ \\
\hline$\beta$-Blockers & SENIORS ${ }^{43}$ & 2005 & Nebivolol & $\begin{array}{l}\text { HF hospitalization within } \\
\text { recent } 12 \text { months and/or } \\
\text { LVEF } \leq 35 \% \text { within recent } \\
6 \text { months, } \geq 70 \text { years old, } \\
\text { HF with LVEF }>35 \%\end{array}$ & 1.8 & $\begin{array}{l}\text { Combined all-cause mortality } \\
\text { or cardiovascular } \\
\text { hospitalization reduced by } \\
14 \%(31 \% \text { vs. } 35 \%, P=0.04)\end{array}$ \\
\hline Digitalis & DIG-PEF44 & 1997 & Digoxin & $\begin{array}{l}\text { HF with LVEF }>45 \% \text {, } \\
\text { sinus rhythm }\end{array}$ & 3.1 & $\begin{array}{l}\text { Combined HF mortality or } \\
\text { HF hospitalization did not } \\
\text { differ }(21 \% \text { vs. } 24 \%, P=0.14)\end{array}$ \\
\hline
\end{tabular}

ACEi, angiotensin-converting enzyme inhibitor; BNP, B-type natriuretic peptide; BSA, body surface area; HARM-Alternative, Candesartan in Heart Failure Assessment of Reduction in Mortality and Morbidity; CHARM-Preserved, Candesartan Cilexetil in Heart Failure Assessment of Reduction in Mortality; CIBIS II, Cardiac Insufficiency Bisoprolol Study II; CONSENSUS, Cooperative North Scandinavian Enalapril Survival Study; COPERNICUS, Carvedilol Prospective Randomized Cumulative Survival; DIG-PEF, ancillary Digitalis Investigation Group trial; EMPHASIS-HF, Eplerenone in Mild Patients Hospitalization and Survival Study in Heart Failure; HF, heart failure; I-PRESERVE, Irbesartan in Heart Failure with Preserved Ejection Fraction Study; LV, left ventricular; LVEF, left ventricular ejection fraction; LVID, left ventricular internal dimension; MERIT-HF, Metoprolol CR/XL Randomised Intervention Trial in Congestive Heart Failure; NT-proBNP, N-terminal pro B-type natriuretic peptide; PEP-CHF, Perindopril in Elderly People with Chronic Heart Failure; RALES, Randomized Aldactone Evaluation Study; SENIORS, Study of the Effects of Nebivolol Intervention on Outcomes and Rehospitalisations in Seniors with Heart Failure; SOLVD-Treatment, Studies of Left Ventricular Dysfunction Treatment Trial; TOPCAT, Treatment of Preserved Cardiac Function Heart Failure with an Aldosterone Antagonist; Val-HeFT, Valsartan Heart Failure Trial.

Table 9. COR and LOE for Ivabradine

\begin{tabular}{|c|c|c|c|c|}
\hline & COR & LOE & $\begin{array}{c}\text { GOR } \\
\text { (MINDS) }\end{array}$ & $\begin{array}{c}\text { LOE } \\
\text { (MINDS) }\end{array}$ \\
\hline $\begin{array}{l}\text { Ivabradine should be considered to reduce admission for heart failure and } \\
\text { risk of cardiovascular death in symptomatic HFrEF (LVEF } \leq 35 \%) \text { patients } \\
\text { with sinus rhythm and heart rate } \geq 75 \text { bpm despite optimum pharmacologic } \\
\text { therapy ( } \beta \text {-blockers, ACE inhibitors [or ARB], and MRA at the maximum dose } \\
\text { or maximum tolerable dose) }\end{array}$ & Ila & B & B & II \\
\hline $\begin{array}{l}\text { Ivabradine should be considered to reduce admission for heart failure and } \\
\text { risk of cardiovascular death in symptomatic HFrEF (LVEF } \leq 35 \% \text { ) patients } \\
\text { with sinus rhythm, resting heart rate } \geq 75 \text { bpm despite receiving ACE inhibitors } \\
\text { (or ARB) and MRA and intolerance or contraindicated for } \beta \text {-blockers }\end{array}$ & Ila & C & B & III \\
\hline
\end{tabular}

ACE, angiotensin-converting enzyme; ARB, angiotensin receptor blocker; COR, class of recommendation; GOR, grade of recommendation (Medical Information Network Distribution Service [MINDS]); HFrEF, heart failure with reduced ejection fraction; LOE, level of evidence (MINDS); LVEF, left ventricular ejection fraction; MRA, mineralocorticoid receptor antagonist. 
no large-scale clinical study in which ivabradine was administered and death and admission for heart failure were observed in patients with HFpEF for a prolonged period. Only small-scale clinical studies observing the influence of ivabradine on exercise tolerance of patients with HFpEF have been performed. Exercise tolerance improved in some studies, ${ }^{\mathbf{5 1}}$ but it did not change in others, ${ }^{\mathbf{5 2}}$ showing inconsistency of the effects. Therefore, at present, the indication of ivabradine should be limited to HFrEF following that in Western countries.

\section{ARNI: Sacubitril/Valsartan}

Sacubitril/valsartan is a compound containing an ARB, valsartan, and a prodrug of neprilysin inhibitor, sacubitril (AHU-377) bonded at 1: 1 per molecule and it is a new type of drug termed ARNI (Table 10). Sacubitril is converted to the active form (LBQ657) 3-4 hours after absorption and shows neprilysin-inhibitory action. LBQ657 mainly inhibits the degradation of endogenous natriuretic peptide, but it does not inhibit ACE or aminopeptidase P. Accordingly, its bradykinin degradation inhibitory action is weaker than that of omapatrilat, which simultaneously inhibits ACE and neutral endopeptidase so that it causes less angioedema than omapatrilat. In addition, the blood BNP level increases immediately after sacubitril/valsartan administration and gradually decreases as heart failure improves, whereas NT-proBNP is not influenced by neprilysin and starts to decrease immediately after administration, reflecting improvement of heart failure..$^{53}$

The PARADIGM-HF study clarified that sacubitril/ valsartan exhibits a survival-improving effect exceeding that of an ACE inhibitor, enalapril, ${ }^{54}$ and change from ACE inhibitors to ARNI in patients with HFrEF (EF of $\leq 35 \%$ ) with symptoms even after receiving the standard treatment with ACE inhibitors, $\beta$-blockers, and MRA has been already described as class I, evidence level B treatment in the guidelines in Western countries. ${ }^{\mathbf{5 5 , 5 6}}$ Furthermore, in the PIONEER-HF study, when sacubitril/valsartan was administered to patients with acute decompensated heart failure with $\mathrm{HFrEF}$ after stabilization of hemodynamics before discharge, NT-proBNP significantly decreased 8 weeks after discharge compared with that in thecontrol group treated with enalapril alone, ${ }^{57}$ and significant improvement was also noted in the exploratory composite of heart failure rehospitalization or cardiovascular death from randomization through week 12.58 About one-half of these patients had not been medicated with oral ACE inhibitors or ARB at the time of registration. Based on these studies, it is described in the 2019 ESC clinical practice update that ARNI may be administered from the beginning, not after switching, for the first heart failure episode after admission and decompensated heart failure. ${ }^{59}$ In the PARALLEL-HF study, a phase III study in Japan, 225 Japanese patients with HFrEF (NYHA functional class II-IV, LVEF of $\leq 35 \%$ ) were randomized (1:1) to receive sacubitril/valsartan $200 \mathrm{mg}$ twice daily or enalapril $10 \mathrm{mg}$ twice daily. Over a median follow-up of 33.9 months, no significant between-group difference was observed for the primary composite outcome of cardiovascular death and heart failure hospitalization (HR 1.09; 95\% CI 0.65-1.82; $\mathrm{P}=0.6260$ ), which might be a result of variation owing to a small number of the target patients. Early and sustained reductions in NT-proBNP from baseline were observed with sacubitril/valsartan compared with enalapril (betweengroup difference at week 2 of $25.7 \%[\mathrm{P}<0.01]$ and at month 6 of $18.9 \%$ [P=0.01], favoring sacubitril/valsartan). ${ }^{60}$

In contrast, in the PARAGON-HF study involving patients with heart failure retaining LVEF (HFpEF) including Japanese patients, the sacubitril/valsartan group and valsartan group were compared and significant differences were not observed in the composite primary end point of total (first and recurrent) hospitalizations for heart failure and cardiovascular death. However, in a subgroup analysis specified beforehand, significant effects of sacubitril/valsartan were noted in the primary end point, female or a LVEF of $57 \%$ or less. ${ }^{61}$ Similarly, sacubitril/valsartan was more effective in patients with a low LVEF in a subsequent analysis combining the PARADIGM-HF and PARAGON-HF studies, ${ }^{\mathbf{6}}$ suggesting that sacubitril/ valsartan exerts its effects in patients with $\mathrm{HFmrEF}$ $(40 \leq \mathrm{LVEF}<50 \%)$. On February 2021, the US Food and Drug Administration (FDA) approved the following expanded indication for sacubitril/valsartan: to decrease the risk of cardiovascular death and hospitalization for heart failure in adult patients with chronic heart failure. The benefits are most clearly evident in patients with a LVEF that is less than normal. The label also states that LVEF is a variable measure and clinical judgment should

\begin{tabular}{|c|c|c|c|c|}
\hline & COR & LOE & $\begin{array}{c}\text { GOR } \\
\text { (MINDS) }\end{array}$ & $\begin{array}{c}\text { LOE } \\
\text { (MINDS) }\end{array}$ \\
\hline $\begin{array}{l}\text { Switch from ACE inhibitors (or ARB) to ARNI is recommended when } \\
\text { symptoms are present or the effects are insufficient in HFrEF already treated } \\
\text { with ACE inhibitors (or ARB), } \beta \text {-blockers, and MRA }\end{array}$ & I & A & A & II \\
\hline $\begin{array}{l}\text { Administration of ARNI during hospitalization should be considered for } \\
\text { HFrEF untreated with ACE inhibitors (or ARB) }\end{array}$ & Ila & $\mathrm{B}$ & B & II \\
\hline $\begin{array}{l}\text { Switch from ACE inhibitors (or ARB) to ARNI should be considered for NYHA } \\
\text { classification functional class II or greater HFmrEF treated with diuretics }\end{array}$ & Ila & $\mathrm{B}$ & B & II \\
\hline Administration of ARNI for HFpEF may be considered & Ilb & B & $\mathrm{C} 1$ & II \\
\hline
\end{tabular}

ACE, angiotensin-converting enzyme; ARB, angiotensin receptor blocker; ARNI, angiotensin receptor neprilysin inhibitor; GOR, grade of recommendation (Medical Information Network Distribution Service [MINDS]); HFpEF, heart failure with preserved ejection fraction; HFrEF, heart failure with reduced ejection fraction; LOE, level of evidence (MINDS); LVEF, left ventricular ejection fraction; MRA, mineralocorticoid receptor antagonist; NYHA, New York Heart Association. *It is not covered by insurance in Japan, but it is described in the European Society of Cardiology clinical practice update ${ }^{59}$ that administration may be considered. 
be used in deciding whom to treat.

Regarding adverse events, the incidences of symptomatic hypotension and nonsevere angioedema were higher in patients treated with sacubitril/valsartan than enalapril or valsartan in both PARADIGM-HF and PARAGON-HF, but the incidences of kidney disorder and hyperkalemia were lower. The rate of patients with angioedema was $0.5-0.6 \%$, being not high, in the sacubitril/valsartan group. In the PARALLEL-HF study involving Japanese, a 36-hour washout period, about 3 times longer than the elimination half-life of ACE inhibitors and LBQ657, was set, and no obvious angioedema was observed. ${ }^{60}$ For the actual use, it is recommended to discontinue ACE inhibitor administration 36 hours before the initiation of sacubitril/ valsartan administration and combination with ACE inhibitors is contraindicated. Amyloid $\beta$ is known as a substrate of neprilysin. ${ }^{63}$ LBQ657 crosses the blood-brain barrier, but because many enzymatic pathways are involved in removal of amyloid $\beta$ in the brain, it is unclear whether long-term inhibition of neprilysin leads to amyloid $\beta$ accumulation in the brain; at present, no increase has been observed in the incidence of dementia or related adverse events. Currently, the PERSPECTIVE study is underway, in which cognitive function and amyloid deposition in the brain on PET are planned to be evaluated 3 years after the administration of sacubitril/valsartan in patients with heart failure and it is scheduled to complete in March 2022. However, this study does not include Asians. It may be necessary to perform long-term evaluation of cognitive function in Japanese in the future.

\section{SGLT2 Inhibitors}

SGLT2 inhibitors have been expected as a new drug to be selected aiming at primary and secondary prevention and treatment of heart failure. By 2018, the guidelines and statements in Western countries ${ }^{\mathbf{5 9 , 6 4}} \mathbf{6 6}$ recommended GLP-1 receptor agonists to patient with type 2 diabetes mellitus (T2DM) with major angiopathy and active use of SGLT2 inhibitors to patients with T2DM complicated by heart failure and chronic kidney disease (CKD; stage 3 or milder) based on evidence of a cardiovascular safety study (CVOT) of so-called antidiabetic drugs. A similar tendency was confirmed in a subanalysis also in Japanese, ${ }^{67,68}$ and the use of SGLT2 inhibitors for diabetes treatment of patients with heart failure can be actively recommended also in Japan. It is worth mentioning the subanalysis results ${ }^{\mathbf{6 9}, 70}$ that significant heart failure development-reducing effects of SGLT2 inhibitors were observed especially in patients with heart failure complicated by diabetes with a past medical history of cardiovascular disease. Table 11 summarizes the known pharmacologic action mechanisms and treatment effects on heart failure expected based on these mechanisms. ${ }^{71-86}$

In 2019, the DAPA-HF study, a global large-scale randomized controlled trial demonstrated that, among patients with HFrEF, the risk of worsening heart failure or death from cardiovascular causes was lower among those who received dapagliflozin, an SGLT2 inhibitor, than those who received placebo, regardless of the presence or absence of diabetes mellitus, ${ }^{\mathbf{8 7}, \mathbf{8 8}}$ showing that SGLT2 inhibitors are a new option for the treatment of heart failure, independent from diabetes. In the DAPAHF study, patients with heart failure complicated by T2DM were included in the participants and it is worthy of a special mention that in a subanalysis comparing the T2DM-compicated HFrEF patient group and non-T2DM-complicated HFrEF patient group, the HR of heart failure aggravation and cardiovascular death was $0.73(95 \%$ CI $0.60-0.88)$ in the non-T2DM-complicated HFrEF patient group, and 0.75 (95\% CI 0.63-0.90) in the T2DM-complicated HFrEF group, clarifying that aggravation of heart failure and cardiovascular death events were inhibited regardless of the presence or absence of complication by T2DM (interaction $\mathrm{P}=0.80) .{ }^{88}$ In response to this study, the use of dapagliflozin for HFrEF was approved regardless of the presence or absence of diabetes by the FDA and, subsequently, the administration of dapagliflozin for HFrEF to patients in whom the standard heart failure treatment based on the

\begin{tabular}{|c|c|}
\hline Pharmacologic action & Effects on heart failure \\
\hline Urination (natriuresis + osmotic diuresis) ${ }^{71,72}$ & $\begin{array}{l}\text { Reduction of cardiac volume overload, more useful than loop } \\
\text { diuretics for improvement of interstitial edema, }{ }^{72} \text { weight loss }\end{array}$ \\
\hline Reduction of sympathetic hyperactivity ${ }^{73,74}$ & $\begin{array}{l}\text { Reduction of blood pressure elevation, }{ }^{75} \text { reduction of positive } \\
\text { chronotropic/inotropic action }\end{array}$ \\
\hline $\begin{array}{l}\text { Improvement of metabolic efficiency of myocardial } \\
\text { energy }{ }^{76,77}\end{array}$ & Improvement of cardiac contractile force ${ }^{77,78}$ \\
\hline $\begin{array}{l}\text { Increase in hematocrit owing to enhanced secretion } \\
\text { of erythropoietin }{ }^{71,78,79}\end{array}$ & Improved oxygen supply to the whole body ${ }^{80}$ \\
\hline $\begin{array}{l}\text { Reduction of chronic inflammation (inflammasome- } \\
\text { inhibitory effect, AMPK activation) }\end{array}$ & Inhibition of cardiac remodeling \\
\hline $\begin{array}{l}\text { Reduction of oxidative stress (improvement of } \\
\text { mitochondrial function) }{ }^{77}\end{array}$ & Inhibition of cardiac remodeling \\
\hline Improvement of glucose metabolism ${ }^{82}$ & $\begin{array}{l}\text { Reduction of glucotoxicity, improvement of obesity, inhibition } \\
\text { of arteriosclerosis }\end{array}$ \\
\hline Improvement of obesity ${ }^{83}$ & $\begin{array}{l}\text { Reduction of cardiac load (pressure/volume load), reduction } \\
\text { of chronic inflammation }\end{array}$ \\
\hline $\begin{array}{l}\text { Renal protective action, reduction of renal tubular } \\
\text { disorder }{ }^{84,85}\end{array}$ & Inhibition of aggravation of cardiorenal syndrome ${ }^{71,78,86}$ \\
\hline
\end{tabular}

AMPK, adenosine monophosphate-activated protein kinase. 


\begin{tabular}{|c|c|c|c|c|c|c|}
\hline SGLT2 inhibitor & Study name & $\begin{array}{l}\text { No. of } \\
\text { registered } \\
\text { patients }\end{array}$ & $\begin{array}{c}\text { Target } \\
\text { disease }\end{array}$ & $\begin{array}{l}\text { Duration of } \\
\text { study }\end{array}$ & Primary end point & $\begin{array}{l}\text { (Secondary end } \\
\text { point) Admission } \\
\text { for heart failure }\end{array}$ \\
\hline Empagliflozin & EMPAREG-OUTCOME ${ }^{96}$ & 7,028 & T2DM+CVD & 3 years & $\begin{array}{l}\text { 3P-MACE } \\
0.86 \\
(P=0.04)\end{array}$ & $\begin{array}{l}\text { Hazard ratio } \\
0.65 \\
(P=0.0017)\end{array}$ \\
\hline Dapagliflozin & DECLARE-TIMI5897 & 17,276 & T2DM+CVD & 4.2 years & $\begin{array}{l}\text { 3P-MACE } \\
0.93 \\
(P=0.17) \\
\text { for superiority } \\
(P<0.001) \\
\text { for noninferiority } \\
\text { Cardiovascular } \\
\text { death or admission } \\
\text { for heart failure } \\
0.83 \\
(P=0.005)\end{array}$ & $\begin{array}{l}\text { Hazard ratio } \\
P=0.73\end{array}$ \\
\hline \multirow[t]{2}{*}{ Canagliflozin* } & CANVAS Program 98,100 & 10,142 & T2DM & 6 years & $\begin{array}{l}\text { 3P-MACE } \\
0.86 \\
(P=0.02)\end{array}$ & $\begin{array}{l}\text { Hazard ratio } \\
0.67 \\
(P=0.002)\end{array}$ \\
\hline & CANVAS 99,100 & 4,330 & T2DM & 6 years & $\begin{array}{l}0.88 \\
(P=0.112)\end{array}$ & $\begin{array}{l}0.68 \\
(P=0.003)\end{array}$ \\
\hline $\begin{array}{l}\text { Ertugliflozin (not } \\
\text { released in Japan) }\end{array}$ & VERTIS CV ${ }^{101}$ & 8,246 & T2DM+CVD & 6 years & $\begin{array}{l}\text { 3P-MACE } \\
0.97 \\
(P<0.001) \\
\text { for noninferiority }\end{array}$ & $\begin{array}{l}\text { Hazard ratio } \\
0.70 \\
(P=0.006)\end{array}$ \\
\hline $\begin{array}{l}\text { Sotagliflozin } \\
\text { (SGLT1 and } \\
\text { SGLT2 inhibitors } \\
\text { not released in } \\
\text { Japan) }\end{array}$ & SCORED ${ }^{102}$ & $10,584^{\dagger}$ & $\begin{array}{l}\text { T2DM } \\
\quad \stackrel{+}{\text { CVD/CKD }}\end{array}$ & $\begin{array}{c}1.3 \text { years } \\
\text { (early } \\
\text { termination) }{ }^{\dagger}\end{array}$ & $\begin{array}{l}\text { 3P-MACE } \\
0.74 \\
(P<0.001)\end{array}$ & $\begin{array}{l}\text { Hazard ratio } \\
0.67 \\
(P<0.001)\end{array}$ \\
\hline
\end{tabular}

CVD, cardiovascular disease; CKD, chronic kidney disease; 3P-MACE, one of cardiovascular death, nonfatal myocardial infarction, and nonfatal stroke; SGLT1, sodium glucose cotransporter 1; SGLT2, sodium glucose cotransporter 2; T2DM, type 2 diabetes mellitus. ${ }^{*}$ The CANVAS Program is the result of an integrated analysis of the CANVAS study, which is the original cardiovascular outcome study, and the CANVASRenal (CANVAS-R) study, which confirms the effect on albuminuria and post-marketing cardiovascular safety. ${ }^{\dagger}$ Owing to social circumstances (coronavirus disease 2019 pandemic, suspension of funding from pharmaceutical companies), patient enrollment was completed on schedule, but the observation period was shorter than planned. $¥$ An estimated glomerular filtration rate of $44.5 \mathrm{~mL} / \mathrm{min} / 1.73 \mathrm{~m}^{2}$, urinary albumin $74 \mathrm{mg} / \mathrm{g}$ creatinine (median).

treatment guidelines (GDMT representing $\beta$ receptor blockers, MRAs, and ARB/ACE inhibitors) has been introduced was approved in Japan on November 27, 2020. The EMPEROR-Reduced study also demonstrated, that among patients receiving recommended therapy for HFrEF, the empagliflozin group had a lower risk of cardiovascular death or hospitalization for heart failure than the placebo group, regardless of the presence or absence of diabetes, ${ }^{\mathbf{8 9}, 90}$ clarifying that SGLT2 inhibitors contribute to the primary and secondary prevention of heart failure aggravation as a class effect in patients with HFrEF independent from diabetes, including a meta-analysis and subanalysis of these evidences. ${ }^{\text {90-92 }}$ Furthermore, clinical studies (EMMY study, EMPACT-MI study) to confirm the usefulness for not only patients with HFrEF but also patients with $\mathrm{HFpEF}$, and patients with ischemic heart failure are being continued. ${ }^{71,93-95}$ Table 12 ${ }^{96-102}$ and Table 1387,88,103,104 summarize the clinical studies demonstrating important evidence and currently on-going clinical studies.

The clinically important point is the timing of initiation of heart failure treatment with SGLT2 inhibitors after the onset of heart failure. In subanalysis of the EMPERORReduced study, admission for heart failure and events of aggravation significantly decreased from day 12 after initiation of empagliflozin administration, ${ }^{103}$ and it was suggested that treatment with SGLT2 inhibitors may effective from earlier initiation. Furthermore, the results of the SOLOIST-WHF study were published in November 2020 , in which the influence of sotagliflozin administration in the acute and subacute phases of heart failure was evaluated in patients complicated by T2DM defined based on execution of intravenous diuretic administration and clarified the usefulness of introduction of sotagliflozin in the acute phase of heart failure aggravation. ${ }^{104}$ However, attention should be paid to the fact that sotagliflozin also has SGLT1-inhibitory action, it has not been released in Japan, and patient registration was completed early, decreasing the number of registered patients from the planned number in this SOLOIST-WHF study owing to unexpected conditions (the COVID-19 pandemic and suspension of funding from pharmaceutical developer), so that attention should be paid to the fact that the analytical design was changed, "emergency visit for heart failure aggravation" was added to the primary end point, and 1,222 patients ( $\mathrm{HFrEF} 79 \%$, HFpEF $21 \%$ ) collected in the 36-week period from study initiation to suspension were analyzed. Although the efficacy of SGLT2 inhibitors in HFpEF was based on such limited evidence at the present time, they are expected to become part of the GDMT for HFrEF. Indeed, in clinical decision analysis (statistical verification model of decision-making in heart failure treatment) of data from 3.1 million patients with $\mathrm{HFrEF}$ 
Table 13. Studies of SGLT2 Inhibitors Involving Patients With Heart Failure

\begin{tabular}{|c|c|c|c|c|c|c|} 
Drug name & Study name & $\begin{array}{c}\text { No. of } \\
\text { registered } \\
\text { patients }\end{array}$ & Target disease & $\begin{array}{c}\text { Duration of } \\
\text { study (years) }\end{array}$ & Primary end point \\
results
\end{tabular}

\begin{tabular}{|c|c|c|c|c|c|c|}
\hline \multicolumn{7}{|c|}{ Studies targeting patients with chronic heart failure (including patients complicated by diabetes mellitus) } \\
\hline \multirow[t]{5}{*}{ Empagliflozin } & $\begin{array}{l}\text { EMPEROR- } \\
\text { Preserved }\end{array}$ & 4,126 & HFpEF & 3.3 years & $\begin{array}{l}\text { Cardiovascular death or } \\
\text { admission for heart failure }\end{array}$ & Ongoing \\
\hline & $\begin{array}{l}\text { EMPEROR- } \\
\text { Reduced }^{103}\end{array}$ & 2,850 & HFrEF & 3.2 years & $\begin{array}{l}\text { Cardiovascular death or } \\
\text { admission for heart failure }\end{array}$ & $\begin{array}{l}\text { Hazard ratio } \\
0.75 \\
(\mathrm{P}<0.001)\end{array}$ \\
\hline & $\begin{array}{l}\text { EMPERIAL- } \\
\text { Preserved }\end{array}$ & 300 & HFpEF & 1.3 years & 6-minute walk distance & Ongoing \\
\hline & $\begin{array}{l}\text { EMPERIAL- } \\
\text { Reduced }\end{array}$ & 300 & HFrEF & 1.3 years & 6-minute walk distance & Ongoing \\
\hline & Empire HF & 189 & HFrEF & 12 weeks & Changes in NT-proBNP & Ongoing \\
\hline \multirow[t]{6}{*}{ Dapagliflozin } & DAPA-HF 87,88 & 4,500 & HFrEF & 2.8 years & $\begin{array}{l}\text { Cardiovascular death or } \\
\text { admission for heart failure }\end{array}$ & $\begin{array}{l}\text { Hazard ratio } \\
0.74 \\
(\mathrm{P}<0.001)\end{array}$ \\
\hline & DELIVER & 6,100 & HFpEF & 2.8 years & $\begin{array}{l}\text { Cardiovascular death or } \\
\text { admission for heart failure }\end{array}$ & Ongoing \\
\hline & PRESERVED-HF & 320 & HFpEF & 2 years & Changes in NT-proBNP & Ongoing \\
\hline & $\begin{array}{l}\text { DETERMINE- } \\
\text { Reduced }\end{array}$ & 313 & HFrEF & 16 weeks & $\begin{array}{l}\text { Heart failure symptoms } \\
\text { (KCCQ-TSS) }\end{array}$ & Ongoing \\
\hline & $\begin{array}{l}\text { DETERMINE- } \\
\text { Preserved }\end{array}$ & 504 & HFpEF & 16 weeks & $\begin{array}{l}\text { Heart failure symptoms } \\
\text { (KCCQ-TSS) }\end{array}$ & Ongoing \\
\hline & DEFINE-HF & 263 & HFrEF & 12 weeks & Changes in NT-proBNP & Ongoing \\
\hline $\begin{array}{l}\text { Ertugliflozin (not } \\
\text { available in Japan) }\end{array}$ & ERTU-GLS & 120 & $\mathrm{HF}$ & 24 weeks & $\begin{array}{l}\text { GLS value of strain } \\
\text { echocardiography }\end{array}$ & Ongoing \\
\hline \multicolumn{7}{|c|}{ Studies targeting acute and subacute patients with heart failure (including patients complicated by diabetes mellitus) } \\
\hline $\begin{array}{l}\text { Sotagliflozin } \\
\text { (SGLT1 and } \\
\text { SGLT2 inhibitors } \\
\text { not available in } \\
\text { Japan) }\end{array}$ & SOLOIST-WHF104 & $1,222^{*}$ & $\begin{array}{l}\text { Type } 2 \text { diabetes } \\
\text { mellitus patients } \\
\text { admitted for heart } \\
\text { failure and treated } \\
\text { with intravenous } \\
\text { injection of diuretics }^{\dagger}\end{array}$ & 36 weeks & $\begin{array}{l}\text { Cardiovascular death, } \\
\text { admission for heart failure, } \\
\text { emergency visit for } \\
\text { aggravation of heart failure }\end{array}$ & $\begin{array}{l}\text { Hazard ratio } \\
0.67 \\
(\mathrm{P}<0.001)^{*}\end{array}$ \\
\hline
\end{tabular}

GLS, global longitudinal strain; HF, heart failure; HFpEF, heart failure with preserved ejection fraction; HFrEF, heart failure with reduced ejection fraction; KCCQ-TSS, Kansas City Cardiomyopathy Questionnaire total symptom score; NT-proBNP, N-terminal pro-brain natriuretic peptide; SGLT2, sodium glucose cotransporter 2. *Owing to social circumstances (coronavirus disease 2019 pandemic, suspension of funding from pharmaceutical companies), study enrollment was terminated early and the number of registered patients was lower than planned, so emergency visit for heart failure aggravation was added to the primary end point to allow the analysis of the 1,222 patients collected during the 36 weeks from study initiation to suspension. THFrEF (79\%) and HFpEF (21\%).

in the United States in 2019, the number needed to treat in decreasing the risk of all-cause mortality in patients with HFrEF was 22 (42 months) for ACE inhibitors/ARBs, 36 (27 months) for ARNIs, and 34 (12 months) for $\beta$-blockers, compared with 43 (18 months) for SGLT2 inhibitors. ${ }^{105}$

The benefit of the renal-protective effects of SGLT2 inhibitors are important as a mechanism of the cardioprotective effects of SGLT2 inhibitors. ${ }^{65,69}$ The CREDENCE study ${ }^{106}$ (canagliflozin) evaluating the influence of SGLT2 inhibitors on admission for heart failure in patients with T2DM complicated by CKD as a secondary end point and the SCORED ${ }^{102}$ study (sotagliflozin) evaluating this as a primary end point are the only evidence acquired as of 2020. In the CREDENCE study, a significant decrease in the risk of either cardiovascular death, myocardial infarction, or stroke was noted in the active drug group of patients with T2DM complicated by CKD (moderate renal hypofunction; estimated glomerular filtration rate [eGFR] $\left.56.2 \mathrm{~mL} / \mathrm{min} / 1.73 \mathrm{~m}^{2}\right)$, a median urinary albumin/creatinine ratio of $927 \mathrm{mg} / \mathrm{g}$ (HR $0.80,95 \% \mathrm{CI} 0.67-0.95, \mathrm{P}=0.01)$ and admission owing to the heart failure (HR $0.61,95 \% \mathrm{CI}$ $0.47-0.80, \mathrm{P}<0.001)$. In the SCORED study, cardiovascular death, all admissions for heart failure, and emergency visit were significantly decreased by $33 \%$ in the active drug group of type 2 patients complicated by CKD (moderate renal hypofunction [median eGFR $44.5 \mathrm{~mL} / \mathrm{min} / 1.73 \mathrm{~m}^{2}$, median urinary albumin $74 \mathrm{mg} / \mathrm{gCr}$ ) ( $\mathrm{HR} 0.67,95 \% \mathrm{CI}$ $0.55-0.82, \mathrm{P}<0.001)$. No significant difference was noted in cardiovascular death alone between the groups (HR 0.90, 95\% CI $0.73-1.12, \mathrm{P}=0.35$ ), which may have been due to the shortened study observation period caused by social circumstances (see footnote to Table 12). ${ }^{102}$ Both of these drugs are SGLT2 inhibitors with SGLT1-inhibitory action, ${ }^{107}$ but no data of comparison with an SGLT2specific either inhibitor is available, and it is unclear whether the effects are limited to the overlapping SGLT1/2inhibitory action. The SGLT1-inhibitory action leads to a more effective blood glucose-improving effect in patients complicated by renal dysfunction, ${ }^{102}$ which may be indirectly resulting in usefulness for cardiovascular events through the vascular protective action.

For the renal-protective effects of SGLT2 inhibitors, evidence not limited to T2DM is being clarified. It has been confirmed that dapagliflozin significantly inhibited aggra- 
Table 14. Remaining Clinical Questions and Reference Matters to Be Considered in the Use of SGLT2 Inhibitors in Patients With Heart Failure

\section{Clinical question}

\section{Evidence gaps}

\section{Off-target action on heart failure}

Can SGLT2 inhibitors administration be recommended for all stages of heart failure stage?

Recommendation of optimum timing of initiation of SGLT2

inhibitor administration after the onset of heart failure
Preventive or therapeutic

Acute phase or chronic phase (the usefulness of acute phase administration was shown by the SOLOIST-WHF study [the study was suspended]) ${ }^{104}$ EMPULSE (ClinicalTrials.gov Identifier: NCT04157751) and DAPA ACT HF-TIMI 68 (ClinicalTrials.gov Identifier: NCT04363697)

Propriety of combination with loop diuretics for patients with heart failure

Careful combination is possible by giving education on adverse events to patients ${ }^{110}$

Difference in the usefulness of SGLT2 inhibitor administration by Clinical study is underway ${ }^{71}$ cardiac function (HFrEF vs HFpEF)

Can SGLT2 inhibitor administration be recommended regardless of the cause of heart failure?

Are there differences in the heart failure-preventive effects between ischemic and nonischemic heart failure?

Usefulness of SGLT1-inhibitory action

Influence by the cause, such as ischemia, valvular disease, and secondary cardiomyopathy

EMMY study, ${ }^{94}$ EMPACT-MI study ${ }^{95}$

No study compared SGLT1/2 inhibitors and SGLT2 inhibitors

Off-target action of renal protective action

Efficacy for nondiabetic renal failure, optimize use for stage 4 or higher CKD cases

DAPA-CKD study, ${ }^{108}$ EMPA-KIDNEY study ${ }^{109}$

Adverse effects ${ }^{80}$

Consideration for adverse events, such as genitourinary tract infection, euglycemic ketosis, promotion of natriuresis and intravascular volume depletion, fracture, and sarcopenia, and consideration for patients with heart failure for whom complication by these risks is of concern

Concern for aggravation of peripheral arterial disease (canagliflozin)

Concern for aggravation of diabetic lower limb lesions (diabetic foot) and cellulitis

Especially, administration to the elderly ${ }^{111}$ and clinical status to avoid the administration of SGLT2 inhibitors

Complication by PAD in SGLT2 inhibitor-treated cases has not been reported other than cases treated with canagliflozin. Boxed warning about risk of leg and foot amputations for canagliflozin was removed by the FDA in 2020 based on safety information from recent clinical trials, however, its amputation risk remains and is still described in the Warnings and Precautions section of the prescribing information

CKD, chronic kidney disease; HFpEF, heart failure with preserved ejection fraction; HFrEF, heart failure with reduced ejection fraction; FDA, US Food and Drug Administration; PAD, peripheral arterial disease; SGLT1, sodium glucose cotransporter 1; SGLT2, sodium glucose cotransporter 2.

Table 15. COR and LOE for SGLT2 Inhibitors

Dapagliflozin* or empagliflozin ${ }^{\dagger}$ is recommended to reduce risk of worsening heart failure and cardiovascular death in patients with symptomatic heart failure with reduced ejection fraction (LVEF $\leq 40 \%$ ) despite optimum pharmacologic therapy ( $\beta$-blockers, ACE inhibitors [or ARB], and MRA at the maximum dose or maximum tolerable dose)

ACE, angiotensin-converting enzyme; ARB, angiotensin II receptor blocker; COR, class of recommendation; GOR, grade of recommendation (Medical Information Network Distribution Service [MINDS]); LOE, level of evidence (MINDS); LVEF, left ventricular ejection fraction; MRA, mineralocorticoid receptor antagonist; SGLT2, sodium glucose cotransporter 2. *Approved in Japan. Hunapproved in Japan.

vation of renal function regardless of the presence or absence of the T2DM (continuous decline in the eGFR by $50 \%$ or more, progression to end-stage renal failure) or death (cardiovasculardeath, death from renal failure) (DAPA-CKD study) ${ }^{\mathbf{1 0 8}}$ in an international multicenter randomized double-blind study comparing 4,304 patients with stage 2-4 CKD with an increase in albuminuria with the placebo group. By following a currently on-going clinical study (EMPA-KIDNEY study ${ }^{109}$ ), evaluation as a class effect is expected.

The remaining clinical questions to be considered in the use of SGLT2 inhibitors in patients with heart failure include comparisons in each heart failure stage, evidence for the optimum timing of the initiation of drug administration after the onset of heart failure, difference in the effects by cardiac function (ie, HFrEF or HFpEF), comparison of the effects between the presence and absence of concomitant ischemic heart disease, and the usefulness and its mechanism of concomitant SGLT1 inhibitors (Table 14). ${ }^{\mathbf{7 1 , 8 0 , 9 4 , 9 5 , 1 0 4 , 1 0 8 - 1 1 1}}$ A combination of loop diuretics and SGLT2 inhibitors is worth mentioning. Natriuresis is enhanced by combination of loop diuretics and SGLT2 inhibitors. ${ }^{110,112}$ In the ACC/ 
AHA expert consensus ${ }^{\mathbf{1 0 2}}$ published in 2020, consideration of natriuresis induced by combination of loop diuretics and SGLT2 inhibitors is recommended, and the combination is not prohibited. In a recent randomized crossover study, unlike loop diuretics alone, the use of SGLT2 inhibitors in addition to loop diuretics decreased volume loading without causing elevation of the noradrenaline level or latent kidney disorder (KIM-1 elevation). ${ }^{12}$ The urinary volume was increased, but urinary sodium excretion was not influenced in another report, ${ }^{113}$ so that when administration of loop diuretics and SGLT2 inhibitors in combination to patients with heart failure is newly initiated, currently, it is recommended to ensure educating patients sufficiently (calling attention to promotion of natriuresis, staggering, orthostatic hypotension-like symptoms, and systemic malaise as intravascular volume depletion-induced subjective symptoms, euglycemic diabetic ketoacidosis-induced subjective symptoms, such as abdominal pain, vomiting, nausea, and malaise, and urinary tract and genital infection) $)^{110}$ and prevent adverse events via mutual communication by both medical professionals and patients. As suggested by subanalysis of heart failure in the EMPAREGOUTCOME study, ${ }^{114}$ a decrease in the frequency of the use of loop diuretics in management of heart failure by SGLT2 inhibitors is expected. SGLT2 inhibitors are expected to be a new GDMT for patients with heart failure based on the decrease in cardiac and renal events associated with the improvement in quality of life in comparison with the current standard of care (Table 15).

\section{Newer Drugs}

\subsection{Soluble Guanylate Cyclase Stimulator: Vericiguat}

Although the outcomes of HFrEF has improved by existing therapeutic drugs for heart failure, they are still poor and no drug with evidence for improvement of the outcome of HFpEF has been developed. From this viewpoint, the development of a novel therapeutic drug for heart failure is awaited.115 In patients with heart failure, endothelial dysfunction and increased production of reactive oxygen species decrease the production and bioavailability of nitric oxide (NO) and activity of the NO receptor, soluble guanylate cyclase (sGC), resulting in decreased activation of cyclic guanosine monophosphate (cGMP), as well as conversion to the NO-insensitive (inactive) sGC by reactive oxygen species. Accordingly, cGMP-mediated intracellular signaling has attracted attention as a potential treatment target in HFrEF and HFpEF.115-117 Two types of drugs acting on sGC in a manner independent from NO, an sGC stimulator and an sGC activator, have recently been developed. The sGC stimulants not only directly stimulate $\mathrm{sGC}$ through a region other than the binding region of $\mathrm{NO}$ in a manner independent from NO and promotes cGMP production, but also exhibits a synergistic effect with NO. In contrast, sGC activators bind to oxidized or heme-free non-NO-reactive inactive sGC (also termed apo-sGC) and directly activate sGC. Vericiguat described in this section is an sGC stimulator. ${ }^{115,117}$

A dose-setting phase II randomized controlled study of vericiguat (SOCRATES-REDUCED) has been performed involving patients with HFrEF with an LVEF $45 \%$ or less and a significant dose-dependent relationship was noted between the secondary end point, dose of vericiguat, and reduction of the NT-proBNP level. ${ }^{118}$ Because patients with
HFrEF were shown to be tolerable to vericiguat, a phase III placebo-controlled randomized study (VICTORIA) was performed in 42 countries, including Japan. In this study, a total of 5,050 patients were registered and patients with a LVEF of $45 \%$ or less and a NYHA classification functional class pg II-IV with $300 \mathrm{pg} / \mathrm{mL}$ BNP or $1,000 \mathrm{pg} / \mathrm{mL}$ NT-proBNP in those with sinus rhythm and $500 \mathrm{pg} / \mathrm{mL}$ BNP or $1,600 \mathrm{pg} / \mathrm{mL}$ or higher NT-proBNP in those with atrial fibrillation were selected. ACE inhibitors or ARB were administered to $73 \%, \beta$-blockers were administered to $93 \%$, and MRA was administered to $70 \%$. The mean age of all patients was 67.3 years old and males accounted for $76.1 \%$ of these patietns. ${ }^{119}$ Vericiguat exhibited a significant effect in the composite primary end point of cardiovascular death and admission for heart failure compared with the effect of placebo. Because vericiguat exhibited a significant effect in patients with $5,314 \mathrm{pg} / \mathrm{mL}$ or lower NT-proBNP accounting for threequarters of all patients, it may be necessary to initiate treatment before progressing to severe heart failure with a marked elevation of the NT-proBNP level. In addition, ARNI, which increases cGMP production through membrane form, GC was taken by $14.5 \%$ of patients, but there was no difference in the effect of vericiguat owing to the presence or absence of ARNI, suggesting an independent effect of sGC stimulants. Because the mean age of the participants was 67 years old, further investigation may be necessary for the efficacy for the elderly. Regarding adverse events, the frequencies of anemia and blood pressure reduction tended to be higher in the vericiguat group, but the differences were not significant. The adverse effects, reduction of the renal function and hyperkalemia, were equivalent to those in the placebo group. ${ }^{120}$ The VICTORIA study included many patients with severe heart failure and patients with severe renal dysfunction (eGFR $\geq 15 \mathrm{~mL}$ / $\mathrm{min} / 1.73 \mathrm{~m}^{2}$ ) were also registered.

In contrast, a phase II randomized study (VITALITY-HFpEF study) involving 789 patients with HFpEF with an LVEF of $45 \%$ or greater has been performed, but no useful effect on HFpEF was observed. The primary end point was changes in the Kansa City Cardiomyopathy Questionnaire physical limitation score at 24 hours after treatment, and the secondary end point was the 6-minute walk test, but no significant effect of vericiguat was observed in either end point. ${ }^{121}$

The simultaneous application of vericiguat as a therapeutic drug for HFrEF has been filed in Japan and Western countries. It was approved by the FDA on February 2021 with the following indication: to decrease the risk of cardiovascular death and heart failure hospitalization following a hospitalization for heart failure or need for outpatient intravenous diuretics, in adults with symptomatic chronic heart failure and an EF of less than $45 \%$.

\section{4.2 Cardiac Myosin Activator: Omecamtiv Mecarbil}

Omecamtiv mecarbil is a drug that binds to the catalyst domain of myosin and increases the rate of strong bonding between myosin and actin, which increases the cardiac contractile force. ${ }^{122}$ Accordingly, unlike so-called cardiotonics, such as $\beta$ receptor stimulants and phosphodiesterase III inhibitors, it is not accompanied by increases in intracellular calcium, suggesting that cardiac function can be increased without affecting survival, unlike conventional cardiotonics, and the drug is expected as a new therapeutic 


\begin{tabular}{|c|c|}
\hline \multicolumn{2}{|c|}{$\begin{array}{l}\text { Table 16. Pharmacologic Therapy for HFrEF: Drug Name, } \\
\text { Administration, and Dosage }\end{array}$} \\
\hline Drug $^{*}$ & Administration and dosage \\
\hline $\begin{array}{l}\text { If channel blocker } \\
\text { Ivabradine }\end{array}$ & $\begin{array}{l}\text { Starting dose: } 5 \mathrm{mg} / \mathrm{d} \\
\text { Maintenance dose: } 5,10 \text {, or } 15 \mathrm{mg} / \mathrm{d} \\
\text { Twice daily Target resting heart rate: } \\
50-60 \mathrm{bpm}\end{array}$ \\
\hline $\begin{array}{l}\text { ARNI } \\
\text { Sacubitril/valsartan }\end{array}$ & $\begin{array}{l}\text { Starting dose: } 100 \mathrm{mg} / \mathrm{d} \\
\text { Maintenance dose: } 100,200 \text { or } 400 \mathrm{mg} / \mathrm{d} \\
\text { Twice daily If tolerable, increase dose } \\
\text { stepwise to target dose of } 400 \mathrm{mg} / \mathrm{d}\end{array}$ \\
\hline $\begin{array}{l}\text { SGLT2 inhibitor } \\
\text { Dapagliflozin }\end{array}$ & $\begin{array}{l}10 \mathrm{mg} / \mathrm{d} \\
\text { Once daily }\end{array}$ \\
\hline
\end{tabular}

ARNI, angiotensin receptor neprilysin inhibitor; HFrEF, heart failure with reduced ejection fraction; SGLT2, sodium glucose cotransporter 2. *Limited to drugs covered by insurance.

drug for heart failure. In a study using isolated heart muscle, strengthening of contraction not accompanied by a transient calcium increase, and prolongation of the contraction time were observed. ${ }^{\mathbf{1 2 2}}$ The result of the initial human study of omecamtiv mecarbil was published in 2011 and it was confirmed in healthy participants that the intravenous administration of omecamtiv mecarbil increased the systolic ejection time in a dose-dependent manner and the stroke volume and LVEF. ${ }^{\mathbf{1 2 3}}$ In COSMICHF, ${ }^{124} 448$ patients with HFrEF with an LVEF of $40 \%$ or less were randomly allocated to a group treated with $25 \mathrm{mg}$ omecamtiv mecarbil twice a day, a group with dose escalation up to $50 \mathrm{mg}$ while observing pharmacologic dynamics, or a placebo group, and received administration for 20 weeks. In the group with dose escalation up to $50 \mathrm{mg}$, the ejection time at the 20th week was increased compared with that in the placebo group, and the cardiac output was increased, the left ventricular end-diastolic diameter was shortened, and the heart rate decreased. No significant difference was noted in adverse events among the 3 groups.

In the phase III study to confirm the effect on cardiovascular death or heart failure events, GALACTIC-HF study, 8,256 patients with $\mathrm{HFrEF}$ ( $\mathrm{LVEF}$ of $\leq 35 \%$ ) (inpatients and outpatients) were randomly allocated to omecamtiv mecarbil treatment groups (twice daily pharmacologic dynamicsguided doses of $25.0,37.5$, or $50.0 \mathrm{mg}$ ) or placebo group and the drug or placebo was administered in addition to the standard heart failure treatment. The primary end point was the first heart failure event (admission or emergency visit for heart failure) and complex with cardiovascular death. During the observation period with a median duration of 21.8 months, it occurred in 1,523 of the 4,120 patients $(37.0 \%)$ in the omecamtiv mecarbil group and 1,607 of 4,112 patients $(39.1 \%)$ in the placebo group (HR $0.92,95 \%$ CI $0.86-0.99, \mathrm{P}=0.03)$. No difference was noted in cardiovascular death $(19.6 \%$ vs $19.4 \%$, HR $1.01,95 \%$ CI $0.92-1.11)$. No difference was noted in changes in the total symptom score of the Kansas City Cardiomyopathy Questionnaire. In subgroup analysis, the effect was larger in the group with an LVEF of $28 \%$ or less (HR $0.84,95 \%$ CI $0.77-0.92$, interaction $\mathrm{P}=0.003)$. In addition, NT-proBNP at week 24 was $10 \%$ lower in the omecamtiv mecarbil group. Myocardial ischemia and ventricular arrhythmia events were similar between the 2 groups. Based on the finding that omecamtiv mecarbil improved the outcome of HFrEF, the drug is expected to be positioned as a therapeutic drug for heart failure in the future. ${ }^{\mathbf{2 5}}$

\section{Therapeutic Drugs for HFrEF}

\section{Nonpharmacologic Therapy}

\section{Percutaneous Mitral Valve Repair System (MitraClip ${ }^{\circledR}$ )}

Surgical treatment is recommended for patients with severe primary chronic mitral regurgitation resulting in HFrEF
(Table 17). In contrast, the treatment for severe functional mitral regurgitation is controversial. The initial steps should be the optimization of GDMT for HFrEF.

Percutaneous mitral valve repair is considered for patients at high risk of open heart surgery, although a decrease in subjective symptoms and improvement in quality of life by therapeutic intervention for mitral regurgitation are

\begin{tabular}{|l|c||c|c|}
\hline Table 17. COR and LOE for Percutaneous Mitral Valve Repair & COR & LOE & $\begin{array}{c}\text { GOR } \\
\text { (MINDS) }\end{array}$ \\
(MINDS)
\end{tabular}

COR, class of recommendation; GOR, grade of recommendation (Medical Information Network Distribution Service [MINDS]); HFrEF, heart failure with reduced ejection fraction; LOE, level of evidence (MINDS); LVEF, left ventricular ejection fraction. 
expected among patients with heart failure with organic or functional mitral regurgitation. Percutaneous mitral valve repair using the MitraClip ${ }^{\circledR}$ system enables ambulation early after surgery in patients with organic or functional mitral regurgitation compared with that after open heart surgery and the degree of improvement of patient' subjective symptoms at 30 days after surgery has been reported to be superior, ${ }^{126-128}$ but the outcomeimproving effects are not clear.

The Mitra-FR study ${ }^{\mathbf{1 2 9}}$ and COAPT study ${ }^{\mathbf{1 3 0}}$ were published in 2018. In both studies, patients with HFrEF (LVEF of $20-50 \%$ ) in whom severe functional mitral regurgitation remained and manifested symptoms, even though sufficient pharmacologic therapy was performed were randomly allocated to a group with addition of treatment with MitraClip ${ }^{\circledR}$ and a group with continuation of pharmacologic therapy and the outcome was prospectively investigated. In the COAPT study, the primary end point, all admissions for heart failure by year 2 , decreased by $47 \%$ compared with that in the pharmacologic therapy group, and the MitraClip ${ }^{\circledR}$ group was significantly superior in all items including the separately set secondary end points and all deaths. A recent work of COAPT with extended follow-up through 36 months demonstrated that there was no loss of effectiveness with MitraClip ${ }^{\circledR}$ treatment nor did new safety concerns emerge. ${ }^{131}$ In addition, compared with patients who continued treatment with GDMT alone, patients assigned to GDMT alone who crossed over and received a MitraClip ${ }^{\circledR}$ experienced fewer subsequent heart failure hospitalizations and deaths, with rates comparable with patients originally treated with the MitraClip ${ }^{\circledR}$. Thus, patients meeting COAPT eligibility criteria might benefit from MitraClip ${ }^{\circledR}$ reduction of severe mitral regurgitation even after an extended period of GDMT. In response to this, the FDA expanded the indication of MitraClip ${ }^{\circledR}$ to functional mitral regurgitation in April 2019. In Japan, through the AVJ-514 clinical trial, ${ }^{132}$ the system became covered by insurance in April 2018 for patients difficult to treat with open heart surgery among patients with symptomatic severe mitral regurgitation with an LVEF of $30 \%$ or greater, and the indication was expanded to a lower limit of LVEF from $30 \%$ to $20 \%$ in April 2020. In contrast, in the Mitra-FR study, no outcome-improving effect was observed. The influences of the baseline pharmacologic therapy and degree of myocardial remodeling on the efficacy of MitraClip ${ }^{\circledR}$ are still being discussed, and it has been pointed out that MitraClip ${ }^{\circledR}$ may be especially effective when severe mitral regurgitation mismatched with the left ventricular end-diastolic volume is present. ${ }^{133}$ Evaluation by a multidisciplinary valvular disease team is essential for making a decision on the indications.

\section{Transcatheter Aortic Valve Implantation}

The indication of TAVI or transcatheter aortic valve replacement at present is symptomatic severe aortic stenosis and its surgical indication and timing of surgery follows those of surgical aortic valve replacement (SAVR) (Table 18). For the details, refer to the recent guidelines. ${ }^{\mathbf{1 3 4}-136}$

Generally, patients with heart failure are likely to be at high risk and the optimum treatment method is selected after comprehensive evaluation of the surgical risk and sufficient investigation of the risk and benefit of various treatment methods. For patients with valvular disease for whom the investigation of treatment with surgery and catheter intervention is necessary, decision on treatment strategy by the "heart team" is important. ${ }^{137,138}$ The heart team should be comprised of specialists of valvular disease treatment as well as cardiologists, cardiac surgeons, structural heart disease interventionalists, imaging diagnosticians, anesthesiologists, geriatricians, and intensivists. It is important to deal with from patient selection to procedure and perioperative management by the entire heart team. In Japan, the surgical records, equipment, personnel, qualification requirement of facility, and registry registration are specified in the implementation facility criteria established by the transcatheter aortic valve replacement-related academic society conference, and heart team formation is included in the personnel requirement. Only facilities fulfilling these requirements can perform TAVI. ${ }^{135,139}$ For surgical risk assessment, the Society of

\begin{tabular}{|c|c|c|c|c|}
\hline & COR & LOE & $\begin{array}{c}\text { GOR } \\
\text { (MINDS) }\end{array}$ & $\begin{array}{c}\text { LOE } \\
\text { (MINDS) }\end{array}$ \\
\hline TAVI is recommended to be conducted by the multidisciplinary heart team & I & C & $\mathrm{C} 1$ & VI \\
\hline $\begin{array}{l}\text { TAVI is recommended to be conducted only at medical institutions with } \\
\text { cardiovascular surgery }\end{array}$ & I & $\mathrm{C}$ & C1 & VI \\
\hline $\begin{array}{l}\text { TAVI is recommended for patients with aortic valve stenosis who cannot } \\
\text { undergo cardiotomy and are expected to survive for at least } 1 \text { year after the } \\
\text { procedure }\end{array}$ & 1 & A & A & II \\
\hline $\begin{array}{l}\text { TAVI is recommended as an alternative procedure for patients who are } \\
\text { indicated for aortic valve replacement but are at high risk for surgery }\end{array}$ & I & A & B & II \\
\hline $\begin{array}{l}\text { TAVI should be considered for elderly patients (about } 80 \text { years and higher) } \\
\text { who are indicated for aortic valve replacement but are at moderate or low } \\
\text { surgery risk }\end{array}$ & Ila & A & C1 & II \\
\hline $\begin{array}{l}\text { TAVI may be considered for patients with aortic valve stenosis with reduced } \\
\text { LVEF }\end{array}$ & $\mathrm{llb}$ & C & $\mathrm{C} 2$ & IVa \\
\hline $\begin{array}{l}\text { TAVI is not recommended for patients in whom treatment of aortic stenosis is } \\
\text { not expected to improve postoperative QOL or prognosis }\end{array}$ & $\begin{array}{l}\text { III (No } \\
\text { benefit) }\end{array}$ & A & $\mathrm{D}$ & II \\
\hline
\end{tabular}

COR, Class of Recommendation; GOR, grade of recommendation (Medical Information Network Distribution Service [MINDS]); QOL, quality of life; LOE, level of evidence (MINDS); TAVI, transcatheter aortic valve implantation. 
Thoracic Surgeons score is generally used, ${ }^{\mathbf{1 4 0 , 1 4 1}}$ but comprehensive judgment in consideration of organ complication, history of radiotherapy, factors making surgery of porcelain aorta difficult, and frailty not included in the score is necessary. ${ }^{134,137,142-145}$

TAVI is recommended for patients with severe aortic stenosis judged as inappropriate for surgery by the heart team and expected to survive for more than 1 year after surgery. ${ }^{146-149}$ TAVI should be also considered for patients for whom SAVR can be indicated, for whom but TAVI is judged as preferable by the heart team based on the risk and anatomic conditions of individual patients. ${ }^{148-151}$ In contrast, for patients for whom TAVI was judged as high risk or not applicable based on the anatomic conditions (the diameter of the aortic annulus incompatible with the TAVI device, left ventricular thrombus, active endocarditis, coronary artery ostial occlusion, and plaque accompanied by mobility of the ascending aorta and aortic $\operatorname{arch}^{\mathbf{1 3 5 , 1 3 6}}$ ), SAVR should be reconsidered. Moreover, patients for whom improvement of symptoms and quality of life by treatment cannot be expected are excluded from the indication. ${ }^{137,146-149}$ The indication of TAVI in Japan was limited to inoperable or high-risk patients, but multiple randomized controlled trials involving patients at moderate risk have been published in Western countries and the superiority ${ }^{152,153}$ or noninferiority ${ }^{154}$ of TAVI through the transfemoral arterial approach to SAVR have been demonstrated, based on which class IIa and class I are indicated for patients at moderate risk in the AHA guidelines (2017) ${ }^{\mathbf{1 5 5}}$ and ESC/European Association of CardioThoracic Surgery guidelines (2017).156 Thereafter, a randomized controlled trial targeting patients at low risk was performed and noninferiority ${ }^{157}$ or superiority ${ }^{158}$ of TAVI using a next-generation device, such as Edwards
SAPIEN 3 and CoreValve Evolut R/PRO, was demonstrated 1-2 years after surgery. Based on these findings, TAVI for low-risk patients has been approved by the FDA in 2019. However, because sufficient data on long-term durability of biological catheter valve are still not available and no treatment method of deteriorated catheter valve has been established, the age should be also considered for the indication of TAVI for moderate- or low-risk patients. In the ESC guidelines, consideration of TAVI for patients 75 years old or greater is described, but because the life expectancy of Japanese patients is longer by about 3-5 years than those in advanced Western countries, SAVR and TAVI should be considered for patients younger than 75 years old and those aged 80 years or older, respectively, with additional consideration of the frailty score, activities of daily living, and cognitive function.

For patients with severe aortic stenosis with reduced left ventricular function, attention should be paid to the condition of low-flow/low-gradient (valvular area $<1 \mathrm{~cm}^{2}$, LVEF $<40 \%$, mean pressure gradient $<40 \mathrm{mmHg}$ ) and dobutamine stress echocardiography is useful for its differentiation. ${ }^{\mathbf{1 5 9 , 1 6 0}}$ Complete improvement of left ventricular function and symptoms cannot be expected in patients with reduced left ventricular function not definitely judged as caused by an increase in afterload, but survival improves. ${ }^{161}$ Regarding the outcome of TAVI in patients with LV dysfunction, the outcome was favorable early after surgery in some reports, ${ }^{\mathbf{1 6 2}, \mathbf{1 6 3}}$ but LV dysfunction was a factor of poor outcome in others, ${ }^{\mathbf{1 6 4}, 165}$ and no consistent viewpoint has been obtained. However, it has recently been reported that the efficacy of TAVI is not affected by LVEF or systolic reserve, so that the indication of TAVI for patients with severe LV dysfunction (LVEF of $<30 \%$ ) should be also investigated. ${ }^{\mathbf{1 6 6}}$

\section{v. Comorbidities}

\section{Atrial Fibrillation}

\section{I1.1 Heart Rate Adjustment Therapy (Rate Control)}

In a multicenter prospective observational study performed in Japan in which the influence of resting heart rate on the outcome of patients with heart failure with reduced cardiac function was surveyed, the outcome of patients admitted for heart failure showed poorer prognosis in the patients with a resting heart rate at discharge of higher than $81 \mathrm{bpm}$ as compared with the patients with $81 \mathrm{bpm}$ or lower heart rate (Table 19). ${ }^{167}$ In a registration study in Sweden, the mortality of patients with HFrEF increased according to the heart rate increase in patients with sinus rhythm, but the mortality increased only when the heart rate exceeded $100 \mathrm{bpm}$ in patients with atrial fibrillation, suggesting the effect of $\beta$-blockers on the prognosis observed in patients with either sinus rhythm or atrial fibrillation. ${ }^{168}$ It is necessary to clarify the relationship between the target heart rate of atrial fibrillation and long-term outcome and risk of recurrence of heart failure in patients with heart failure by a large-scale study in the future.

The available $\beta$-blockers for heart rate control in Japan include bisoprolol and carvedilol. Bisoprolol has strong heart rate-reducing effect with high $\beta 1$ selectivity. In contrast, carvedilol is a drug having both nonselectivity and $\alpha_{1}$ blocking action and it is useful for mild rate control in the elderly. ${ }^{169} \beta$-Blockers may aggravate heart failure when initiated in an acutely decompensated state or if low perfusion is suspected. The concomitant use of diuretics may be required with the initiation or uptitration of $\beta$-blockers. $\beta$-Blockers are used not only for heart rate control but for the treatment of asymptomatic and symptomatic LV dysfunction.

Oral digoxin has positive inotropic action in addition to negative chronotropic effect and is administered for patients with heart failure. However, its effect of heart rate control during daytime activities is not so strong compared with that of $\beta$-blockers. ${ }^{170}$ A subanalysis of the AF-CHF study clarified that long-term digoxin administration in the patients with heart failure with reduced cardiac function aggravated the outcome owing to arrhythmia-related death, so that the long-term use of digoxin should be avoided. ${ }^{169}$

\section{I1.2 Sinus Rhythm Maintenance Therapy (Rhythm Control)}

In the 2018 JCS/JHRS guidelines on nonpharmacotherapy of cardiac arrhythmias, ${ }^{171}$ elective radiofrequency catheter 
Table 19. COR and LOE for the Management of Atrial Fibrillation as a Comorbidity of Heart Failure

\begin{tabular}{|c|c|c|c|c|}
\hline & COR & LOE & $\begin{array}{c}\text { GOR } \\
\text { (MINDS) }\end{array}$ & $\begin{array}{c}\text { LOE } \\
\text { (MINDS) }\end{array}$ \\
\hline \multicolumn{5}{|l|}{ Acute phase treatment for tachycardiac atrial fibrillation complicating acute heart failure } \\
\hline $\begin{array}{l}\text { Immediate electrical defibrillation is recommended for patients with hemodynamically unstable } \\
\text { tachyarrhythmia whose heart rate is difficult to control with medical therapy }\end{array}$ & 1 & $\mathrm{C}$ & $\mathrm{C} 1$ & VI \\
\hline Intravenous landiolol should be considered for heart rate control & Ila & B & B & II \\
\hline Intravenous digoxin should be considered for heart rate control & Ila & $\mathrm{C}$ & B & II \\
\hline Intravenous amiodarone may be considered for heart rate control & $\mathrm{Ilb}$ & $\mathrm{C}$ & $\mathrm{C} 1$ & $\mathrm{IVb}$ \\
\hline $\begin{array}{l}\text { Intravenous nondihydropyridine calcium antagonist should not be administered for heart rate control in } \\
\text { patients with reduced ejection function }\end{array}$ & $\begin{array}{l}\text { III } \\
(\text { Harm })\end{array}$ & $\mathrm{C}$ & $\mathrm{D}$ & II \\
\hline $\begin{array}{l}\text { Intravenous sodium channel blockers (with strong blocking action) should not be administered in } \\
\text { patients with reduced cardiac function to restore sinus rhythm and maintain sinus rhythm after } \\
\text { defibrillation }\end{array}$ & $\begin{array}{l}\text { III } \\
(\text { Harm })\end{array}$ & C & $\mathrm{D}$ & II \\
\hline \multicolumn{5}{|l|}{ Rhythm control therapy for atrial fibrillation complicating HFrEF (left ventricular ejection fraction $<40 \%$ ) } \\
\hline Oral administration of amiodarone should be considered to maintain sinus rhythm & $\mathrm{Ila}$ & B & B & $\mathrm{IVb}$ \\
\hline $\begin{array}{l}\text { Elective electrical cardioversion is considered for patients with persistent atrial fibrillation lasting less } \\
\text { than } 1 \text { year without marked dilatation of left atrium }\end{array}$ & Ila & $\mathrm{C}$ & $\mathrm{C} 1$ & VI \\
\hline $\begin{array}{l}\text { Catheter ablation should be considered for symptomatic atrial fibrillation that is refractory to rate } \\
\text { control and heart failure pharmacologic therapy }\end{array}$ & Ila & B & B & II \\
\hline $\begin{array}{l}\text { Oral administration of sodium channel blockers (with strong blocking action) should not be } \\
\text { administered to restore sinus rhythm and maintain sinus rhythm after defibrillation }\end{array}$ & $\begin{array}{l}\text { III } \\
(\text { Harm })\end{array}$ & A & $\mathrm{D}$ & II \\
\hline \multicolumn{5}{|l|}{ Rate control for atrial fibrillation complicating HFrEF (left ventricular ejection fraction $<40 \%$ ) } \\
\hline $\begin{array}{l}\text { Oral } \beta \text {-blockers are recommended to be administered in small doses and titrated upward to heart rate } \\
\text { control }\end{array}$ & 1 & A & A & I \\
\hline $\begin{array}{l}\text { Biventricular pacing therapy + atrioventricular nodal ablation may be considered for atrial fibrillation } \\
\text { with drug-refractory heart rate control }\end{array}$ & $\mathrm{Ilb}$ & $\mathrm{C}$ & B & IVb \\
\hline $\begin{array}{l}\text { Oral amiodarone as rate control therapy may be considered for atrial fibrillation with refractory heart } \\
\text { rate control by } \beta \text {-blockers or digoxin alone or their combination }\end{array}$ & $\mathrm{Ilb}$ & $\mathrm{C}$ & $\mathrm{C} 1$ & VI \\
\hline Oral nondihydropyridine calcium antagonists should not be administered & $\begin{array}{l}\text { III } \\
(\text { Harm })\end{array}$ & $\mathrm{C}$ & $\mathrm{D}$ & II \\
\hline Long-term oral digoxin should not be administered & $\begin{array}{l}\text { III } \\
(\text { Harm })\end{array}$ & $\mathrm{C}$ & $\mathrm{D}$ & II \\
\hline \multicolumn{5}{|l|}{ Anticoagulant therapy for atrial fibrillation complicating heart failure } \\
\hline $\begin{array}{l}\text { Evaluation concerning anticoagulant therapy by the } \mathrm{CHADS}_{2} \text { score and HAS-BLED score is } \\
\text { recommended }\end{array}$ & 1 & B & A & $\mathrm{IVb}$ \\
\hline $\begin{array}{l}\text { Oral anticoagulant therapy (excluding contraindication) for atrial fibrillation complicating heart failure is } \\
\text { recommended }\end{array}$ & 1 & A & A & 1 \\
\hline $\begin{array}{l}\text { Anticoagulant therapy for } 3 \text { weeks before defibrillation and } 4 \text { weeks after defibrillation is recommended } \\
\text { in patients with atrial fibrillation persisting for } 48 \text { hours or longer scheduled for pharmacologic/electrical } \\
\text { defibrillation }\end{array}$ & 1 & B & A & II \\
\hline $\begin{array}{l}\text { Electrical defibrillation using heparin after ruling out intracardiac thrombus by transesophageal } \\
\text { echocardiography is recommended for patients with atrial fibrillation untreated with anticoagulant } \\
\text { therapy }\end{array}$ & 1 & $\mathrm{C}$ & A & II \\
\hline DOAC should be considered as the first choice rather than warfarin & Ila & B & A & II \\
\hline $\begin{array}{l}\text { Combination of dual antiplatelet therapy and anticoagulant therapy may be considered after coronary } \\
\text { artery intervention for ischemic heart disease }\end{array}$ & $\mathrm{Ilb}$ & $\mathrm{C}$ & $\mathrm{C} 2$ & II \\
\hline DOAC should not be used for prosthetic valve (mechanical valve) and rheumatic mitral valve diseases & $\begin{array}{l}\text { III } \\
(\text { Harm })\end{array}$ & B & $\mathrm{D}$ & II \\
\hline
\end{tabular}

COR, class of recommendation; DOAC, direct oral anticoagulant; GOR, grade of recommendation (Medical Information Network Distribution Service [MINDS]); HFrEF, heart failure with reduced ejection fraction; LOE, level of evidence (MINDS).

ablation for symptomatic paroxysmal atrial fibrillation ${ }^{\mathbf{1 7 2}}$ is indicated as recommendation class I for drug-resistant cases and class IIa for cases, even though not treated with antiarrhythmic drugs. ${ }^{173,174}$ Tachycardia-induced cardiomyopathy is a pathophysiology in which tachycardiac atrial arrhythmia triggers a decrease in cardiac function ${ }^{175}$ and the cardiac function recovers after the disappearance of the tachycardia. Differential diagnosis from underlying heart disease, such as dilated cardiomyopathy, is often difficult in the acute phase and can be diagnosed consequently as a result when cardiac function recovered. In addition, it has been reported that conversion of atrial fibrillation to sinus 
rhythm by catheter ablation is effective to recover transiently decreased cardiac function in tachycardiainduced cardiomyopathy. ${ }^{\mathbf{1 7 5}}$

Previous meta-analysis of catheter ablation performed in the patients with atrial fibrillation combined with heart failure has reported improvement of LVEF and the decrease of NT-proBNP level, ${ }^{59}$ but it had been uncertain the longterm outcome by the catheter ablation. Recently, the CASTLE-AF study was published in 2018 in which the patients with heart failure combined with atrial fibrillation were randomly allocated to a catheter ablation group and pharmacologic therapy group (rate or rhythm control). ${ }^{\mathbf{1 7 6}}$ The primary end point - deaths from all causes or admission owing to aggravation of heart failure - was significantly decreased in the catheter ablation group and deaths from all causes, admission for heart failure, and cardiovascular death also decreased by about $50 \%$ in the catheter ablation group, demonstrating the efficacy of catheter ablation. Based on this result, catheter ablation is now considered as promising treatment in terms of prognosis in patients with atrial fibrillation combined with heart failure, for which the same indication level is applied regardless of the presence or absence of heart failure. ${ }^{171}$

Furthermore, the CABANA study was conducted in patients with atrial fibrillation in which $15.3 \%$ of the patients had heart failure and investigated whether catheter ablation for atrial fibrillation decreases combined primary end points: all-cause death, stroke, severe hemorrhage, and cardiac arrest, compared with the standard pharmacologic therapy (sinus rhythm maintenance therapy, heart rate control therapy). ${ }^{177}$ The intention-to-treat analysis showed no significant difference in the combined primary end points between the 2 groups, since $27.5 \%$ and $9.2 \%$ crossover were noted in the pharmacologic therapy group and ablation treatment group, respectively. However, when it was investigated by protocol in a per protocol analysis, the incidences of the primary end points were significantly lower in the ablation group at 12 months. A meta-analysis of studies comparing catheter ablation and pharmacologic therapy including the CABANA study ${ }^{177}$ clarified that all causes of death, development of cerebral infarction, and admission for heart failure were decreased by $38 \%, 37 \%$, and $36 \%$, respectively. ${ }^{178}$ Since the efficacy and safety of catheter ablation for atrial fibrillation have been proved with advancement of medical technology and devices, catheter ablation is considered as a promising treatment for the patients with heart failure combined with atrial fibrillation. ${ }^{171,176,179}$ However, there are risks of procedurerelated serious complications and recurrence of atrial fibrillation, so that it is important to decide the indication of catheter ablation by considering comprehensively the severity of subjective symptoms, age, and the duration of atrial fibrillation.

The recently reported EAST-AFNET 4 study demonstrated that early interventions by sinus rhythm maintenance therapy significantly decreased the primary end points of deaths from all causes, cardiovascular death, stroke, admission owing to aggravation of heart failure, and acute coronary syndrome in patients with atrial fibrillation diagnosed within 1 year. ${ }^{\mathbf{1 8 0}}$

\section{I1.3 Anticoagulant Therapy}

The $\mathrm{CHA}_{2} \mathrm{DS}_{2}-\mathrm{VASc}$ score consisting of the $\mathrm{CHADS}_{2}$ score combined with an additional risk index is widely adopted for risk assessment of cerebral infarction and systemic embolism development in the patients with atrial fibrillation in Western countries. However, an integrated analysis of Japanese registry studies (J-RHYTHM Registry, Fushimi AF Registry, Shinken Database) ${ }^{\mathbf{1 8 1}}$ clarified that the age (65-74 years old), vascular disease, and being female included in the $\mathrm{CHA}_{2} \mathrm{DS}_{2}$-VASc score are not significant risk factors of thromboembolism for Japanese patients untreated with anticoagulation therapy. Therefore, the conventional $\mathrm{CHADS}_{2}$ score was once again adopted in the JCS/JHRS 2020 Guideline on Pharmacotherapy of Cardiac Arrhythmias. ${ }^{182}$ The CHADS 2 score in the patients with atrial fibrillation combined with heart failure is scored at least 1 point. Although there is no precise definition of heart failure for indication of anticoagulation therapy, anticoagulation therapy is recommended in case of the presence of heart failure symptoms, examination findings indicating heart failure, or receiving pharmacologic therapy for heart failure; otherwise, it is not contraindicated. Because the prevention of recurrence of atrial fibrillation and heart rate control are difficult in patients with heart failure and a therapeutic intervention, such as pharmacologic therapy and electrical defibrillation is required in the treatment course, especially in acute patients with heart failure, rapid introduction of anticoagulant therapy is recommended. However, because there are limited data for the $\mathrm{CHADS}_{2}$ score or $\mathrm{CHA}_{2} \mathrm{DS}_{2}-\mathrm{VASc}$ score targeting acute patients with heart failure, it is necessary to confirm anticoagulant therapy for patients with acute heart failure in the future.

Atrial fibrillation concomitantly developing with chronic heart failure has been treated with anticoagulation therapy with warfarin, but its effects vary owing to interaction with vitamin $\mathrm{K}$ and drugs, for which it was necessary to confirm the prothrombin time-international normalized ratio (PTINR) value and adjust the dose. However, the development of direct oral anticoagulants (DOAC) has changed the therapeutic strategy for the anticoagulation in patients with atrial fibrillation combined with heart failure. The efficacy of DOAC in the patients with heart failure was equivalent to that of warfarin, but the incidence of massive bleeding including intracranial bleeding is lower, being superior in the safety in patients receiving DOAC compared with those receiving warfarin. ${ }^{183,184}$ For the use of DOAC in patients with heart failure, symptoms and renal function may change with drug administration and clinical course. In such cases, the dose reduction and careful administration of DOAC need to be paid attention to. When warfarin is used to treat nonvalvular disease-associated atrial fibrillation, the target PT-INR value is recommended to be maintained between 1.6 and 2.6, regardless of the age in patients with no past medical history of cerebral infarction or a high risk of thromboembolism in the JCS/JHRS 2020 Guideline on Pharmacotherapy of Cardiac Arrhythmias. ${ }^{182}$ The guidelines in Western countries recommended the target PT-INR of 2-3 for the management of patients with nonvalvular disease-associated atrial fibrillation. However, in Japan, a target INR of between 1.6 and 2.6 has been recommended for patients 70 years of age and older with nonvalvular AF. ${ }^{185}$ The J-RHYTHM Registry of 7,406 Japanese patients also confirmed a target of 1.6-2.6 is safe and effective at preventing thromboembolic events in patients with nonvalvular AF, particularly for patients aged 70 years or more and that an INR of $2.60-2.99$ is associated with a slightly increased risk of major hemor- 


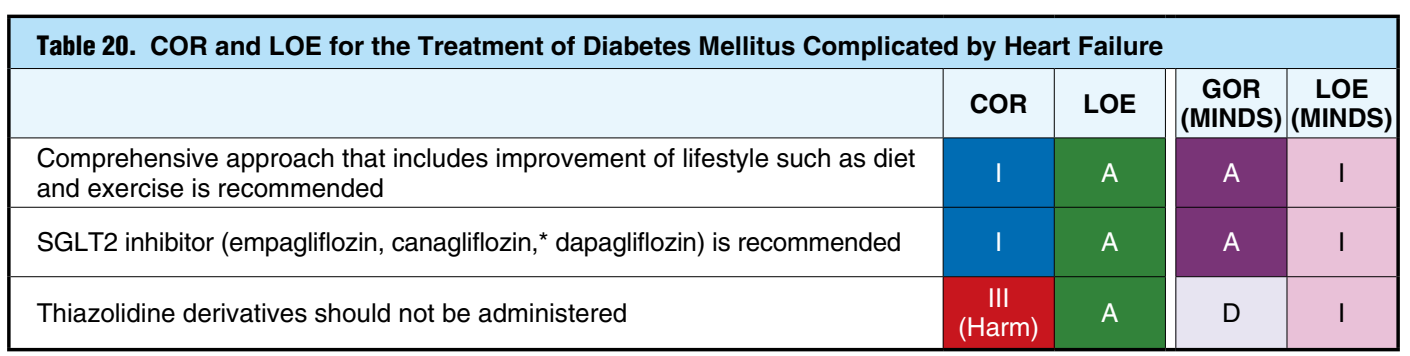

COR, class of recommendation; GOR, grade of recommendation (Medical Information Network Distribution Service [MINDS]); LOE, level of evidence (MINDS); SGLT2, sodium glucose cotransporter 2. *CANVAS study ${ }^{98}$ included doses unapproved in Japan.

rhage. ${ }^{186}$ Therefore, in the JCS/JHRS 2020 Guideline on Pharmacotherapy of Cardiac Arrhythmias, ${ }^{\mathbf{1 8 2}}$ a target PT-INR value is recommended to be maintained between 1.6 and 2.6, regardless of the age in patients with no past medical history of cerebral infarction or a high risk of thromboembolism, when warfarin is used to treat nonvalvular disease-associated atrial fibrillation.

\section{Diabetes Mellitus}

Studies performed in Western countries have demonstrated that biguanide widely used to treat diabetes decreases admission for heart failure and death of patients with diabetes complicated by heart failure (Table 20). ${ }^{187-191}$ Accordingly, biguanide is regarded as the first-line drug for heart failure-complicated patients with diabetes with stable renal function $\left(\mathrm{eGFR}>30 \mathrm{~mL} / \mathrm{min} / 1.73 \mathrm{~m}^{2}\right.$ ) in Western countries. ${ }^{\mathbf{6}}$ In contrast, in the most recent Expert Consensus Decision Pathway on Novel Therapies for Cardiovascular Risk Reduction in Patients With Type 2 Diabetes by the $\mathrm{ACC}$, there is no clear recommendation for biguanide to be considered as the first-line therapy in patients with diabetes and heart failure. $\mathbf{1 1 0}^{\mathbf{1}}$

However, in Japan, the consensus for the possibility of a recommendation similar to that in Western countries has not been reached because the drug is contraindicated for patients with heart failure. After the FDA proposed a cardiovascular outcome study upon approval of a novel antidiabetic drug in 2008, large-scale clinical studies of incretinrelated drugs (dipeptidyl peptidase-4 inhibitors, ${ }^{12-196}$ and glucagon-like peptide-1 [GLP-1] receptor agonists ${ }^{197-203}$ ), and SGLT2 inhibitors ${ }^{\mathbf{9 6}-98}$ have been reported recently, providing important findings to diabetes treatment in anticipation of improvement of the cardiovascular outcome.

Regarding SGLT2 inhibitors, admission for heart failure of patients with type 2 diabetes at high risk of cardiovascular disease was decreased in an evaluation of the secondary end point in the EMPA-REG OUTCOME study (Empagliflozin), ${ }^{96}$ CANVAS study (canagliflozin), ${ }^{\mathbf{9}}$ DECLARETIMI 58 study ${ }^{97}$ (dapagliflozin), and VERTIS CV trial (ertugliflozin). ${ }^{204}$ This effect was noted in a metaanalysis, regardless of the presence or absence of complication by arteriosclerotic disease and heart failure, ${ }^{\mathbf{2 0 5}}$ suggesting that this is a class effect. However, the rate of registered patients complicated by heart failure in these studies was only $10-15 \%$ of all patients and information on their heart failure was insufficient. In addition, in the DAPA-HF study (dapagliflozin) and EMPEROR-Reduced study (empagliflozin) targeting HFrEF regardless of the presence or absence of type 2 diabetes, a decrease in the primary end points of admission for heart failure (including emergency hospital visit for aggravation of heart failure in the DAPA-HF study) and cardiovascular death, was noted in both studies. ${ }^{\mathbf{8 7}, 89}$ Based on these findings, SGLT2 inhibitors are associated with a decrease in the risk of admission for heart failure in patients with type 2 diabetes with broad cardiovascular disease risk. Recently, the SOLOIST-WHF trial demonstrated that sotagliflozin, initiated before or shortly after discharge, resulted in a significantly lower total number of deaths from cardiovascular causes and hospitalizations and urgent visits for heart failure than placebo in patients with diabetes and recent worsening heart failure. ${ }^{\mathbf{1 0 4}}$ This trial had intended to evaluate whether the benefits of SGLT2 inhibition extend to patients with $\mathrm{HFpEF}$ and indeed demonstrated no evidence of heterogeneity of treatment effect according to LVEF. However, early termination of the trial and the small sample size of his subgroup made it difficult to draw any firm conclusion in this regard. Therefore, 2 additional on-going trials, the Empagliflozin Outcome Trial in Patients with Chronic Heart Failure with Preserved Ejection Fraction (EMPEROR-Preserved; NCT03057951) and Dapagliflozin Evaluation to Improve the Lives of patients with Preserved Ejection Fraction Heart Failure (DELIVER; ClinicalTrials. gov number, NCT03619213), are examining SGLT2 inhibitors in patients with HFpEF with or without diabetes mellitus. Moreover, the safety and efficacy in frailty (such as sarcopenia, cognitive decline, and reduction of activities of daily living) also remain as future participants; thus, careful administration is required.

Regarding incretin-related drugs, because the drug was noninferior to placebo in the secondary end point, as admission for heart failure, in most cardiovascular outcome studies, it may be considered diabetes treatment of patients complicated by heart failure. However, in the SAVORTIMI 53 study (saxagliptin), ${ }^{197,206}$ Because admissions for heart failure increased significantly in the saxagliptin treatment group compared with the placebo group (risk factors were previous heart failure or moderate or severer renal dysfunction in both groups), attention has to be paid to patients with heart failure (NYHA classification functional class III-IV) and moderate or severer renal dysfunction. In contrast, in meta-analysis of 7 cardiovascular outcome studies using GLP-1 receptor agonists, although GLP-1 receptor agonists reduced admission for heart failure, no decrease in admissions for heart failure was noted in any study excluding the Harmony Outcome study (albiglutide [unapproved in Japan]). ${ }^{207}$ Furthermore, in the FIGHT study (liraglutide), ${ }^{208}$ targeting patients with 
HFrEF admitted for acute heart failure, the risk of heart failure tended to increase in patients complicated by diabetes in the liraglutide treatment group, and in the LIVE study (liraglutide), ${ }^{209}$ targeting chronic heart failure (HFrEF), occurrence of cardiovascular events increased in the liraglutide treatment group compared with that in the placebo group. Based on these findings, the influence of incretinrelated drugs on heart failure is small, but for some drugs and clinical states, individual risk consideration of heart failure is necessary. Especially, further confirmation of the safety and efficacy of GLP-1 receptor agonists for patients complicated by heart failure is necessary.

Based on these findings, in treatment of patients with diabetes and complicated by heart failure, hypoglycemia is avoided and therapeutic drugs are selected according to the clinical state referring to the characteristics of antidiabetic drugs and previous clinical study results. Among these results, in the consensus statement concerning diagnosis, prevention, and treatment of circulatory disease in patients with disorder of carbohydrate metabolism published by the JCS and Japan Diabetes Society in March 2020, SGLT2 inhibitors are recommended as a diabetes treatment considering inhibition of novel development and aggravation of heart failure for the stage $\mathrm{B}$ latent heart failure group at high risk (BNP of $\geq 100 \mathrm{pg} / \mathrm{mL}$ or NT-proBNP of $\geq 400 \mathrm{pg} / \mathrm{mL}$, previous myocardial infarction, and CKD excluding that with an eGFR of $<30 \mathrm{~mL} / \mathrm{min} / 1.73 \mathrm{~m}^{2}$ ) and stage C/D symptomatic heart failure, in addition to comprehensive intervention for improvement of lifestyle and risk factors. ${ }^{210-212}$

\section{Surgical Treatment}

\section{Mechanical Circulatory Support}

Among VADs currently available in Japan, paracorporeal VADs are pulsatile pumps, whereas implantable VADs are nonpulsatile (continuous flow) pumps. Because these devices support the left ventricle in most cases, they are called left VADs (LVADs). Paracorporeal VADs that support the right ventricle are called right VADs. Implantable right VADs are not approved in Japan. In Japan, paracorporeal VADs are available only for use in the in-hospital setting.

The use of paracorporeal VADs may increase the risk of serious complications such as cerebrovascular disorder and infections, and pump exchanges owing to pump thrombosis or device malfunctions are common. Although implantable LVADs are superior to paracorporeal ones in terms of quality of life improvement and the risk of complications, the implantable LVADs are reimbursed only in patients listed (or being listed) for heart transplantation.

\begin{tabular}{|c|c|c|c|}
\hline Profile & $\begin{array}{l}\text { INTERMACS } \\
\text { J-MACS }\end{array}$ & Status & Options of device therapy \\
\hline 1 & $\begin{array}{l}\text { Critical cardiogenic shock: } \\
\text { "Crash and burn" }\end{array}$ & $\begin{array}{l}\text { Patients with compromised hemodynamics } \\
\text { and peripheral hypoperfusion despite rapid } \\
\text { escalation of intravenous inotropes and/or } \\
\text { introduction of mechanical circulatory support }\end{array}$ & $\begin{array}{l}\text { IABP, peripheral VA-ECMO, percutaneous } \\
\text { VAD, centrifugal pumps for extracorporeal } \\
\text { circulation, and paracorporeal VADs }\end{array}$ \\
\hline 2 & $\begin{array}{l}\text { Progressive decline despite } \\
\text { inotropic support: } \\
\text { "Sliding on inotropes" }\end{array}$ & $\begin{array}{l}\text { Patients with declining renal function, } \\
\text { nutritional status, and signs of congestion } \\
\text { despite intravenous inotropes and required } \\
\text { incremental doses }\end{array}$ & $\begin{array}{l}\text { IABP, peripheral VA-ECMO, percutaneous } \\
\text { VAD, centrifugal pumps for extracorporeal } \\
\text { circulation, paracorporeal VADs, implantable } \\
\text { LVADs }\end{array}$ \\
\hline 3 & $\begin{array}{l}\text { Stable but inotrope-dependent: } \\
\text { "Dependent stability" }\end{array}$ & $\begin{array}{l}\text { Patients with stable hemodynamics on } \\
\text { intravenous inotropes at relatively low doses, } \\
\text { but physicians are not able to discontinue the } \\
\text { intravenous treatment because of the risk of } \\
\text { hypotension, worsening symptoms of heart } \\
\text { failure, or worsening renal function }\end{array}$ & Implantable LVADs \\
\hline 4 & $\begin{array}{l}\text { Resting symptoms: } \\
\text { "Frequent flyer" }\end{array}$ & $\begin{array}{l}\text { Patients who can be weaned from intravenous } \\
\text { inotropic support temporarily and be discharged } \\
\text { from hospital, but may soon repeat } \\
\text { hospitalizations for worsening heart failure }\end{array}$ & $\begin{array}{l}\text { Consider implantable LVADs (especially } \\
\text { patients with modifier } A^{*} \text { ) }\end{array}$ \\
\hline 5 & $\begin{array}{l}\text { Exertion intolerant: } \\
\text { "House-bound" }\end{array}$ & $\begin{array}{l}\text { Patients who can do daily routines in the } \\
\text { house, but have significant limitations in } \\
\text { activities of daily living, and hardly go out }\end{array}$ & \multirow[t]{3}{*}{$\begin{array}{l}\text { Consider implantable LVADs for patients with } \\
\text { modifier } A^{*}\end{array}$} \\
\hline 6 & $\begin{array}{l}\text { Exertion limited: } \\
\text { "Walking wounded" }\end{array}$ & $\begin{array}{l}\text { Patients who can go out, but have difficulty in } \\
\text { doing anything other than light activities, and } \\
\text { have symptoms while walking less than } \\
\text { 100-meter }\end{array}$ & \\
\hline 7 & $\begin{array}{l}\text { Advanced NYHA classification } \\
\text { functional class III: } \\
\text { "Placeholder" }\end{array}$ & $\begin{array}{l}\text { Patients can walk more than } 100 \text { meters } \\
\text { without fatigue, and have had no } \\
\text { hospitalizations in the recent } 6 \text { months }\end{array}$ & \\
\hline
\end{tabular}

IABP, intra-aortic balloon pump; VAD, ventricular assist device; VA-ECMO, venoarterial extracorporeal membrane oxygenation. *Recurrent appropriate implantable cardioverter-defibrillator shocks owing to life-threatening ventricular arrhythmias. (Source: Prepared based on Stevenson et al, $2009^{215}$ and Kinugawa et al, 2020. ${ }^{216}$ ) 
Advanced heart failure is classified by the Interagency Registry for Mechanically Assisted Circulatory Support (INTERMACS) profiles or the Japanese registry for Mechanically Assisted Circulatory Support (J-MACS) profiles (Table 21). ${ }^{213-216}$ According to the J-MACS registry, The 1- and 2-year survival rates of patients with implantable LVADs were $93.6 \%$ and $89.8 \%$, respectively, which were higher than the corresponding rates in patients with paracorporeal LVADs. ${ }^{217}$ Complications requiring rehospitalization reported in patients with implantable LVADs include cerebrovascular disorder, device thrombosis, and drive-line infections. ${ }^{218}$ Several complications such as gastrointestinal arteriovenous malformation, gastrointestinal bleeding, lateonset right-sided heart failure, and aortic regurgitation are rare among patients using pulsatile LVADs, but have been known to be more common in patients using continuous flow LVADs.

The most recent J-MACS registry ${ }^{216}$ revealed that gastrointestinal bleeding occurred only in $6 \%$ or patients within 720 days of implantation in Japan, which was lower than reported in the 2020 annual report of INTERMACS (28.3\% at 24 months) $)^{219}$ or in the HM3 arm results of the MOMENTUM3 final report (24.5\% at 2 years). ${ }^{220}$ The reason responsible for the discrepancy in the rates of gastrointestinal bleeding between the reports has not yet been elucidated. Pump thrombosis is another major complication for implantable LVADs, especially in the era of HM II and HVAD, and the 2020 annual report of INTERMACS still showed a $14.3 \%$ occurrence at 24 months. In Japan, pump thrombosis was reported at very low rate (3\% at 720 days), ${ }^{216}$ even though the most popular device of J-MACS was still HM II. The reason for the lower incidence of pump thrombosis in Japan has neither been clarified.

\section{Catheter-Based Transaortic Microaxial Pumps (Impella $\left.{ }^{\circledR}\right)$}

A left ventricular assist catheter pump became available in Japan in October 2019 (Table 21). It provides flow assistance at a maximum rate of about $3.7 \mathrm{~L} / \mathrm{min}$, and it can be percutaneously inserted using a sheath. Judgement of the indication based on an algorithm using a hemodynamic index has recently been recommended in the United States and Japan..$^{215,216}$

\section{Disease Management}

After publication of the Guidelines on Diagnosis and Treatment of Acute and Chronic Heart Failure, ${ }^{2}$ new evidence for disease management of patients with heart failure by a multidisciplinary team has been reported, statements on nutritional assessment and management have been published, ${ }^{221}$ and the guidelines have been revised with regard to the indication for and management of pregnancy and delivery of patients with heart disease. ${ }^{222}$ In addition, in 2020, the JCS founded certified heart failure educators. The guidelines are revised with regard to disease management in consideration of these matters (Table 22).

\section{Certified Heart Failure Educator}

Disease management programs for patients with heart failure are performed by a multidisciplinary (physicians, nurses, pharmacists, and nutritionist) medical care team and it is necessary to include multiple medical care workers as team members with specialized knowledge and techniques

\begin{tabular}{|l|c|c||c|c|}
\hline \multicolumn{1}{|c|}{ Table 22. COR and LOE for Disease Management of Heart Failure } & COR & LOE & $\begin{array}{c}\text { GOR } \\
\text { (MINDS) }\end{array}$ & $\begin{array}{c}\text { LOE } \\
\text { (MINDS) }\end{array}$ \\
\hline $\begin{array}{l}\text { Education and support to improve adherence and self-care using a } \\
\text { multidisciplinary team approach are recommended }\end{array}$ & I & A & A \\
\hline Discharge support and continuous follow-up are recommended & I & A & B \\
\hline Smoking cessation education and support are recommended & I & C & B & IVb \\
\hline $\begin{array}{l}\text { Symptom monitoring is recommended } \\
\text { Monitoring and specialists' treatment for psychiatric symptoms are } \\
\text { recommended }\end{array}$ & I & C & B 1 & VI \\
\hline $\begin{array}{l}\text { Educational support for patients at high risk for worsening heart failure and } \\
\text { the use of social resources for those living alone, the elderly, and those who } \\
\text { also have dementia are recommended }\end{array}$ & I & A & A \\
\hline $\begin{array}{l}\text { Influenza vaccine is recommended to prevent infection } \\
\text { Low-salt diet (<6 g/d) should be considered }\end{array}$ & I & A & B & IVa \\
\hline Moderation in drinking should be considered & Ila & C & C1 & VI \\
\hline
\end{tabular}

COR, class of recommendation; GOR, grade of recommendation (Medical Information Network Distribution Service [MINDS]); LOE, level of evidence (MINDS). 
Table 23. Role of Certified Heart Failure Educators

- They understand the importance of preventing the development and progression of heart failure and are capable of participating in the prevention and educational activities

- They understand the concept, clinical state, examinations, and treatment of heart failure and are able to identify the symptoms

- They understand prevention and treatment according to the progression and stage of heart failure and are capable of performing basic and comprehensive medical treatment guidance

- They are capable of collaborating with physicians and other medical specialists and contributing to promotion of team medicine in medical institutions or regions

- They have basic knowledge of support for decision-making and palliative care for the patient with heart failure

(Japanese Circulation Society, 2020.223)

of treatment, management, and care of heart failure, such as certified heart failure educators. The certified heart failure educator has been established as a measure to develop human resources in The Five-Year Plan for Overcoming Stroke and Cardiovascular Disease formulated by the JCS and Japan Stroke Society in December 2016. Health care providers eligible to take the qualification of certified heart failure educators include nurses, public health nurses, dietitians, physiotherapists, occupational therapists, pharmacists, clinical engineers, certified psychologist, social workers, and dental hygienists. This qualification targets acquisition of common knowledge and techniques by various specialties, and it is a common qualification to smoothly promote team medical care in a multidisciplinary heart failure medical team comprised of various professional qualifications. The main role is giving the optimum medical treatment guidance by medical specialists possessing broad specialized knowledge and techniques other than physicians to patients and contributing to promotion of team medical care in cooperation with other fields and regions, being expected to be the key player of team medical care centering patients (Table 23). ${ }^{223}$ It is necessary to confirm the effect of medical treatment guidance given by certified heart failure educators in the future.

\section{Disease Management Program}

\subsection{Support by Multidisciplinary Team for Patients and Caregivers}

Appropriate self-care by patients plays an important role in the prevention of heart failure aggravation and improvement of survival and quality of life can be expected.224-226 Patient self-care behavior is evaluated and supported by the multidisciplinary team comprised of physicians and nurses, and at the same time, for patients judged as having limitation of self-management, such as the elderly, people living alone, and patients complicated by cognitive decline, education of and support for their families and active use of social resources are investigated.

Suspension of treatment including medication is an aggravation inducer and it also increases the risk of death and readmission. ${ }^{227,228}$ Through the practice of pharmacologic therapy by pharmacists in cooperation with other health care workers, avoidance of readmission and improvement of medication adherence can be expected. ${ }^{229}$
Regarding medication, the name of drugs, content of instruction on the medication method, and information on adverse effects are provided to patients, their families, and caregivers. In addition, adherence to treatment is evaluated periodically, adverse effects are monitored, the treatment content is revised as needed, and patient education is strengthened.

The influence on living in patients with heart failure depends on not only physical hypofunction, but also psychological adjustment, and attention has to be paid so as to prevent the social and mental isolation of patients. Social activity according to capability of activities is recommended and, if possible, it is necessary to continue working according to exercise ability. Physicians cooperate with medical social workers and public institutions and support adjustment of working conditions according to patient's clinical state and symptoms.

\subsection{Remote Monitoring Systems}

Although evidence has not been established in Japan, the use of a noninvasive remote monitoring system in which biological data including patient's blood pressure and body weight are sent from home to medical institutions by telephone or the Internet. Medical staff encourage hospital visit and support self-care based on the data and these can be expected to improve self-care and avoid readmission. ${ }^{230,231}$

\subsection{Salt Management}

The salt intake is specified to less than $3 \mathrm{~g} / \mathrm{d}$ for stage $\mathrm{C}$ or $\mathrm{D}$ patients in the ACCF/AHA guidelines for the management of heart failure (2013), and avoidance of excessive salt intake exceeding $6 \mathrm{~g} / \mathrm{d}$ is recommended in the ESC guidelines (2016), ${ }^{\mathbf{5 5 , 2 3 2}}$ but no clear evidence for the effect of salt restriction on the outcome of heart failure has been reported. ${ }^{233}$ In the present guidelines, the target of salt reduction in patients with chronic heart failure is set at less than $6 \mathrm{~g} / \mathrm{d}$ in consideration of Japanese eating habits. For severe heart failure, stricter salt restriction is investigated. For guidance on salt reduction in patient education, the patient's medical record handbook and teaching materials of low-salt diet are used. In the elderly, because excess salt reduction decreases appetite and causes undernourishment, appropriate adjustment is necessary.

\subsection{Nutrition Management}

Undernutrition of patients with heart failure shortens their lives. ${ }^{234,235}$ In nutritional guidance and nutrition management, the heart failure notebook, ${ }^{\mathbf{2 3 6}}$ and statements concerning nutritional assessment and management ${ }^{221}$ of patients with heart failure are used, and nutrition management is performed according to the clinical state and stage. However, nutritional therapy according to the stage or severity for patients with heart failure has not been established and future studies are needed. Regarding meals after discharge, nutritional guidance according to patient's lifestyle in consideration of concomitant disease is necessary.

\subsection{Prevention of Infection and Vaccination}

Patients receive education that infection, especially respiratory infection, becomes a risk of heart failure aggravation. Influenza vaccination in the early epidemic has been 
demonstrated to contribute to a decrease in the mortality rate of patients with heart failure. ${ }^{237}$ It is necessary to receive vaccination against influenza and pneumococcus regardless of the cause of disease. Infection, especially respiratory infection, is a risk of heart failure aggravation, encouraging daily handwashing, and body temperature management are effective for the prevention of infection and appropriate telemedicine follow-up by physicians is to be promoted. Because the COVID-19 is a risk of aggravation of heart failure and complication, it is necessary to make efforts to prevent the infection, including vaccination..$^{238}$

\subsection{Travel}

Travels and leisure are to be planned in consideration of physical ability. Attention should be paid to air travel and travel to high altitude destinations, taking the influence of the altitude and atmospheric pressure on oxygenation into consideration. ${ }^{55}$ Air travel is not recommended to NYHA classification functional class IV patients because of the high risk for aggravation. When air travel is unavoidable, oxygen administration during flying is investigated. ${ }^{239}$ In air travel, oral drugs are brought onto the airplane. In air travel and travel to a region with a humid climate, adjustment of water intake according to the humidity is necessary. .5

When a patients with heart failure travels, information on the possibility of negative influences of the content of food and changes in meal time and climate on water balance during the travel is to be provided. For traveling, the patient is to be instructed to bring materials showing the generic names and doses of therapeutic drugs. When a drug exhibiting an adverse effect is exposed to sunlight, instruct the patient to observe the adverse effect-induced symptoms. ${ }^{55}$ When a patient with an implantable cardioverter defibrillator-implanted travels, provide information on driving regulations at the destination and dealing with security checks. ${ }^{55}$

\section{| 2.7 Pregnancy}

Pregnancy and delivery are possible in many cases of NYHA classification functional class II or milder, but some fatal cases have been noted. ${ }^{222}$ For risk assessment of pregnancy in patients with heart failure, it is dangerous to
Table 24. Heart Diseases for Which Strict Attention Should Be Paid in Case of Pregnancy or Its Avoidance Is Strongly Needed

- Pulmonary hypertension (Eisenmenger syndrome)

- Left ventricular outflow tract obstruction (mean pressure $>40-50 \mathrm{mmHg}$ )

- Heart failure (NYHA classification functional class III-IV, LVEF $<35 \%-40 \%)$

- Marfan syndrome (ascending aortic diameter $>40 \mathrm{~mm}$ )

- Mechanical valve

- Cyanotic heart disease $\left(\mathrm{SpO}_{2}<85 \%\right)$

LVEF, left ventricular ejection fraction; NYHA, New York Heart Association. (Japanese Circulation Society, Japan Society of Obstetrics and Gynecology, 2019. ${ }^{222}$ )

make a definite judgment by presuming the outcome based on the NYHA functional classification alone, and it is necessary to understand the underlying clinical state, investigate the risk, and share the information with the patient. ${ }^{222}$ Diseases requiring strict attention to pregnancy or strongly needed to avoid pregnancy in the guidelines concerning the indication and management of pregnancy and delivery of heart disease patients (2018 revised edition) ${ }^{222}$ are shown in Table 24. For the details of management of patients with heart failure during pregnancy, refer to the guidelines.

\section{2.8 Planning and Support for Discharge, Support for Transition, and Continuous Follow-up}

Planning and support for discharge from early after admission are effective to avoid readmission of patients with heart failure early after discharge. ${ }^{240}$ In planning for discharge during hospitalization, the necessity of support for discharge is evaluated, the specific content of support is investigated, and at the same time, patient education is performed to strengthen self-care capability of the patient. The frequency of hospital visit after discharge is associated with the risk of readmission after discharge. ${ }^{241}$ Monitoring of symptoms, evaluation of adherence, and strengthening of education after discharge, especially early after discharge, are effective to avoid readmission and improve quality of life. ${ }^{242,243}$

\section{Palliative Care}

\section{Symptoms and Treatment of End-Stage Heart Failure}

Typical symptoms of end-stage heart failure include dyspnea, generalized malaise, pain, anorexia, and depression. Because heart failure itself is considered to develop these symptoms by causing fluid retention and low cardiac output, heart failure treatment in stage D should be continued in combination with the treatments to control these symptoms.

\section{Additional Medical Fee for Palliative Care}

The additional medical fee for palliative care was approved in the 2018 revision of medical service fees ${ }^{244}$ for team medical care involved in alleviation of symptoms (palliative care team) performed during hospitalization in patients with end-stage heart failure having physical symptoms, such as pain, malaise, and difficulty in breathing, or mental symptoms, such as anxiety and depression.

In the 2020 revision of medical service fees, a fee for outpatient palliative care management was added for 
Table 25. Patient Qualification for Palliative Care Based on Requirements for Additional Medical Fee by Ministry of Health, Labour, and Welfare

A condition meeting all of (i)-(iii) with one of (iv)-(vi):

(i) Execution of appropriate treatment for heart failure

(ii) Chronically meeting NYHA classificationfunctionalclass IV symptoms owing to cardiac dysfunction despite appropriate treatment being performed and requiring frequent or continuous intravenous pharmacologic therapy

(iii) Twice or more urgent admissionsowingto heart failure within a past 1 year

(iv) Left ventricular ejection fraction of $20 \%$ or lower

(v) Medically judged as end stage

(vi) Similar state as the conditions (iv) or (v)

(Source: Ministry of Health, Labour and Welfare. ${ }^{244}$ )

Table 26. Care Team Qualification for Palliative Care Given to Patients With End-Stage Heart Failure Based on Requirements for Additional Medical Fee by the Ministry of Health, Labour, and Welfare

Setting of a team involved in palliative care (palliative care team) formed by the 4 members in authorized insurance medical institutions:

(i) Full-time physicians in charge of alleviation of physical symptoms*

(ii) Full-time physicians in charge of alleviation of mental symptoms

(iii) Full-time nurses with experience of palliative care

(iv) Full-time pharmacists with experience of palliative care

One of (i)-(iv) has to work exclusively, but nonexclusive work by all of them is allowable when the number of patients treated by the palliative care team per day is within 15 .

*Dedicated physicians in charge of alleviation of physical symptoms have to have completed one of the trainings below:

(i) Palliative care workshops for physicians engaged in palliative care for cancer patients following the Guidance for holding palliative care workshop

(ii) Prefectural instructor workshops for basic education of palliative care (hosted by National Research and Development Agency, National Cancer Center Hospital), etc.

(iii) Basic palliative care training courses for heart failure conducted by the Japanese Heart Failure Society

(Source: Ministry of Health, Labour and Welfare. ${ }^{244}$ )

treatment by the palliative care team performed for patients requiring non-in-patient palliative care, such as outpatient service and in-home medical care (limited to patients treated with narcotics to alleviate symptoms). At the same time, the medical fee for palliative care for individual nutrition and diet management involved in palliative care performed in patients who are admitted to a general ward of hospital and require palliative care and the medical fee for palliative care at medical clinics with beds performed in patients who are admitted to a general ward of medical clinics and require palliative care were also newly added. ${ }^{244}$ Patient requirements and palliative care team requirements are shown in Table $\mathbf{2 5}{ }^{\mathbf{2 4 4}}$ and Table $\mathbf{2 6 ,},{ }^{\mathbf{2 4 4}}$ respectively.

\section{Quality Evaluation Index of Palliative Care}

Palliative care is multidisciplinary treatment aiming at
Table 27. Practical Test for Measuring the Proposed Quality Indicators

Domain 1: Structure and process of disease care

1. Presence of multidisciplinary teams

2. Availability of multidisciplinary teams

3. Regular discussion by multidisciplinary teams

4. Intervention by multidisciplinary teams

Domain 2: Appropriate heart failure treatment and care

5. Consideration of $\beta$-blocker prescription

6. Consideration of ACEI/ARB prescription

7. Consideration of MRA prescription

8. Explanation of ICD therapy

9. Explanation of CRT

10. Consideration of cardiac transplantation

11. Evaluation of $C A D$ and valvular heart disease

12. Education for secondary prevention

13. Consultation services for ICD implantation

Domain 3: Total pain management

14. Preparation of screening sheet for total pain

15. Description of goals of total pain management

16. Symptom evaluation using quantitative scales

17. Management of physical pain

18. Preparation of opioid instruction

19. Opioid therapy for patients with refractory dyspnea

20. Evaluation of constipation during opioid therapy

21. Evaluation of nausea and vomiting during opioid therapy

22. Screening for psychological symptoms

23. Availability of psychiatrists

24. Grief care for family members

25. Survey of family structure

26. Conferencing for discharge support

27. Consideration of withholding/withdrawing life-prolonging treatment

28. Multidisciplinary discussion about ICD deactivation at the end of life

29. ICD deactivation prior to death

30. Multidisciplinary team discussion about palliative sedation for symptom relief such as pain hard to be controlled by opioids

31. Informed consent of palliative sedation

Domain 4: Decision support and ethical issue management

32. Preparation of instruction for the illness trajectory of heart failure

33. Preparation of medical manual on advance care planning

34. Multidisciplinary team discussion about life-prolonging treatment

35. Advisory committee for consultation of ethical issues

$\mathrm{ACE}$, angiotensin-converting enzyme; $\mathrm{ARB}$, angiotensin II receptor blocker; CAD, coronary arterial disease; CRT, cardiac resynchronization therapy; ICD, implantable cardioverter defibrillator; MRA mineralocorticoid receptor antagonist. (Source: Hamatani et al, 2020. ${ }^{245}$ )

improvement of quality of life and quality of treatment is required. Indices of chronic heart failure have been formulated using the Delphi method also in Japan. Thirty-five index items comprised of the following 4 domains were selected by 15 panel committee members, including cardio- 
vascular specialists, palliative care specialists, nurses, and pharmacists with experience in palliative care for heart failure: (1) structure and process of care, (2) treatment and care of heart failure according to the stage, (3) relief of total pain, and (4) support for decision-making and dealing with ethical problems (Table $27^{245}$ ). These indices are measurable from treatment records and expected to be useful. ${ }^{244}$ For the acute phase of circulatory disease, 21 items composed of 9 structural indices, 11 process indices, and 1 outcome index (bereaved family survey) have been selected as evaluation indices by a multidisciplinary group consisting of 20 members based on discussion using the Delphi method. Processes of symptom alleviation and support for decision-making are domains of these 21 items; these are not limited to heart failure, and indices more specialized to palliative care were extracted, and these are different points from the evaluation indices described elsewhere in this article. ${ }^{246}$ An evaluation of the validity is necessary for all indices in the future.

\section{Provision of Palliative Care for Heart Failure and Educational System}

To provide palliative care for patients with heart failure, it is necessary to evaluate the total pain of individuals while performing heart failure treatment according to the stage and cooperation between the team engaged in heart failure treatment and team providing palliative care is important. ${ }^{247}$ It has been reported that items concerning basic palliative care to be learned by the team engaged in heart failure treatment include prediction of the outcome, communication, setting the target of care, discussion about requests for resuscitation, understanding palliative care, introduction to specialized palliative care, methodology of alleviation of symptoms, and ethical judgment of discontinuation of the defibrillation function of an implantable cardioverter defibrillator. ${ }^{248}$

Palliative care training in Japan has been based on the Cancer Control Act. To acquire a basic knowledge of palliative care and provide palliative care from the early step of cancer therapy, notification from the director of Health Service Bureau, Ministry of Health, Labour and Wealth, "Guidance for holding palliative care workshop for physicians engaged in clinical practice for cancer treatment" (Kenhatsu No. 0401016 dated April 1, 2008) was issued to each prefecture. In response, an education program, Palliative care Emphasis program on symptom management and Assessment for Continuous medical Education (PEACE) was developed and implemented mainly by the Japanese Society for Palliative Medicine. ${ }^{249}$

However, because the main subject of this training is cancer, a "Working groups for how the palliative careproviding system should be for circulatory disease patients" set by the Ministry of Health, Labour and Welfare in 2017 presented the necessity of providing a place for education and training of palliative care for noncancer diseases. In addition, "The Basic Law on Stroke and Cardiovascular Disease Countermeasures" was established in December 2018 and a palliative care promotion committee was established by the JHFS. A basic palliative care training course for heart failure (HEart failure Palliative care Training program for comprehensive care provider: HEPT) ${ }^{\mathbf{2 5 0}}$ conducted by the society has just been approved as a requirement of physicians in charge of alleviation of physical symptoms in the 2020 revision of medical service fees.

Heart failure workshops for medical staff engaged in palliative medicine centering cancer are planned within the framework of PEACE in the future and smooth cooperation among professions is expected.

\section{Complementary Therapy}

\section{WAON Therapy}

WAON therapy is a heart failure treatment method developed by Tei et $\mathrm{al}^{251}$ and it is unique to Japan. After a 15 -minute $60^{\circ} \mathrm{C}$ dry sauna bath using a far-infrared dry sauna device, warmth is retained at rest for 30 minutes, which increases the deep body temperature by about $1{ }^{\circ} \mathrm{C}$. It has been reported to exhibit an effect improving hemodynamics, heart failure symptoms, quality of life, exercise tolerance, neurohumoral factor, endothelial function, and outcomes. ${ }^{251}$ In a multicenter randomized controlled study,
WAON-CHF, ${ }^{252}$ no difference was noted in the primary end point (BNP ratio before and after treatment), but there was no problem with safety. In March 2020, the therapy became covered by insurance in Japan only for the 30-day acute phase in patients admitted for acute exacerbation of heart failure among patients with NYHA classification functional class III or IV HFrEF without left ventricular outflow obstruction (BNP of $\geq 200 \mathrm{pg} / \mathrm{mL}$ or NT-proBNP of $\geq 900 \mathrm{pg} / \mathrm{mL}$ ). It may be positioned as a method of cardiac rehabilitation when exercise therapy is difficult, such as that in acute phase of heart failure, in the future.

\section{Conclusions}

The JCS/JHFS 2021 Guideline Focused Update on Diagnosis and Treatment of Acute and Chronic Heart Failure was based on JCS 2017/JHFS 2017 guideline on diagnosis and treatment of acute and chronic heart failure that has provided a practical, streamlined resource for healthcare professionals involved in the diagnosis and treatment of patients with heart failure. Since the publication of the JCS 2017/JHFS 2017 guideline, new therapies have emerged that expand the treatment of patients with heart failure. In particular, the emergence of ivabradine, ARNI, SGLT2 
inhibitors, and percutaneous therapy for mitral regurgitation represent significant advances in the treatment of HFrEF. As such, a focused update to the JCS 2017/JHFS 2017 guideline that incorporates these advances into the recommendations is warranted. This update can serve as interim guidance to clinicians while we await the comprehensive and definitive heart failure guideline updated by the JCS in the future. This Guideline Focused Update will streamline care to realize the best possible patient outcomes in heart failure at the present time.

\section{References}

1. MINDS Guideline Center. Japan Council for Quality Health Care. MINDS handbook for clinical practice guideline development 2007. Igaku-Shoin 2007: 15-16.

2. The Japanese Circulation Society, Japanese Heart Failure Society. JCS 2017/JHFS 2017 guideline on diagnosis and treatment of acute and chronic heart failure. Available at: https://www.j-circ. or.jp/cms/wp-content/uploads/2017/06/JCS2017_tsutsui_h.pdf (accessed February 18, 2021).

3. Tsuji K, Sakata Y, Nochioka K, Miura M, Yamauchi T, Onose T, et al. Characterization of heart failure patients with mid-range left ventricular ejection fraction: A report from the CHART-2 Study. Eur J Heart Fail 2017; 19: 1258-1269.

4. Savarese G, Vedin O, D'Amario D, Uijl A, Dahlström U, Rosano G, et al. Prevalence and prognostic implications of longitudinal ejection fraction change in heart failure. $J A C C$ Heart Fail 2019; 7: 306-317.

5. Yancy CW, Jessup M, Bozkurt B, Butler J, Casey DE Jr, Drazner MH, et al. 2013 ACCF/AHA guideline for the management of heart failure: A report of the American College of Cardiology Foundation/American Heart Association Task Force on Practice Guidelines. J Am Coll Cardiol 2013; 62: e147-e239.

6. Ponikowski P, Voors AA, Anker SD, Bueno H, Cleland JG, Coats AJ, et al. 2016 ESC guidelines for the diagnosis and treatment of acute and chronic heart failure: The task force for the diagnosis and treatment of acute and chronic heart failure of the European Society of Cardiology (ESC). Developed with the special contribution of the Heart Failure Association (HFA) of the ESC. Eur J Heart Fail 2016; 18: 891-975.

7. Ushigome R, Sakata Y, Nochioka K, Miyata S, Miura M, Tadaki S, et al. Temporal trends in clinical characteristics, management and prognosis of patients with symptomatic heart failure in Japan: Report from the CHART Studies. Circ J 2015; 79: $2396-2407$.

8. Vasan RS, Levy D. Defining diastolic heart failure: A call for standardized diagnostic criteria. Circulation 2000; 101: 2118-2121.

9. Yaku H, Ozasa N, Morimoto T, Inuzuka Y, Tamaki Y, Yamamoto E, et al. KCHF study investigators. Demographics, management, and in-hospital outcome of hospitalized acute heart failure syndrome patients in contemporary real clinical practice in Japan: Observations from the prospective, multicenter Kyoto Congestive Heart Failure (KCHF) registry. Circ J 2018; 82: $2811-2819$.

10. Nagueh SF, Smiseth OA, Appleton CP, Byrd BF 3rd, Dokainish $\mathrm{H}$, Edvardsen T, et al. Recommendations for the evaluation of left ventricular diastolic function by echocardiography: An update from the American Society of Echocardiography and the European Association of Cardiovascular Imaging. $J$ Am Soc Echocardiogr 2016; 29: 277-314.

11. Pieske B, Tschöpe C, de Boer RA, Fraser AG, Anker SD, Donal E, et al. How to diagnose heart failure with preserved ejection fraction: The HFA-PEFF diagnostic algorithm: A consensus recommendation from the Heart Failure Association (HFA) of the European Society of Cardiology (ESC). Eur Heart J 2019; 40: 3297-3317.

12. Ho JE, Lyass A, Lee DS, Vasan RS, Kannel WB, Larson MG, et al. Predictors of new-onset heart failure: Differences in preserved versus reduced ejection fraction. Circ Heart Fail 2013; 6: $279-286$

13. Reddy YNV, Carter RE, Obokata M, Redfield MM, Borlaug BA. A simple, evidence-based approach to help guide diagnosis of heart failure with preserved ejection fraction. Circulation 2018; 138: 861-870.

14. Tsuchihashi-Makaya M, Hamaguchi S, Kinugawa S, Yokota T, Goto D, Yokoshiki H, et al. Characteristics and outcomes of hospitalized patients with heart failure and reduced vs. preserved ejection fraction: Report from the Japanese Cardiac Registry of Heart Failure in Cardiology (JCARE-CARD). Circ J 2009; 73: $1893-1900$

15. Steinberg BA, Zhao X, Heidenreich PA, Peterson ED, Bhatt
DL, Cannon CP, et al. Trends in patients hospitalized with heart failure and preserved left ventricular ejection fraction: Prevalence, therapies, and outcomes. Circulation 2012; 126: $65-75$.

16. Takei M, Kohsaka S, Shiraishi Y, Goda A, Nagatomo Y, Mizuno A, et al. Heart failure with midrange ejection fraction in patients admitted for acute decompensation: A report from the Japanese multicenter registry. J Card Fail 2019; 25: 666-673.

17. Nauta JF, Hummel YM, van Melle JP, van der Meer P, Lam CSP, Ponikowski P, et al. What have we learned about heart failure with mid-range ejection fraction one year after its introduction? Eur J Heart Fail 2017; 19: 1569-1573.

18. Lam CSP, Gamble GD, Ling LH, Sim D, Leong KTG, Yeo PSD, et al. Mortality associated with heart failure with preserved vs. reduced ejection fraction in a prospective international multi-ethnic cohort study. Eur Heart J 2018; 39: 1770-1780.

19. Bhatia RS, Tu JV, Lee DS, Austin PC, Fang J, Haouzi A, et al. Outcome of heart failure with preserved ejection fraction in a population-based study. $N$ Engl J Med 2006; 355: 260-269.

20. van Veldhuisen DJ, Linssen GC, Jaarsma T, van Gilst WH, Hoes AW, Tijssen JG, et al. B-type natriuretic peptide and prognosis in heart failure patients with preserved and reduced ejection fraction. J Am Coll Cardiol 2013; 61: 1498-1506.

21. Punnoose LR, Givertz MM, Lewis EF, Pratibhu P, Stevenson LW, Desai AS. Heart failure with recovered ejection fraction: A distinct clinical entity. $J$ Card Fail 2011; 17: 527-532.

22. Clarke CL, Grunwald GK, Allen LA, Baron AE, Peterson PN, Brand DW, et al. Natural history of left ventricular ejection fraction in patients with heart failure. Circ Cardiovasc Qual Outcomes 2013; 6: 680-686.

23. Kalogeropoulos AP, Fonarow GC, Georgiopoulou V, Burkman G, Siwamogsatham S, Patel A, et al. Characteristics and outcomes of adult outpatients with heart failure and improved or recovered ejection fraction. JAMA Cardiol 2016; 1: $510-518$.

24. Halliday BP, Wassall R, Lota AS, Khalique Z, Gregson J, Newsome $S$, et al. Withdrawal of pharmacological treatment for heart failure in patients with recovered dilated cardiomyopathy (TRED-HF): An open-label, pilot, randomised trial. Lancet 2019; 393: 61-73.

25. Lupon J, Gavidia-Bovadilla G, Ferrer E, de Antonio M, PereraLluna A, Lopez-Ayerbe J, et al. Heart failure with preserved ejection fraction infrequently evolves toward a reduced phenotype in long-term survivors. Circ Heart Fail 2019; 12: e005652.

26. Ueda T, Kawakami R, Nishida T, Onoue K, Soeda T, Okayama $\mathrm{S}$, et al. Left ventricular ejection fraction (EF) of $55 \%$ as cutoff for late transition from heart failure (HF) with preserved $\mathrm{EF}$ to HF with mildly reduced EF. Circ J 2015; 79: 2209-2215.

27. Cole GD, Dhutia NM, Shun-Shin MJ, Willson K, Harrison J, Raphael CE, et al. Defining the real-world reproducibility of visual grading of left ventricular function and visual estimation of left ventricular ejection fraction: Impact of image quality, experience and accreditation. Int J Cardiovasc Imaging 2015; 31: $1303-1314$.

28. Karlsen S, Dahlslett T, Grenne B, Sjøli B, Smiseth O, Edvardsen $\mathrm{T}$, et al. Global longitudinal strain is a more reproducible measure of left ventricular function than ejection fraction regardless of echocardiographic training. Cardiovasc Ultrasound 2019; 17: 18.

29. Pellikka PA, She L, Holly TA, Lin G, Varadarajan P, Pai RG, et al. Variability in ejection fraction measured by echocardiography, gated single-photon emission computed tomography, and cardiac magnetic resonance in patients with coronary artery disease and left ventricular dysfunction. JAMA Netw Open 2018; 1: e181456.

30. CONSENSUS Trial Study Group. Effects of enalapril on mortality in severe congestive heart failure: Results of the Cooperative North Scandinavian Enalapril Survival Study (CONSENSUS). $N$ Engl J Med 1987; 316: 1429-1435.

31. The SOLVD Investigators. Effect of enalapril on survival in 
patients with reduced left ventricular ejection fractions and congestive heart failure. $N$ Engl J Med 1991; 325: 293-302.

32. Cohn JN, Tognoni G, Valsartan Heart Failure Trial Investigators. A randomized trial of the angiotensin-receptor blocker valsartan in chronic heart failure. $N$ Engl J Med 2001; 345: 1667-1675.

33. Granger CB, McMurray JJ, Yusuf S, Held P, Michelson EL, Olofsson B, et al. Effects of candesartan in patients with chronic heart failure and reduced left-ventricular systolic function intolerant to angiotensin-convertingenzyme inhibitors: The CHARM-Alternative trial. Lancet 2003; 362: 772-776.

34. CIBIS-II Investigators and Committees. The Cardiac Insufficiency Bisoprolol Study II (CIBIS-II): A randomised trial. Lancet 1999; 353: 9-13.

35. MERIT-HF Study Group. Effect of metoprolol CR/XL in chronic heart failure: Metoprolol CR/XL Randomised Intervention Trial in Congestive Heart Failure (MERIT-HF). Lancet 1999; 353: 2001-2007.

36. Packer M, Coats AJ, Fowler MB, Katus HA, Krum H, Mohacsi P, et al. Effect of carvedilol on survival in severe chronic heart failure. $N$ Engl J Med 2001; 344: 1651-1658.

37. Pitt B, Zannad F, Remme WJ, Cody R, Castaigne A, Perez A, et al. The effect of spironolactone on morbidity and mortality in patients with severe heart failure. $N$ Engl J Med 1999; 341: $709-717$.

38. Zannad F, McMurray JJ, Krum H, van Veldhuisen DJ, Swedberg K, Shi H, et al. Eplerenone in patients with systolic heart failure and mild symptoms. N Engl J Med 2011; 364: $11-21$.

39. Cleland JG, Tendera M, Adamus J, Freemantle N, Polonski L, Taylor J. The perindopril in elderly people with chronic heart failure (PEP-CHF) study. Eur Heart J 2006; 27: 2338-2345.

40. Yusuf S, Pfeffer MA, Swedberg K, Granger CB, Held P, McMurray JJ, et al. Effects of candesartan in patients with chronic heart failure and preserved left-ventricular ejection fraction: The CHARM-Preserved Trial. Lancet 2003; 362: 777 781.

41. Massie BM, Carson PE, McMurray JJ, Komajda M, McKelvie $\mathrm{R}$, Zile MR, et al. Irbesartan in patients with heart failure and preserved ejection fraction. $N$ Engl J Med 2008; 359: 2456-2467.

42. Pitt B, Pfeffer MA, Assmann SF, Boineau R, Anand IS, Claggett B, et al. Spironolactone for heart failure with preserved ejection fraction. N Engl J Med 2014; 370: 1383-1392.

43. Flather MD, Shibata MC, Coats AJ, Van Veldhuisen DJ, Parkhomenko A, Borbola J, et al. Randomized trial to determine the effect of nebivolol on mortality and cardiovascular hospital admission in elderly patients with heart failure (SENIORS). Eur Heart J 2005; 26: 215-225.

44. Digitalis Investigation Group. The effect of digoxin on mortality and morbidity in patients with heart failure. N Engl J Med 1997; 336: $525-533$.

45. Swedberg K, Komajda M, Böhm M, Borer JS, Ford I, DubostBrama A, et al. Ivabradine and outcomes in chronic heart failure (SHIFT): A randomised placebo-controlled study. Lancet 2010; 376: $875-885$.

46. Böhm M, Swedberg K, Komajda M, Borer JS, Ford I, DubostBrama A, et al. Heart rate as a risk factor in chronic heart failure (SHIFT): The association between heart rate and outcomes in a randomised placebo-controlled trial. Lancet 2010; 376: $886-$ 894.

47. Zugck C, Martinka P, Stöckl G. Ivabradine treatment in a chronic heart failure patient cohort: Symptom reduction and improvement in quality of life in clinical practice. $A d v$ Ther 2014; 31: 961-974.

48. Müller-Werdan U, Stöckl G, Werdan K. Advances in the management of heart failure: The role of ivabradine. Vasc Health Risk Manag 2016; 12: 453-470.

49. Kang S, Li CJ, Zhang XM. Ivabradine has a neutral effect on mortality in randomized controlled trials. Medicine (Baltimore) 2017; 96: e8067.

50. Tsutsui H, Momomura SI, Yamashina A, Shimokawa H, Kihara Y, Saito Y, et al. Efficacy and safety of ivabradine in Japanese patients with chronic heart failure: J-SHIFT study. Circ J 2019; 83: 2049-2060.

51. Kosmala W, Holland DJ, Rojek A, Wright L, PrzewlockaKosmala M, Marwick TH. Effect of $I_{\mathrm{f}}$-channel inhibition on hemodynamic status and exercise tolerance in heart failure with preserved ejection fraction: A randomized trial. $\mathrm{J} \mathrm{Am}$ Coll Cardiol 2013; 62: 1330-1338.

52. Pal N, Sivaswamy N, Mahmod M, Yavari A, Rudd A, Singh S, et al. Effect of selective heart rate slowing in heart failure with preserved ejection fraction. Circulation 2015; 132: 1719-1725.

53. Myhre PL, Vaduganathan M, Claggett B, Packer M, Desai AS, Rouleau JL, et al. B-type natriuretic peptide during treatment with sacubitril/valsartan: The PARADIGM-HF trial. $J \mathrm{Am}$ Coll Cardiol 2019; 73: 1264-1272.

54. McMurray JJ, Packer M, Desai AS, Gong J, Lefkowitz MP, Rizkala AR, et al. Angiotensin-neprilysin inhibition versus enalapril in heart failure. N Engl J Med 2014; 371: 993-1004.

55. Ponikowski P, Voors AA, Anker SD, Bueno H, Cleland JGF, Coats AJS, et al. 2016 ESC guidelines for the diagnosis and treatment of acute and chronic heart failure: The task force for the diagnosis and treatment of acute and chronic heart failure of the European Society of Cardiology (ESC). Developed with the special contribution of the Heart Failure Association (HFA) of the ESC. Eur Heart J 2016; 37: 2129-2200.

56. Yancy CW, Jessup M, Bozkurt B, Butler J, Casey DE Jr, et al. 2016 ACC/AHA/HFSA focused update on new pharmacological therapy for heart failure: an update of the 2013 ACCF/AHA guideline for the management of heart failure: A report of the American College of Cardiology/American Heart Association Task Force on Clinical Practice Guidelines and the Heart Failure Society of America. Circulation 2016; 134: e282-e293.

57. Velazquez EJ, Morrow DA, DeVore AD, Duffy CI, Ambrosy AP, McCague K, et al. Angiotensin-neprilysin inhibition in acute decompensated heart failure. $N$ Engl JMed 2019; 380: $539-548$

58. Morrow DA, Velazquez EJ, DeVore AD, Desai AS, Duffy CI, Ambrosy AP, et al. Clinical outcomes in patients with acute decompensated heart failure randomly assigned to sacubitril/ valsartan or enalapril in the PIONEER-HF trial. Circulation 2019; 139: 2285-2288.

59. Seferovic PM, Ponikowski P, Anker SD, Bauersachs J, Chioncel $\mathrm{O}$, Cleland JGF, et al. Clinical practice update on heart failure 2019: Pharmacotherapy, procedures, devices and patient management. An expert consensus meeting report of the Heart Failure Association of the European Society of Cardiology. Eur J Heart Fail 2019; 21: 1169-1186.

60. Tsutsui H, Momomura SI, Saito Y, Ito H, Yamamoto K, Sakata Y, et al. Efficacy and safety of sacubitril/valsartan in Japanese patients with chronic heart failure and reduced ejection fraction: Results from the PARALLEL-HF study. Circ J 2021; 85: $584-594$.

61. Solomon SD, McMurray JJV, Anand IS, Ge J, Lam CSP, Maggioni AP, et al. Angiotensin-neprilysin inhibition in heart failure with preserved ejection fraction. N Engl J Med 2019; 381: $1609-1620$

62. Solomon SD, Vaduganathan M, L Claggett B, Packer M, Zile M, Swedberg K, et al. Sacubitril/valsartan across the spectrum of ejection fraction in heart failure. Circulation 2020; 141: 352 361 .

63. Vodovar N, Paquet C, Mebazaa A, Launay JM, Hugon J, Cohen-Solal A. Neprilysin, cardiovascular, and Alzheimer's diseases: The therapeutic split? Eur Heart J 2015; 36: 902-905.

64. Dunlay SM, Givertz MM, Aguilar D, Allen LA, Chan M, Desai AS, et al. Type 2 diabetes mellitus and heart failure: A scientific statement from the American Heart Association and the Heart Failure Society of America: This statement does not represent an update of the 2017 ACC/AHA/HFSA heart failure guideline update. Circulation 2019; 140: e294-e324.

65. American Diabetes Association. 10. Cardiovascular disease and risk management: Standards of medical care in diabetes-2020. Diabetes Care 2020; 43(Suppl 1): S111-S134.

66. Cosentino F, Grant PJ, Aboyans V, Bailey CJ, Ceriello A, Delgado V, et al. 2019 ESC guidelines on diabetes, prediabetes, and cardiovascular diseases developed in collaboration with the EASD. The task force for diabetes, prediabetes, and cardiovascular diseases of the European Society of Cardiology (ESC) and the European Association for the Study of Diabetes (EASD). Eur Heart J 2020; 41: 255-323.

67. Kaku K, Lee J, Mattheus M, Kaspers S, George J, Woerle HJ. Empagliflozin and cardiovascular outcomes in Asian patients with type 2 diabetes and established cardiovascular disease: Results from EMPA-REG OUTCOME ${ }^{\circledR}$. Circ J 2017; 81: $227-$ 234.

68. Kadowaki T, Nangaku M, Hantel S, Okamura T, von Eynatten $\mathrm{M}$, Wanner C, et al. Empagliflozin and kidney outcomes in Asian patients with type 2 diabetes and established cardiovascular disease: Results from the EMPA-REG OUTCOME ${ }^{\circledR}$ trial. $J$ Diabetes Investig 2019; 10: 760-770.

69. Böhm M, Slawik J, Brueckmann M, Mattheus M, George JT, 
Ofstad AP, et al. Efficacy of empagliflozin on heart failure and renal outcomes in patients with atrial fibrillation: Data from the EMPA-REG OUTCOME trial. Eur J Heart Fail 2020; 22: $126-135$.

70. Zelniker TA, Bonaca MP, Furtado RHM, Mosenzon O, Kuder $\mathrm{JF}$, Murphy SA, et al. Effect of dapagliflozin on atrial fibrillation in patients with type 2 diabetes mellitus: Insights from the DECLARE-TIMI 58 trial. Circulation 2020; 141: 1227-1234.

71. Zelniker TA, Braunwald E. Mechanisms of cardiorenal effects of sodium-glucose cotransporter 2 inhibitors: JACC state-ofthe-art review. J Am Coll Cardiol 2020; 75: 422-434.

72. Hallow KM, Helmlinger G, Greasley PJ, McMurray JJV, Boulton DW. Why do SGLT2 inhibitors reduce heart failure hospitalization?: A differential volume regulation hypothesis. Diabetes Obes Metab 2018; 20: 479-487.

73. Matthews VB, Elliot RH, Rudnicka C, Hricova J, Herat L, Schlaich MP. Role of the sympathetic nervous system in regulation of the sodium glucose cotransporter 2. J Hypertens 2017; 35: 2059-2068.

74. Herat LY, Magno AL, Rudnicka C, Hricova J, Carnagarin R, Ward NC, et al. SGLT2 inhibitor-induced sympathoinhibition: A novel mechanism for cardiorenal protection. JACC Basic Transl Sci 2020; 5: 169-179.

75. Kario K, Okada K, Kato M, Nishizawa M, Yoshida T, Asano $\mathrm{T}$, et al. 24-hour blood pressure-lowering effect of an SGLT-2 inhibitor in patients with diabetes and uncontrolled nocturnal hypertension: Results from the randomized, placebo-controlled SACRA study. Circulation 2018; 139: 2089-2097.

76. Santos-Gallego CG, Requena-Ibanez JA, San Antonio R, Ishikawa K, Watanabe S, Picatoste B, et al. Empagliflozin ameliorates adverse left ventricular remodeling in nondiabetic heart failure by enhancing myocardial energetics. $\mathrm{J} \mathrm{Am}$ Coll Cardiol 2019; 73: 1931-1944.

77. Verma S, Rawat S, Ho KL, Wagg CS, Zhang L, Teoh H, et al. Empagliflozin increases cardiac energy production in diabetes: Novel translational insights into the heart failure benefits of SGLT2 inhibitors. JACC Basic Transl Sci 2018; 3: 575-587.

78. Verma S, McMurray JJV. SGLT2 inhibitors and mechanisms of cardiovascular benefit: A state-of-the-art review. Diabetologia 2018; 61: 2108-2117.

79. Maruyama T, Takashima H, Oguma H, Nakamura Y, Ohno $\mathrm{M}$, Utsunomiya $\mathrm{K}$, et al. Canagliflozin improves erythropoiesis in diabetes patients with anemia of chronic kidney disease. Diabetes Technol Ther 2019; 21: 713-720.

80. Mazer CD, Hare GMT, Connelly PW, Gilbert RE, Shehata N, Quan A, et al. Effect of empagliflozin on erythropoietin levels, iron stores, and red blood cell morphology in patients with type 2 diabetes mellitus and coronary artery disease. Circulation 2020; 141: 704-707.

81. Ye Y, Bajaj M, Yang HC, Perez-Polo JR, Birnbaum Y. SGLT-2 inhibition with dapagliflozin reduces the activation of the Nlrp3/ASC inflammasome and attenuates the development of diabetic cardiomyopathy in mice with type 2 diabetes. Further augmentation of the effects with saxagliptin, a DPP4 inhibitor. Cardiovasc Drugs Ther 2017; 31: 119-132.

82. Cherney DZ, Kanbay M, Lovshin JA. Renal physiology of glucose handling and therapeutic implications. Nephrol Dial Transplant 2020; 35: i3-i12.

83. Heerspink HJ, Perkins BA, Fitchett DH, Husain M, Cherney DZ. Sodium glucose cotransporter 2 inhibitors in the treatment of diabetes mellitus: Cardiovascular and kidney effects, potential mechanisms, and clinical applications. Circulation 2016; 134: $752-772$.

84. Opingari E, Verma S, Connelly KA, Mazer CD, Teoh H, Quan A, et al. The impact of empagliflozin on kidney injury molecule-1: A subanalysis of the effects of empagliflozin on cardiac structure, function, and circulating biomarkers in patients with type 2 diabetes CardioLink-6 trial. Nephrol Dial Transplant 2020; 35: 895-897.

85. Dekkers CCJ, Petrykiv S, Laverman GD, Cherney DZ, Gansevoort RT, Heerspink HJL. Effects of the SGLT-2 inhibitor dapagliflozin on glomerular and tubular injury markers. Diabetes Obes Metab 2018; 20: 1988 - 1993.

86. Cherney DZ, Odutayo A, Aronson R, Ezekowitz J, Parker JD Sodium glucose cotransporter-2 inhibition and cardiorenal protection: JACC review topic of the week. $J$ Am Coll Cardiol 2019; 74: $2511-2524$

87. McMurray JJV, Solomon SD, Inzucchi SE, Køber L, Kosiborod MN, Martinez FA, et al. Dapagliflozin in patients with heart failure and reduced ejection fraction. $N$ Engl $J$ Med
2019; 381: 1995-2008.

88. Petrie MC, Verma S, Docherty KF, Inzucchi SE, Anand I, Belohlavek J, et al. Effect of dapagliflozin on worsening heart failure and cardiovascular death in patients with heart failure with and without diabetes. JAMA 2020; 323: 1353-1368.

89. Packer M, Anker SD, Butler J, Filippatos G, Pocock SJ, Carson $\mathrm{P}$, et al. Cardiovascular and renal outcomes with empagliflozin in heart failure. $N$ Engl J Med 2020; 383: 1413-1424.

90. Zannad F, Ferreira JP, Pocock SJ, Anker SD, Butler J, Filippatos G, et al. SGLT2 inhibitors in patients with heart failure with reduced ejection fraction: A meta-analysis of the EMPEROR-Reduced and DAPA-HF trials. Lancet 2020; 396: 819-829.

91. Kosiborod MN, Jhund PS, Docherty KF, Diez M, Petrie MC, Verma $S$, et al. Effects of dapagliflozin on symptoms, function, and quality of life in patients with heart failure and reduced ejection fraction: Results from the DAPA-HF trial. Circulation 2020; 141: 90-99.

92. Docherty KF, Jhund PS, Inzucchi SE, Køber L, Kosiborod MN, Martinez FA, et al. Effects of dapagliflozin in DAPAHF according to background heart failure therapy. Eur Heart $J$ 2020; 41: 2379-2392.

93. Anker SD, Butler J, Filippatos GS, Jamal W, Salsali A, Schnee J, et al. Evaluation of the effects of sodium-glucose co-transporter 2 inhibition with empagliflozin on morbidity and mortality in patients with chronic heart failure and a preserved ejection fraction: Rationale for and design of the EMPEROR-Preserved Trial. Eur J Heart Fail 2019; 21: 1279-1287.

94. Tripolt NJ, Kolesnik E, Pferschy PN, Verheyen N, Ablasser K, Sailer S, et al. Impact of EMpagliflozin on cardiac function and biomarkers of heart failure in patients with acute MYocardial infarction-The EMMY trial. Am Heart J 2020; 221: 39-47.

95. Boehringer Ingelheim. EMPACT-MI: A study to test whether empagliflozin can lower the risk of heart failure and death in people who had a heart attack (myocardial infarction). Available at: https://clinicaltrials.gov/ct2/show/NCT04509674 (accessed February 18, 2021).

96. Zinman B, Wanner C, Lachin JM, Fitchett D, Bluhmki E, Hantel S, et al. Empagliflozin, cardiovascular outcomes, and mortality in type 2 diabetes. N Engl J Med 2015; 373: $2117-$ 2128.

97. Wiviott SD, Raz I, Bonaca MP, Mosenzon O, Kato ET, Cahn A, et al. Dapagliflozin and cardiovascular outcomes in type 2 diabetes. N Engl J Med 2019; 380: 347-357.

98. Neal B, Perkovic V, Mahaffey KW, de Zeeuw D, Fulcher G, Erondu N, et al. Canagliflozin and cardiovascular and renal events in type 2 diabetes. N Engl J Med 2017; 377: 644-657.

99. Janssen Research \& Development, LLC. CANVAS: CANagliflozin cardioVascular Assessment Study (CANVAS). Available at: https://clinicaltrials.gov/ct2/show/NCT01032629 (accessed February 18, 2021).

100. Radholm K, Figtree G, Perkovic V, Solomon SD, Mahaffey $\mathrm{KW}$, de Zeeuw D, et al. Canagliflozin and heart failure in type 2 diabetes mellitus: Results from the CANVAS program. Circulation 2018; 138: 458-468.

101. Cosentino F, Cannon CP, Cherney DZI, Masiukiewicz U, Pratley R, Dagogo-Jack S, et al. Efficacy of ertugliflozin on heart failure-related events in patients with type 2 diabetes mellitus and established atherosclerotic cardiovascular disease: Results of the VERTIS CV trial. Circulation 2020; 142: $2205-$ 2215.

102. Bhatt DL, Szarek M, Pitt B, Cannon CP, Leiter LA, McGuire DK, et al. Sotagliflozin in patients with diabetes and chronic kidney disease. $N$ Engl J Med 2021; 384: 129-139.

103. Packer M, Anker SD, Butler J, Filippatos GS, Ferreira JP, Pocock S, et al. Effect of empagliflozin on the clinical stability of patients with heart failure and a reduced ejection fraction: The EMPEROR-Reduced Trial. Circulation 2021; 143: 326-336.

104. Bhatt DL, Szarek M, Steg PG, Cannon CP, Leiter LA, McGuire DK, et al. Sotagliflozin in patients with diabetes and recent worsening heart failure. N Engl J Med 2021; 384: 117-128.

105. Bassi NS, Ziaeian B, Yancy CW, Fonarow GC. Association of optimal implementation of sodium-glucose cotransporter 2 inhibitor therapy with outcome for patients with heart failure. JAMA Cardiol 2020; 5: 948-951.

106. Perkovic V, Jardine MJ, Neal B, Bompoint S, Heerspink HJL, Charytan DM, et al. Canagliflozin and renal outcomes in type 2 diabetes and nephropathy. $N$ Engl J Med 2019; 380: 22952306.

107. Mudaliar S, Polidori D, Zambrowicz B, Henry RR. Sodium- 
glucose cotransporter inhibitors: Effects on renal and intestinal glucose transport: From bench to bedside. Diabetes Care 2015; 38: $2344-2353$

108. Heerspink HJL, Stefansson BV, Correa-Rotter R, Chertow GM, Greene T, Hou FF, et al. Dapagliflozin in patients with chronic kidney disease. N Engl J Med 2020; 383: 1436-1446.

109. Herrington WG, Preiss D, Haynes R, von Eynatten M, Staplin $\mathrm{N}$, Hauske SJ, et al. The potential for improving cardiorenal outcomes by sodium-glucose co-transporter- 2 inhibition in people with chronic kidney disease: A rationale for the EMPA-KIDNEY study. Clin Kidney J 2018; 11: 749-761.

110. Das SR, Everett BM, Birtcher KK, Brown JM, Januzzi JL Jr, Kalyani RR, et al. 2020 expert consensus decision pathway on novel therapies for cardiovascular risk reduction in patients with type 2 diabetes: A report of the American College of Cardiology Solution Set Oversight Committee. J Am Coll Cardiol 2020; 76: 1117-1145.

111. Martinez FA, Serenelli M, Nicolau JC, Petrie MC, Chiang CE, Tereshchenko S, et al. Efficacy and safety of dapagliflozin in heart failure with reduced ejection fraction according to age: Insights from DAPA-HF. Circulation 2020; 141: 100-111.

112. Griffin M, Rao VS, Ivey-Miranda J, Fleming J, Mahoney D, Maulion C, et al. Empagliflozin in heart failure: Diuretic and cardiorenal effects. Circulation 2020; 142: 1028-1039.

113. Mordi NA, Mordi IR, Singh JS, McCrimmon RJ, Struthers $\mathrm{AD}$, Lang CC. Renal and cardiovascular effects of SGLT2 inhibition in combination with loop diuretics in patients with type 2 diabetes and chronic heart failure: The RECEDE-CHF trial. Circulation 2020; 142: 1713-1724.

114. Fitchett D, Zinman B, Wanner C, Lachin JM, Hantel S, Salsali A, et al. Heart failure outcomes with empagliflozin in patients with type 2 diabetes at high cardiovascular risk: Results of the EMPA-REG OUTCOME ${ }^{\circledR}$ trial. Eur Heart J 2016; 37: 1526 1534.

115. Gheorghiade M, Marti CN, Sabbah HN, Roessig L, Greene SJ, Böhm M, et al. Soluble guanylate cyclase: A potential therapeutic target for heart failure. Heart Fail Rev 2013; 18: 123-134.

116. Greenberg B. Novel therapies for heart failure: Where do they stand? Circ J 2016; 80: 1882-1891.

117. Nossaman B, Pankey E, Kadowitz P. Stimulators and activators of soluble guanylate cyclase: Review and potential therapeutic indications. Crit Care Res Pract 2012; 2012: 290805.

118. Gheorghiade M, Greene SJ, Butler J, Filippatos G, Lam CS, Maggioni AP, et al. Effect of vericiguat, a soluble guanylate cyclase stimulator, on natriuretic peptide levels in patients with worsening chronic heart failure and reduced ejection fraction: The SOCRATES-REDUCED randomized trial. JAMA 2015; 314: $2251-2262$.

119. Pieske B, Patel MJ, Westerhout CM, Anstrom KJ, Butler J, Ezekowitz $\mathrm{J}$, et al. Baseline features of the VICTORIA (Vericiguat Global Study in Subjects with Heart Failure with Reduced Ejection Fraction) trial. Eur J Heart Fail 2019; 21: $1596-1604$.

120. Armstrong PW, Pieske B, Anstrom KJ, Ezekowitz J, Hernandez $\mathrm{AF}$, Butler $\mathrm{J}$, et al. Vericiguat in patients with heart failure and reduced ejection fraction. $N$ Engl J Med 2020; 382: 1883-1893.

121. Armstrong PW, Lam CSP, Anstrom KJ, Ezekowitz J, Hernandez AF, O'Connor CM, et al. Effect of vericiguat vs placebo on quality of life in patients with heart failure and preserved ejection fraction: The VITALITY-HFpEF randomized clinical trial. JAMA 2020; 324: 1512-1521.

122. Malik FI, Hartman JJ, Elias KA, Morgan BP, Rodriguez H, Brejc K, et al. Cardiac myosin activation: A potential therapeutic approach for systolic heart failure. Science 2011; 331: 1439-1443.

123. Teerlink JR, Clarke CP, Saikali KG, Lee JH, Chen MM, Escandon RD, et al. Dose-dependent augmentation of cardiac systolic function with the selective cardiac myosin activator, omecamtiv mecarbil: A first-in-man study. Lancet 2011; 378: $667-675$.

124. Teerlink JR, Felker GM, McMurray JJ, Solomon SD, Adams $\mathrm{KF}$, Cleland JG, et al. Chronic Oral Study of Myosin Activation to Increase Contractility in Heart Failure (COSMICHF): A phase 2, pharmacokinetic, randomised, placebo-controlled trial. Lancet 2016; 388: 2895-2903.

125. Teerlink JR, Diaz R, Felker GM, McMurray JJV, Metra M, Solomon SD, et al. Cardiac myosin activation with omecamtiv mecarbil in systolic heart failure. $N$ Engl J Med 2021; 384: $105-116$.

126. Feldman T, Kar S, Elmariah S, Smart SC, Trento A, Siegel RJ, et al. Randomized comparison of percutaneous repair and surgery for mitral regurgitation: 5-year results of EVEREST II. J Am Coll Cardiol 2015; 66: 2844-2854.

127. Puls M, Lubos E, Boekstegers P, von Bardeleben RS, Ouarrak T, Butter C, et al. One-year outcomes and predictors of mortality after MitraClip therapy in contemporary clinical practice: Results from the German transcatheter mitral valve interventions registry. Eur Heart $J$ 2016; 37: 703-712.

128. Sorajja P, Mack M, Vemulapalli S, Holmes DR, Stebbins A, Kar S, et al. Initial experience with commercial transcatheter mitral valve repair in the United States. J Am Coll Cardiol 2016; 67: $1129-1140$.

129. Obadia JF, Messika-Zeitoun D, Leurent G, Iung B, Bonnet G, Piriou N, et al. Percutaneous repair or medical treatment for secondary mitral regurgitation. N Engl J Med 2018; 379: $2297-$ 2306.

130. Stone GW, Lindenfeld J, Abraham WT, Kar S, Lim DS, Mishell JM, et al. Transcatheter mitral-valve repair in patients with heart failure. N Engl J Med 2018; 379: 2307-2318.

131. Mack MJ, Lindenfeld J, Abraham WT, Kar S, Lim DS, Mishell $\mathrm{JM}$, et al. 3-year outcomes of transcatheter mitral valve repair in patients with heart failure. J Am Coll Cardiol 2021; 77: $1029-1040$.

132. Hayashida K, Yasuda S, Matsumoto T, Amaki M, Mizuno S, Tobaru T, et al. AVJ-514 trial: Baseline characteristics and 30-day outcomes following MitraClip ${ }^{\circledR}$ treatment in a Japanese cohort. Circ J 2017; 81: 1116-1122.

133. Packer M, Grayburn PA. Contrasting effects of pharmacological, procedural, and surgical interventions on proportionate and disproportionate functional mitral regurgitation in chronic heart failure. Circulation 2019; 140: 779-789.

134. Nishimura RA, Otto CM, Bonow RO, Carabello BA, Erwin JP, Guyton RA, et al. 2014 AHA/ACC guideline for the management of patients with valvular heart disease: Executive summary: A report of the American College of Cardiology/American Heart Association Task Force on Practice Guidelines. J Am Coll Cardiol 2014; 63: 2438-2488.

135. Vahanian A, Alfieri O, Andreotti F, Antunes MJ, BaronEsquivias G, Baumgartner $\mathrm{H}$, et al; Joint task force on the management of valvular heart disease of the European Society of Cardiology (ESC). Guidelines on the management of valvular heart disease (version 2012). Eur Heart J 2012; 33: 2451 - 2496.

136. The Japanese Circulation Society. Guidelines for Catheter Intervention for Congenital Heart Disease and Structural Heart Disease. JCS; 2014 https://www.j-circ.or.jp/cms/wpcontent/ uploads/2021/03/JCS2021_Sakamoto_Kawamura.pdf(accessed March 27, 2021).

137. Vahanian A, Alfieri O, Al-Attar N, Antunes M, Bax J, Cormier B, et al. Transcatheter valve implantation for patients with aortic stenosis: A position statement from the European Association of Cardio-Thoracic Surgery (EACTS) and the European Society of Cardiology (ESC), in collaboration with the European Association of Percutaneous Cardiovascular Interventions (EAPCI). Eur Heart J 2008; 29: 1463-1470.

138. Rosenhek R, Iung B, Tornos P, Antunes MJ, Prendergast BD, Otto CM, et al. ESC Working Group on valvular heart disease position paper: Assessing the risk of interventions in patients with valvular heart disease. Eur Heart J 2012; 33: 822-828.

139. Council of Societies Related to Transcatheter Heart Valve Therapy. Institutional standard for transcatheter aortic valve replacement. Available at: http://j-tavr.com/guideline.html (accessed February 18, 2021).

140. Roques F, Nashef SA, Michel P. Risk factors for early mortality after valve surgery in Europe in the 1990s: Lessons from the EuroSCORE pilot program. $J$ Heart Valve Dis 2001; 10: 572 577

141. Ferguson TB, Dziuban SW, Edwards FH, Eiken MC, Shroyer AL, Pairolero PC, et al. The STS National Database: Current changes and challenges for the new millennium. Committee to Establish a National Database in Cardiothoracic Surgery, the Society of Thoracic Surgeons. Ann Thorac Surg 2000; 69: 680691.

142. Svensson LG, Adams DH, Bonow RO, Kouchoukos NT, Miller DC, O'Gara PT, et al. Aortic valve and ascending aorta guidelines for management and quality measures: Executive summary. Ann Thorac Surg 2013; 95: 1491-1505.

143. Dewey TM, Brown D, Ryan WH, Herbert MA, Prince SL, Mack MJ. Reliability of risk algorithms in predicting early and late operative outcomes in high-risk patients undergoing aortic valve replacement. J Thorac Cardiovasc Surg 2008; 135: 180-187.

144. Lee DH, Buth KJ, Martin BJ, Yip AM, Hirsch GM. Frail 
patients are at increased risk for mortality and prolonged institutional care after cardiac surgery. Circulation 2010; 121: 973-978.

145. Thourani VH, Chowdhury R, Gunter RL, Kilgo PD, Chen EP, Puskas JD, et al. The impact of specific preoperative organ dysfunction in patients undergoing aortic valve replacement. Ann Thorac Surg 2013; 95: 838-845.

146. Leon MB, Smith CR, Mack M, Miller DC, Moses JW, Svensson LG, et al. Transcatheter aortic-valve implantation for aortic stenosis in patients who cannot undergo surgery. $N$ Engl J Med 2010; 363: 1597-1607.

147. Kapadia SR, Leon MB, Makkar RR, Tuzcu EM, Svensson LG, Kodali S, et al. 5-year outcomes of transcatheter aortic valve replacement compared with standard treatment for patients with inoperable aortic stenosis (PARTNER 1): A randomised controlled trial. Lancet 2015; 385: 2485-2491.

148. Reardon MJ, Adams DH, Kleiman NS, Yakubov SJ, Coselli JS, Deeb GM, et al. 2-year outcomes in patients undergoing surgical or self-expanding transcatheter aortic valve replacement. J Am Coll Cardiol 2015; 66: 113-121.

149. Adams DH, Popma JJ, Reardon MJ, Yakubov SJ, Coselli JS, Deeb GM, et al. Transcatheter aortic-valve replacement with a self-expanding prosthesis. $N$ Engl J Med 2014; 370: 1790-1798.

150. Smith CR, Leon MB, Mack MJ, Miller DC, Moses JW, Svensson LG, et al. Transcatheter versus surgical aorticvalve replacement in high-risk patients. $N$ Engl $J$ Med 2011; 364: 2187-2198.

151. Mack MJ, Leon MB, Smith CR, Miller DC, Moses JW, Tuzcu EM, et al. 5-year outcomes of transcatheter aortic valve replacement or surgical aortic valve replacement for high surgical risk patients with aortic stenosis (PARTNER 1): A randomised controlled trial. Lancet 2015; 385: 2477-2484.

152. Leon MB, Smith CR, Mack MJ, Makkar RR, Svensson LG, Kodali SK, et al. Transcatheter or surgical aortic-valve replacement in intermediate-risk patients. N Engl J Med 2016; 374: $1609-1620$.

153. Thourani VH, Kodali S, Makkar RR, Herrmann HC, Williams $\mathrm{M}$, Babaliaros V, et al. Transcatheter aortic valve replacement versus surgical valve replacement in intermediate-risk patients: A propensity score analysis. Lancet 2016; 387: 2218-2225.

154. Reardon MJ, Van Mieghem NM, Popma JJ, Kleiman NS, Søndergaard L, Mumtaz M, et al. Surgical or transcatheter aortic-valve replacement in intermediate-risk patients. $N$ Engl $J$ Med 2017; 376: $1321-1331$.

155. Nishimura RA, Otto CM, Bonow RO, Carabello BA, Erwin JP 3rd, Fleisher LA, et al. 2017 AHA/ACC focused update of the 2014 AHA/ACC guideline for the management of patients with valvular heart disease: A report of the American College of Cardiology/American Heart Association Task Force on Clinical Practice Guidelines. J Am Coll Cardiol 2017; 70: 252-289.

156. Baumgartner H, Falk V, Bax JJ, De Bonis M, Hamm C, Holm PJ, et al. 2017 ESC/EACTS guidelines for the management of valvular heart disease. The task force for the management of valvular heart disease of the European Society of Cardiology (ESC) and the European Association for Cardio-Thoracic Surgery (EACTS). Eur Heart J 2017; 38: 2739-2791.

157. Mack MJ, Leon MB, Thourani VH, Makkar R, Kodali SK, Russo M, et al. Transcatheter aortic-valve replacement with a balloon-expandable valve in low-risk patients. $N$ Engl $J$ Med 2019; 380: 1695-1705.

158. Popma JJ, Deeb GM, Yakubov SJ, Mumtaz M, Gada H, O'Hair D, et al. Transcatheter aortic-valve replacement with a self-expanding valve in low-risk patients. N Engl J Med 2019; 380: $1706-1715$.

159. Monin JL, Quere JP, Monchi M, Petit H, Baleynaud S, Chauvel $\mathrm{C}$, et al. Low-gradient aortic stenosis: Operative risk stratification and predictors for long-term outcome: A multicenter study using dobutamine stress hemodynamics. Circulation 2003; 108: $319-324$

160. Levy F, Laurent M, Monin JL, Maillet JM, Pasquet A, Le Tourneau T, et al. Aortic valve replacement for low-flow/ low-gradient aortic stenosis operative risk stratification and long-term outcome: A European multicenter study. J Am Coll Cardiol 2008; 51: 1466-1472.

161. Pereira JJ, Lauer MS, Bashir M, Afridi I, Blackstone EH, Stewart WJ, et al. Survival after aortic valve replacement for severe aortic stenosis with low transvalvular gradients and severe left ventricular dysfunction. J Am Coll Cardiol 2002; 39: $1356-1363$.

162. Bauer F, Coutant V, Bernard M, Stepowski D, Tron C, Cribier
A, et al. Patients with severe aortic stenosis and reduced ejection fraction: Earlier recovery of left ventricular systolic function after transcatheter aortic valve implantation compared with surgical valve replacement. Echocardiography 2013; 30: 865-870.

163. Pilgrim T, Wenaweser P, Meuli F, Huber C, Stortecky S, Seiler $\mathrm{C}$, et al. Clinical outcome of high-risk patients with severe aortic stenosis and reduced left ventricular ejection fraction undergoing medical treatment or TAVI. PLoS One 2011; 6: e27556.

164. Sannino A, Gargiulo G, Schiattarella GG, Brevetti L, Perrino $\mathrm{C}$, Stabile E, et al. Increased mortality after transcatheter aortic valve implantation (TAVI) in patients with severe aortic stenosis and low ejection fraction: A meta-analysis of 6898 patients. Int J Cardiol 2014; 176: 32-39.

165. Eleid MF, Goel K, Murad MH, Erwin PJ, Suri RM, Greason $\mathrm{KL}$, et al. Meta-analysis of the prognostic impact of stroke volume, gradient, and ejection fraction after transcatheter aortic valve implantation. Am J Cardiol 2015; 116: 989-994.

166. Maes F, Lerakis S, Barbosa Ribeiro H, Gilard M, Cavalcante $\mathrm{JL}$, Makkar R, et al. Outcomes from transcatheter aortic valve replacement in patients with low-flow, low-gradient aortic stenosis and left ventricular ejection fraction less than $30 \%$ : A substudy from the TOPAS-TAVI registry. JAMA Cardiol 2019; 4: $64-70$.

167. Suzuki S, Motoki H, Kanzaki Y, Maruyama T, Hashizume N, Kozuka A, et al. Prognostic significance of resting heart rate in atrial fibrillation patients with heart failure with reduced ejection fraction. Heart Vessels 2020; 35: 1109-1115.

168. Li SJ, Sartipy U, Lund LH, Dahlström U, Adiels M, Petzold $\mathrm{M}$, et al. Prognostic significance of resting heart rate and use of $\beta$-blockers in atrial fibrillation and sinus rhythm in patients with heart failure and reduced ejection fraction: Findings from the Swedish Heart Failure Registry. Circ Heart Fail 2015; 8: $871-$ 879.

169. Elayi CS, Shohoudi A, Moodie E, Etaee F, Guglin M, Roy D, et al. Digoxin, mortality, and cardiac hospitalizations in patients with atrial fibrillation and heart failure with reduced ejection fraction and atrial fibrillation: An AF-CHF analysis. Int J Cardiol 2020; 313: 48-54.

170. Khand AU, Rankin AC, Martin W, Taylor J, Gemmell I, Cleland JG. Carvedilol alone or in combination with digoxin for the management of atrial fibrillation in patients with heart failure? J Am Coll Cardiol 2003; 42: 1944-1951.

171. The Japanese Circulation Society, Japanese Heart Rhythm Society. 2018 JCS/JHRS Guideline on non-pharmacotherapy of cardiac arrhythmias. Available at: https://www.j-circ.or.jp/ cms/wp-content/uploads/2018/07/JCS2018_kurita_nogami.pdf (accessed February 18, 2021)

172. Haïssaguerre M, Jaïs P, Shah DC, Takahashi A, Hocini M, Quiniou G, et al. Spontaneous initiation of atrial fibrillation by ectopic beats originating in the pulmonary veins. $N$ Engl J Med 1998; 339: 659-666.

173. The Japanese Circulation Society. Guidelines for indications and procedural techniques of catheter ablation (JCS2012). Available at: https://www.j-circ.or.jp/old/guideline/pdf/JCS2012 okumura_h.pdf (accessed February 18, 2021).

174. Inoue $\mathrm{K}$, Murakawa $\mathrm{Y}$, Nogami A, Shoda M, Naito S, Kumagai K, et al. Current status of catheter ablation for atrial fibrillation-updated summary of the Japanese Catheter Ablation Registry of Atrial Fibrillation (J-CARAF). Circ J 2014; 78: $1112-1120$.

175. Gopinathannair R, Etheridge SP, Marchlinski FE, Spinale FG, Lakkireddy D, Olshansky B. Arrhythmia-induced cardiomyopathies: Mechanisms, recognition, and management. $J \mathrm{Am}$ Coll Cardiol 2015; 66: 1714-1728.

176. Marrouche NF, Brachmann J, Andresen D, Siebels J, Boersma $\mathrm{L}$, Jordaens L, et al. Catheter ablation for atrial fibrillation with heart failure. N Engl J Med 2018; 378: 417-427.

177. Packer DL, Mark DB, Robb RA, Monahan KH, Bahnson TD, Poole JE, et al. Effect of catheter ablation vs antiarrhythmic drug therapy on mortality, stroke, bleeding, and cardiac arrest among patients with atrial fibrillation: The CABANA randomized clinical trial. JAMA 2019; 321: 1261-1274.

178. Saglietto A, De Ponti R, Di Biase L, Matta M, Gaita F, Romero $\mathrm{J}$, et al. Impact of atrial fibrillation catheter ablation on mortality, stroke, and heart failure hospitalizations: A meta-analysis. $J$ Cardiovasc Electrophysiol 2020; 31: 1040-1047.

179. Kirchhof P, Benussi S, Kotecha D, Ahlsson A, Atar D, Casadei B, et al. 2016 ESC guidelines for the management of atrial fibrillation developed in collaboration with EACTS. Eur Heart J 2016; 37: 2893-2962. 
180. Kirchhof P, Camm AJ, Goette A, Brandes A, Eckardt L, Elvan A, et al. Early rhythm-control therapy in patients with atrial fibrillation. N Engl J Med 2020; 383: 1305-1316.

181. Suzuki S, Yamashita T, Okumura K, Atarashi H, Akao M, Ogawa $\mathrm{H}$, et al. Incidence of ischemic stroke in Japanese patients with atrial fibrillation not receiving anticoagulation therapy-pooled analysis of the Shinken Database, J-RHYTHM Registry, and Fushimi AF Registry. Circ J 2015; 79: 432-438.

182. The Japanese Circulation Society, Japanese Heart Rhythm Society. JCS/JHRS 2020 guideline on pharmacotherapy of cardiac arrhythmias. Available at: https://www.j-circ.or.jp/cms/ wp-content/uploads/2020/01/JCS2020_Ono.pdf (accessed February 18, 2021).

183. Ruff CT, Giugliano RP, Braunwald E, Hoffman EB Deenadayalu N, Ezekowitz MD, et al. Comparison of the efficacy and safety of new oral anticoagulants with warfarin in patients with atrial fibrillation: A meta-analysis of randomized trials. Lancet 2014; 383: 955-962.

184. Xiong Q, Lau YC, Senoo K, Lane DA, Hong K, Lip GY Non-vitamin K antagonist oral anticoagulants (NOACs) in patients with concomitant atrial fibrillation and heart failure: A systemic review and meta-analysis of randomized trials. Eur $J$ Heart Fail 2015; 17: 1192-1200.

185. Yasaka M, Minematsu K, Yamaguchi T. Optimal intensity of international normalized ratio in warfarin therapy for secondary prevention of stroke in patients with non-valvular atrial fibrillation. Intern Med 2001; 40: 1183-1188.

186. Inoue $\mathrm{H}$, Okumura $\mathrm{K}$, Atarashi $\mathrm{H}$, Yamashita $\mathrm{T}$, Origasa $\mathrm{H}$, Kumagai N, et al. Target international normalized ratio values for preventing thromboembolic and hemorrhagic events in Japanese patients with non-valvular atrial fibrillation: Results of the J-RHYTHM Registry. Circ J 2013; 77: 2264-2270.

187. Eurich DT, Majumdar SR, McAlister FA, Tsuyuki RT, Johnson JA. Improved clinical outcomes associated with metformin in patients with diabetes and heart failure. Diabetes Care 2005; 28: 2345-2351.

188. Andersson C, Olesen JB, Hansen PR, Weeke P, Norgaard ML, Jørgensen $\mathrm{CH}$, et al. Metformin treatment is associated with a low risk of mortality in diabetic patients with heart failure: A retrospective nationwide cohort study. Diabetologia 2010; 53: $2546-2553$.

189. Aguilar D, Chan W, Bozkurt B, Ramasubbu K, Deswal A. Metformin use and mortality in ambulatory patients with diabetes and heart failure. Circ Heart Fail 2011; 4: 53-58.

190. Eurich DT, Weir DL, Majumdar SR, Tsuyuki RT, Johnson JA, Tjosvold L, et al. Comparative safety and effectiveness of metformin in patients with diabetes mellitus and heart failure: Systematic review of observational studies involving 34,000 patients. Circ Heart Fail 2013; 6: 395-402.

191. Crowley MJ, Diamantidis CJ, McDuffie JR, Cameron CB, Stanifer JW, Mock CK, et al. Clinical outcomes of metformin use in populations with chronic kidney disease, congestive heart failure, or chronic liver disease: A systematic review. Ann Intern Med 2017; 166: 191-200.

192. Scirica BM, Bhatt DL, Braunwald E, Steg PG, Davidson J, Hirshberg B, et al. Saxagliptin and cardiovascular outcomes in patients with type 2 diabetes mellitus. $N$ Engl J Med 2013; 369: $1317-1326$.

193. White WB, Cannon CP, Heller SR, Nissen SE, Bergenstal RM, Bakris GL, et al. Alogliptin after acute coronary syndrome in patients with type 2 diabetes. $N$ Engl J Med 2013; 369: 1327 1335.

194. Green JB, Bethel MA, Armstrong PW, Buse JB, Engel SS, Garg $\mathrm{J}$, et al. Effect of sitagliptin on cardiovascular outcomes in type 2 diabetes. $N$ Engl J Med 2015; 373: 232-242.

195. Rosenstock J, Perkovic V, Johansen OE, Cooper ME, Kahn SE, Marx N, et al. Effect of linagliptin vs placebo on major cardiovascular events in adults with type 2 diabetes and high cardiovascular and renal risk: The CARMELINA randomized clinical trial. JAMA 2019; 321: 69-79.

196. Rosenstock J, Kahn SE, Johansen OE, Zinman B, Espeland MA, Woerle HJ, et al. Effect of linagliptin vs glimepiride on major adverse cardiovascular outcomes in patients with type 2 diabetes: The CAROLINA randomized clinical trial. JAMA 2019; 322: $1155-1166$

197. Pfeffer MA, Claggett B, Diaz R, Dickstein K, Gerstein HC, Køber LV, et al. Lixisenatide in patients with type 2 diabetes and acute coronary syndrome. $N$ Engl J Med 2015; 373: 2247 2257.

198. Marso SP, Daniels GH, Brown-Frandsen K, Kristensen P,
Mann JF, Nauck MA, et al. Liraglutide and cardiovascular outcomes in type 2 diabetes. $N$ Engl J Med 2016; 375: 311-322.

199. Marso SP, Bain SC, Consoli A, Eliaschewitz FG, Jodar E, Leiter LA, et al. Semaglutide and cardiovascular outcomes in patients with type 2 diabetes. $N$ Engl J Med 2016; 375: 1834 1844

200. Holman RR, Bethel MA, Mentz RJ, Thompson VP, Lokhnygina Y, Buse JB, et al. Effects of once-weekly exenatide on cardiovascular outcomes in type 2 diabetes. $N$ Engl J Med 2017; 377: $1228-1239$

201. Hernandez AF, Green JB, Janmohamed S, Sr D'Agostino RB, Granger CB, Jones NP, et al. Albiglutide and cardiovascular outcomes in patients with type 2 diabetes and cardiovascular disease (Harmony Outcomes): A doubleblind, randomised placebo-controlled trial. Lancet 2018; 392: 1519-1529.

202. Gerstein HC, Colhoun HM, Dagenais GR, Diaz R, Lakshmanan $\mathrm{M}$, Pais $\mathrm{P}$, et al. Dulaglutide and cardiovascular outcomes in type 2 diabetes (REWIND): A double-blind, randomised placebo-controlled trial. Lancet 2019; 394: 121-130.

203. Husain M, Birkenfeld AL, Donsmark M, Dungan K, Eliaschewitz FG, Franco DR, et al. Oral semaglutide and cardiovascular outcomes in patients with type 2 diabetes. $N$ Engl J Med 2019; 381: 841-851.

204. Cannon CP, Pratley R, Dagogo-Jack S, Mancuso J, Huyck S, Masiukiewicz U, et al. Cardiovascular outcomes with ertugliflozin in type 2 diabetes. $N$ Engl J Med 2020; 383: 1425-1435.

205. Zelniker TA, Wiviott SD, Raz I, Im K, Goodrich EL, Bonaca MP, et al. SGLT2 inhibitors for primary and secondary prevention of cardiovascular and renal outcomes in type 2 diabetes: A systematic review and meta-analysis of cardiovascular outcome trials. Lancet 2019; 393: 31-39.

206. Scirica BM, Braunwald E, Raz I, Cavender MA, Morrow DA, Jarolim P, et al. Heart failure, saxagliptin, and diabetes mellitus: Observations from the SAVOR-TIMI 53 randomized trial. Circulation 2014; 130: 1579-1588.

207. Kristensen SL, Rørth R, Jhund PS, Docherty KF, Sattar N, Preiss D, et al. Cardiovascular, mortality, and kidney outcomes with GLP-1 receptor agonists in patients with type 2 diabetes: A systematic review and meta-analysis of cardiovascular outcome trials. Lancet Diabetes Endocrinol 2019; 7: 776-785.

208. Margulies KB, Hernandez AF, Redfield MM, Givertz MM, Oliveira GH, Cole R, et al. Effects of liraglutide on clinical stability among patients with advanced heart failure and reduced ejection fraction: A randomized clinical trial. JAMA 2016; 316: $500-508$

209. Jorsal A, Kistorp C, Holmager P, Tougaard RS, Nielsen R, Hänselmann A, et al. Effect of liraglutide, a glucagon-like peptide-1 analogue, on left ventricular function in stable chronic heart failure patients with and without diabetes (LIVE): A multicentre, double-blind, randomised, placebocontrolled trial. Eur J Heart Fail 2017; 19: 69-77.

210. The Japanese Circulation Society, The Japan Diabetes Society. Diagnosis, prevention, and treatment of cardiovascular diseases in people with type 2 diabetes and pre-diabetes: A consensus statement jointly from The Japanese Circulation Society and The Japan Diabetes Society. Nankodo; 2020 (accessed March 20, 2020).

211. Araki E, Tanaka A, Inagaki N, Ito H, Ueki K, Murohara T, et al Diagnosis, prevention, and treatment of cardiovascular diseases in people with type 2 diabetes and prediabetes: A consensus statement jointly from the Japanese Circulation Society and the Japan Diabetes Society. Circ J 2020; 85: 82-125.

212. Araki E, Tanaka A, Inagaki N, Ito H, Ueki K, Murohara T, et al Diagnosis, prevention, and treatment of cardiovascular diseases in people with type 2 diabetes and prediabetes: A consensus statement jointly from the Japanese Circulation Society and the Japan Diabetes Society. Diabetol Int 2021; 12: 1-51.

213. Basir MB, Kapur NK, Patel K, Salam MA, Schreiber T, Kaki A, et al. Improved outcomes associated with the use of shock protocols: Updates from the National Cardiogenic Shock Initiative. Catheter Cardiovasc Interv 2019; 93: 1173-1183.

214. Nakamura M, Imamura T, Ueno H, Kinugawa K. Current indication and practical management of percutaneous left ventricular assist device support therapy in Japan. J Cardiol 2020; 75: 228-232.

215. Stevenson LW, Pagani FD, Young JB, Jessup M, Miller L, Kormos RL, et al. INTERMACS profiles of advanced heart failure: The current picture. J Heart Lung Transplant 2009; 28: $535-541$.

216. Kinugawa K, Nishimura T, Toda K, Saiki Y, Niinami H, 
Nunoda S, et al. The second official report from Japanese registry for mechanical assisted circulatory support (JMACS): First results of bridge to bridge strategy. Gen Thorac Cardiovasc Surg 2020; 68: $102-111$.

217. Nakatani T, Sase K, Oshiyama H, Akiyama M, Horie M, Nawata K, et al. Japanese registry for Mechanically Assisted Circulatory Support: First report. J Heart Lung Transplant 2017; 36: $1087-1096$

218. Kirklin JK, Pagani FD, Kormos RL, Stevenson LW, Blume ED, Myers SL, et al. Eighth annual INTERMACS report: Special focus on framing the impact of adverse events. $J$ Heart Lung Transplant 2017; 36: 1080-1086.

219. Molina EJ, Shah P, Kiernan MS, Cornwell WK 3rd, Copeland H, Takeda K, et al. The Society of Thoracic Surgeons INTERMACS 2020 annual report. Ann Thorac Surg 2021; 111: 778-792.

220. Mehra MR, Uriel N, Naka Y, Cleveland JC Jr, Yuzefpolskaya M, Salerno CT, et al. A fully magnetically levitated left ventricular assist device: Final report. $N$ Engl J Med 2019; 380: 1618-1627.

221. The Japanese Heart Failure Society, Expert Consensus Writing Committee. Japanese Heart Failure Society 2018 scientific statement on nutritional assessment and management in heart failure patients. Available at: https://www.jstage.jst.go.jp/article/ circj/84/8/84_CJ-20-0322/_html/-char/en (accessed February 18, 2021).

222. The Japanese Circulation Society, Japan Society of Obstetrics and Gynecology. JCS 2018 guideline on indication and management of pregnancy and delivery in women with heart disease. Available at: https://www.j-circ.or.jp/cms/wp-content/uploads/2020/02/ JCS2018_akagi_ikeda.pdf (accessed February 18, 2021).

223. Japanese Circulation Society. Guidebook for certification examination for heart failure treatment instructors. Nankodo 2020; 6 (accessed March 20, 2020).

224. Jonkman NH, Westland H, Groenwold RH, Agren S, Atienza F, Blue L, et al. Do self-management interventions work in patients with heart failure?: An individual patient data metaanalysis. Circulation 2016; 133: 1189-1198.

225. Otsu H, Moriyama M. Effectiveness of an educational selfmanagement program for outpatients with chronic heart failure. Jpn J Nurs Sci 2011; 8: 140-152.

226. Kato N, Kinugawa K, Nakayama E, Tsuji T, Kumagai Y, Imamura $\mathrm{T}$, et al. Insufficient self-care is an independent risk factor for adverse clinical outcomes in Japanese patients with heart failure. Int Heart $J$ 2013; 54: 382-389.

227. Tsuchihashi M, Tsutsui H, Kodama K, Kasagi F, Takeshita A. Clinical characteristics and prognosis of hospitalized patients with congestive heart failure: A study in Fukuoka, Japan. Jpn Circ J 2000; 64: 953-959.

228. Wu JR, Lennie TA, Dekker RL, Biddle MJ, Moser DK. Medication adherence, depressive symptoms, and cardiac eventfree survival in patients with heart failure. $J$ Card Fail 2013; 19: 317-324.

229. Parajuli DR, Kourbelis C, Franzon J, Newman P, Mckinnon RA, Shakib S, et al. Effectiveness of the pharmacist-involved multidisciplinary management of heart failure to improve hospitalizations and mortality rates in 4630 patients: A systematic review and meta-analysis of randomized controlled trials. $J$ Card Fail 2019; 25: 744-756.

230. Inglis SC, Clark RA, Dierckx R, Prieto-Merino D, Cleland JG. Structured telephone support or non-invasive telemonitoring for patients with heart failure. Cochrane Database Syst Rev 2015; 10: CD007228.

231. Wagenaar KP, Broekhuizen BDL, Jaarsma T, Kok I, Mosterd A, Willems FF, et al. Effectiveness of the European Society of Cardiology/Heart Failure Association website 'heartfailurematters.org' and an e-health adjusted care pathway in patients with stable heart failure: Results of the 'e-Vita HF' randomized controlled trial. Eur J Heart Fail 2019; 21: 238-246.

232. Yancy CW, Jessup M, Bozkurt B, Butler J, Casey DE, Drazner $\mathrm{MH}$, et al. $2013 \mathrm{ACCF} / \mathrm{AHA}$ guideline for the management of heart failure: A report of the American College of Cardiology Foundation/American Heart Association Task Force on practice guidelines. Circulation 2013; 128: e240-e327.
233. Mahtani KR, Heneghan C, Onakpoya I, Tierney S, Aronson JK, Roberts N, et al. Reduced salt intake for heart failure: A systematic review. JAMA Intern Med 2018; 178: 1693-1700.

234. Anker SD, Ponikowski P, Varney S, Chua TP, Clark AL, Webb-Peploe KM, et al. Wasting as independent risk factor for mortality in chronic heart failure. Lancet 1997; 349: 1050-1053.

235. Kinugasa $Y$, Kato M, Sugihara S, Hirai M, Yamada K, Yanagihara K, et al. Geriatric nutritional risk index predicts functional dependency and mortality in patients with heart failure with preserved ejection fraction. Circ J 2013; 77: 705-711.

236. The Japanese Heart Failure Society. Heart failure notebook. Available at: http://www.asas.or.jp/jhfs/topics/shinhuzentecho. html (accessed February 18, 2021).

237. Modin D, Jørgensen ME, Gislason G, Jensen JS, Køber L, Claggett B, et al. Influenza vaccine in heart failure. Circulation 2019; 139: $575-586$.

238. European Society of Cardiology. ESC Guidance for the diagnosis and management of $\mathrm{CV}$ disease during the COVID-19 pandemic. Available at: https://www.escardio.org/Education/COVID-19and-Cardiology/ESC-COVID-19-Guidance (accessed February 18, 2021).

239. Ahmedzai S, Balfour-Lynn IM, Bewick T, Buchdahl R, Coker RK, Cummin AR, et al. Managing passengers with stable respiratory disease planning air travel: British Thoracic Society recommendations. Thorax 2011; 66(Suppl 1): i1 -i30.

240. Gonçalves-Bradley DC, Lannin NA, Clemson LM, Cameron ID, Shepperd S. Discharge planning from hospital. Cochrane Database Syst Rev 2016; 2016: CD000313.

241. Tsuchihashi M, Tsutsui H, Kodama K, Kasagi F, Setoguchi S, Mohr M, et al. Medical and socioenvironmental predictors of hospital readmission in patients with congestive heart failure. Am Heart J 2001; 142: E7.

242. Hollenberg SM, Warner Stevenson L, Ahmad T, Amin VJ, Bozkurt B, Butler J, et al. 2019 ACC expert consensus decision pathway on risk assessment, management, and clinical trajectory of patients hospitalized with heart failure: A report of the American College of Cardiology Solution Set Oversight Committee. J Am Coll Cardiol 2019; 74: 1966-2011.

243. Blum MR, Øien H, Carmichael HL, Heidenreich P, Owens DK, Goldhaber-Fiebert JD. Cost-effectiveness of transitional care services after hospitalization with heart failure. Ann Intern Med 2020; 172: 248-257.

244. Ministry of Health, Labour and Welfare. Medical service fee revise. Available at: https://www.mhlw.go.jp/stf/seisakunitsuite/ bunya/0000106602.html (accessed February 18, 2021).

245. Hamatani Y, Takada Y, Miyamoto Y, Kawano Y, Anchi Y, Shibata $T$, et al. Development and practical test of quality indicators for palliative care in patients with chronic heart failure. Circ J 2020; 84: 584-591.

246. Mizuno A, Miyashita M, Kohno T, Tokuda Y, Fujimoto S, Nakamura M, et al. Quality indicators of palliative care for acute cardiovascular diseases. J Cardiol 2020; 76: 177-183.

247. Kavalieratos D, Gelfman LP, Tycon LE, Riegel B, Bekelman DB, Ikejiani DZ, et al. Palliative care in heart failure: Rationale, evidence, and future priorities. J Am Coll Cardiol 2017; 70: 1919-1930.

248. Munoz-Mendoza J. Competencies in palliative care for cardiology fellows. J Am Coll Cardiol 2015; 65: 750-752.

249. Japanese Society for Palliative Medicine. Peace (Palliative care Emphasis program on symptom management and Assessment for Continuous medical Education) Project. Available at: http:// www.jspm.ne.jp/jspm_eng/peace.html (accessed February 18, 2021).

250. HEPT: HEart failure Palliative care Training program for comprehensive care provider. Available at: http://hept.main.jp/ (accessed February 18, 2021)

251. Miyata M, Tei C. WAON therapy for cardiovascular disease: Innovative therapy for the 21st century. Circ J 2010; 74: 617-621.

252. Tei $C$, Imamura $T$, Kinugawa $K$, Inoue $T$, Masuyama $T$, Inoue $\mathrm{H}$, et al. WAON therapy for managing chronic heart failure: Results from a multicenter prospective randomized WAON-CHF study. Circ J 2016; 80: 827-834. 


\section{Appendix 1. Details of Members}

Chair

- Hiroyuki Tsutsui, MD, PhD, Department of Cardiovascular Medicine, Graduate School of Medical Sciences, Kyushu University, Fukuoka, Japan

\section{Members}

- Tomomi Ide, MD, PhD, Department of Cardiovascular Medicine, Graduate School of Medical Sciences, Kyushu University, Fukuoka, Japan

- Hiroshi Ito, MD, PhD, Department of Cardiovascular Medicine, Division of Biophysiological Sciences, Okayama University Graduate School of Medicine, Dentistry and Pharmaceutical Sciences, Okayama, Japan

- Yasuki Kihara, MD, PhD, Kobe City Medical Center General Hospital, Kobe, Japan

- Koichiro Kinugawa, MD, PhD, Second Department of Internal Medicine, Faculty of Medicine, University of Toyama, Toyama, Japan

- Shintaro Kinugawa, MD, PhD, Department of Cardiovascular Medicine, Graduate School of Medical Sciences, Kyushu University, Fukuoka, Japan

- Miyuki Makaya, RN, PhD, Kitasato University Graduate School of Nursing, Tokyo, Japan

- Toyoaki Murohara, MD, PhD, Department of Cardiology, Nagoya University Graduate School of Medicine, Nagoya, Japan

- Koichi Node, MD, PhD, Department of Cardiovascular Medicine, Saga University, Saga, Japan

- Yoshihiko Saito, MD, PhD, Department of Cardiovascular Medicine, Nara Medical University, Kashihara, Japan

- Yasushi Sakata, MD, PhD, Department of Cardiovascular Medicine, Osaka University Graduate School of Medicine, Osaka, Japan

- Wataru Shimizu, MD, PhD, Department of Cardiovascular Medicine, Nippon Medical School, Tokyo, Japan

- Kazuhiro Yamamoto, MD, PhD, Department of Cardiovascular Medicine and Endocrinology and Metabolism, Faculty of Medicine, Tottori University, Tottori, Japan

\section{Collaborators}

- Yasuko Bando, MD, PhD, Department of Cardiology, Nagoya University Hospital, Nagoya, Japan

- Yu-ki Iwasaki, MD, PhD, Department of Cardiovascular Medicine, Nippon Medical School, Tokyo, Japan

- Yoshiharu Kinugasa, MD, PhD, Department of Cardiovascular Medicine and Endocrinology and Metabolism, Faculty of Medicine, Tottori University, Tottori, Japan

- Isamu Mizote, MD, PhD, Department of Cardiovascular Medicine, Osaka University Graduate School of Medicine, Osaka, Japan

- Hitoshi Nakagawa, MD, PhD, Department of Cardiovascular Medicine, Nara Medical University, Kashihara, Japan

- Shogo Oishi, MD, PhD, Department of Cardiology, Himeji Brain and Heart Center, Hyogo, Japan

- Akiko Okada, MD, PhD, Kitasato University Graduate School of Nursing, Tokyo, Japan

- Atsushi Tanaka, MD, PhD, Department of Cardiovascular Medicine, Saga University, Saga, Japan

\section{Independent Assessment Committee}

- Takashi Akasaka, MD, PhD, Department of Cardiovascular Medicine, Wakayama Medical University, Wakayama, Japan

- Minoru Ono, MD, PhD, Department of Cardiac Surgery, Graduate School of Medicine and Faculty of Medicine, The University of Tokyo, Tokyo, Japan

- Takeshi Kimura, MD, PhD, Department of Cardiovascular Medicine, Graduate School of Medicine and Faculty of Medicine, Kyoto University, Kyoto, Japan

- Shun Kosaka, MD, PhD, Department of Cardiology, Keio University School of Medicine, Tokyo, Japan

- Masami Kosuge, MD, PhD, Cardiovascular Center, Yokohama City University Medical Center, Yokohama, Japan

- Shin-ichi Momomura, MD, PhD, Saitama Citizens Medical Center, Saitama, Japan

(Listed in alphabetical order; affiliations as of November 2020)

\section{Appendix 2. Disclosure of Conflict of Interest (COI) of the Group Members: JCS/JHFS 2021 Guideline Focused Update on Diagnosis and Treatment of Acute and Chronic Heart Failure (January 1, 2018 to December 31, 2020)}

\begin{tabular}{|c|c|c|c|c|c|c|c|c|c|c|c|c|c|c|}
\hline \multirow{2}{*}{ Author } & \multicolumn{9}{|c|}{ Member's own declaration items } & \multicolumn{3}{|c|}{$\begin{array}{l}\text { COI of the marital partner, first- } \\
\text { degree family members, or those } \\
\text { who share income and property }\end{array}$} & \multicolumn{2}{|c|}{$\begin{array}{l}\text { COI of the head of the organization/ } \\
\text { department to which the member } \\
\text { belongs (if the member is in a position } \\
\text { to collaborate with the head of the } \\
\text { organization/department) }\end{array}$} \\
\hline & $\begin{array}{l}\text { Employer/ } \\
\text { leadership } \\
\text { position } \\
\text { (private } \\
\text { company) }\end{array}$ & Stakeholder & $\begin{array}{l}\text { Patent } \\
\text { royalty }\end{array}$ & Honorarium & $\begin{array}{l}\text { Payment for } \\
\text { manuscripts }\end{array}$ & Research grant & $\begin{array}{c}\text { Scholarship } \\
\text { (educational) grant }\end{array}$ & Endowed chair & $\begin{array}{c}\text { Other } \\
\text { rewards }\end{array}$ & $\begin{array}{c}\text { Employer/ } \\
\text { leadership } \\
\text { position } \\
\text { (private } \\
\text { company) }\end{array}$ & Stakeholder & $\begin{array}{l}\text { Patent } \\
\text { royalty }\end{array}$ & Research grant & $\begin{array}{l}\text { Scholarship } \\
\text { (educational) } \\
\text { grant }\end{array}$ \\
\hline $\begin{array}{l}\text { Chair: } \\
\text { Hiroyuki Tsutsui }\end{array}$ & & & & $\begin{array}{l}\text { AstraZeneca K.K. } \\
\text { Novartis Pharma } \\
\text { K.K. } \\
\text { Bayer Yakuhin, Ltd. } \\
\text { Pfizer Japan Inc. } \\
\text { Kowa Company, } \\
\text { Ltd., } \\
\text { Ono Pharmaceutical } \\
\text { Co., Ltd. } \\
\text { Otsuka } \\
\text { Pharmaceutical } \\
\text { Co., Ltd. } \\
\text { Daiichi Sankyo } \\
\text { Company, Limited } \\
\text { Teijin Pharma } \\
\text { Limited } \\
\text { Mitsubishi Tanabe } \\
\text { Pharma } \\
\text { Corporation } \\
\text { Nippon Boehringer } \\
\text { Ingelheim Co., Ltd. } \\
\text { Bristol-Myers Squibb }\end{array}$ & $\begin{array}{l}\text { Nipponrinsho } \\
\text { Co.,Ltd. }\end{array}$ & $\begin{array}{l}\text { IQVIA Services } \\
\text { Japan K.K. } \\
\text { OMRON } \\
\text { HEALTHCARE } \\
\text { Co., Ltd. } \\
\text { Medical Innovation } \\
\text { Kyushu } \\
\text { MEDINET Co., Ltd. } \\
\text { Daiichi Sankyo } \\
\text { Company, Limited } \\
\text { Mitsubishi Tanabe } \\
\text { Pharma } \\
\text { Corporation } \\
\text { Japan Tobacco Inc. } \\
\text { Nippon Boehringer } \\
\text { Ingelheim Co., Ltd. }\end{array}$ & \begin{tabular}{|l|} 
St.Mary's Hospital. \\
Daiichi Sankyo \\
Company, Limited \\
Teijin Pharma \\
Limited \\
Teijin Healthcare \\
Limited \\
Mitsubishi Tanabe \\
Pharma \\
Corporation \\
Nippon Boehringer \\
Ingelheim Co., \\
Ltd. \\
Abbott Medical \\
Japan L.L.C \\
Otsuka \\
Pharmaceutical \\
Co., Ltd. \\
Boston Scientific \\
Japan K.K. \\
Ono Pharmaceutical \\
Co., Ltd.
\end{tabular} & $\begin{array}{l}\text { Actelion } \\
\text { Pharmaceuticals } \\
\text { Japan Ltd. }\end{array}$ & & & & & & \\
\hline $\begin{array}{l}\text { Members: } \\
\text { Tomomi Ide }\end{array}$ & & & & & & & & $\begin{array}{l}\text { Actelion } \\
\text { Pharmaceuticals } \\
\text { Japan Ltd. }\end{array}$ & & & & & & \\
\hline $\begin{array}{l}\text { Members: } \\
\text { Hiroshi Ito }\end{array}$ & & & & $\begin{array}{l}\text { Ono Pharmaceutical } \\
\text { Co., Ltd. } \\
\text { Novartis Pharma } \\
\text { K.K. } \\
\text { AstraZeneca K.K. } \\
\text { Mitsubishi Tanabe } \\
\text { Pharma } \\
\text { Corporation } \\
\text { Daiichi Sankyo } \\
\text { Company, Limited } \\
\text { Nippon Boehringer } \\
\text { Ingelheim Co., Ltd. }\end{array}$ & & & $\begin{array}{l}\text { Daiichi Sankyo } \\
\text { Company, Limited } \\
\text { Novartis Pharma } \\
\text { K.K. } \\
\text { Mitsubishi Tanabe } \\
\text { Pharma } \\
\text { Corporation } \\
\text { Ono Pharmaceutical } \\
\text { Co., Ltd. } \\
\text { Nippon Boehringer } \\
\text { Ingelheim Co., } \\
\text { Ltd. }\end{array}$ & & & & & & & \\
\hline
\end{tabular}




\begin{tabular}{|c|c|c|c|c|c|c|c|c|c|c|c|c|c|c|}
\hline \multirow{2}{*}{ Author } & \multicolumn{9}{|c|}{ Member's own declaration items } & \multicolumn{3}{|c|}{$\begin{array}{l}\text { COI of the marital partner, first- } \\
\text { degree family members, or those } \\
\text { who share income and property }\end{array}$} & \multicolumn{2}{|c|}{$\begin{array}{l}\text { COI of the head of the organization/ } \\
\text { department to which the member } \\
\text { belongs (if the member is in a position } \\
\text { to collaborate with the head of the } \\
\text { organization/department) }\end{array}$} \\
\hline & $\begin{array}{c}\text { Employer/ } \\
\text { leadership } \\
\text { position } \\
\text { (private } \\
\text { company) }\end{array}$ & Stakeholder & $\begin{array}{l}\begin{array}{l}\text { Patent } \\
\text { royalty }\end{array} \\
\end{array}$ & Honorarium & $\begin{array}{l}\text { Payment for } \\
\text { manuscripts }\end{array}$ & Research grant & $\begin{array}{c}\text { Scholarship } \\
\text { (educational) grant }\end{array}$ & Endowed chair & $\begin{array}{c}\text { Other } \\
\text { rewards }\end{array}$ & \begin{tabular}{|c|} 
Employer/ \\
leadership \\
position \\
(private \\
company) \\
\end{tabular} & Stakeholder & $\begin{array}{l}\text { Patent } \\
\text { royalty }\end{array}$ & Research grant & $\begin{array}{c}\text { Scholarship } \\
\text { (educational) } \\
\text { grant }\end{array}$ \\
\hline $\begin{array}{l}\text { Members: } \\
\text { Yasuki Kihara }\end{array}$ & & & & \begin{tabular}{|l|} 
Daiichi Sankyo \\
Company, Limited \\
Otsuka \\
Pharmaceutical \\
Co., Ltd. \\
Nippon Boenringer \\
Ingelheim Co., Ltd. \\
TEIIIN HOME \\
HEALTHCARE \\
LIMITED \\
Takeda \\
Pharmaceutical \\
Company Limited \\
Teijin Pharma \\
Linited \\
\end{tabular} & & $\begin{array}{l}\text { Teijin Pharma } \\
\text { Limited } \\
\text { EE-CSSU Co., Ltd. } \\
\text { Mebix, Inc. }\end{array}$ & $\begin{array}{l}\text { MSD K.K. } \\
\text { Astellas Pharma Inc. } \\
\text { DDiichi Sankyo } \\
\text { Company, Limited } \\
\text { Sanofi K... } \\
\text { Boston Scientific } \\
\text { Japan K... } \\
\text { Nippon Boehringer } \\
\text { Ingelheim Co., } \\
\text { Ltd. } \\
\text { BIOTRONIK } \\
\text { Japan, Inc. } \\
\text { AKANE-kai } \\
\text { Senoo hospital } \\
\text { Federation of } \\
\text { National Public } \\
\text { Services and } \\
\text { Affiliated } \\
\text { Personnel Mutual } \\
\text { Aid Associations } \\
\text { Kure Kyosai } \\
\text { Hospital } \\
\end{array}$ & & & & & & & \\
\hline $\begin{array}{l}\text { Members: } \\
\text { Koichiro } \\
\text { Kinugawa }\end{array}$ & & & & \begin{tabular}{|l|} 
Otsuka \\
Pharmaceutical \\
Co., Ltd. \\
Oon Pharraceutical \\
Co., Ltd. \\
Daiichi Sankyo \\
Company, Limited \\
Astrazeneca K... \\
Nippon Boehringer \\
Ingeheim Co., Ld. \\
Mitsubishi Tanabe \\
Pharma \\
Corporation \\
Nipro Corporation \\
\end{tabular} & $\begin{array}{l}\text { Otsuka } \\
\text { Pharmaceutical } \\
\text { Co., Ltd. } \\
\end{array}$ & $\begin{array}{l}\text { Ono Pharmaceutical } \\
\text { Co., Ltd. }\end{array}$ & \begin{tabular}{|l|} 
Otsuka \\
Pharmaceutical \\
Co., Ltd. \\
Ono Pharmaceutical \\
Co., Ltd. \\
\end{tabular} & & & & & & & \\
\hline \begin{tabular}{|l|} 
Members: \\
Shintaro \\
Kinugawa \\
\end{tabular} & & & & & & & & \begin{tabular}{|l|} 
Actelion \\
Pharmaceuticals \\
Japan Ltd. \\
\end{tabular} & & & & & & \\
\hline $\begin{array}{l}\text { Members: } \\
\text { Miyuki Makaya }\end{array}$ & & & & \begin{tabular}{|l} 
Otsuka \\
Pharmaceutical \\
Co., Ltd.
\end{tabular} & & & & & & & & & & \\
\hline $\begin{array}{l}\text { Members: } \\
\text { Toyoaki } \\
\text { Murohara }\end{array}$ & & & & 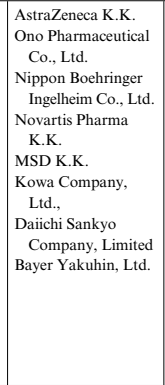 & & & \begin{tabular}{|l|} 
Otsuka \\
Pharmaceutical \\
Co.,Ltd. \\
Bayer Yakuhin, Ltd. \\
Tejiin Pharma \\
Limited \\
Daiich Sankyo \\
Company, Limited \\
Takeda \\
Pharmaceutical \\
Company Limited \\
Sumitomo \\
Dainippon Pharma \\
Co. Ltd. \\
Mitsubishi Tanabe \\
Pharma \\
Corporation \\
MSD K.K.
\end{tabular} & & & & & & & \\
\hline $\begin{array}{l}\text { Members: } \\
\text { Koichi Node }\end{array}$ & & & & \begin{tabular}{|l|} 
MSD K.K. \\
Astellas Pharma Inc. \\
AstraZeneca K.K. \\
Novartis Pharma \\
K.K. \\
Bayer Yakuhin, Ltd. \\
Kowa Company, \\
Ltd., \\
Ono Pharmaceutical \\
Co., Ltd. \\
Otsuka \\
Pharmaceutical \\
Co. Ltd. \\
Daiichi Sankyo \\
Company, Limited \\
Mitsubishh Tanabe \\
Pharma \\
Corporation \\
Eli Lilly Japan K.. \\
Nippon Boenringer \\
Ingeelheim Co., Ltd. \\
Takeda \\
Pharmaceutical \\
Company Limited
\end{tabular} & & \begin{tabular}{|l} 
Astellas Pharma Inc. \\
TERUMO \\
CORPORATION \\
Asahi Kasei \\
Corporation. \\
Teijin Pharma \\
Limited \\
Mitsubishi Tanabe \\
Pharma \\
Corporation \\
Nippon Boehringer \\
Ingelheim Co., Ltd.
\end{tabular} & \begin{tabular}{|l} 
Bayer Yakuhin, Ltd. \\
Daiichi Sankyo \\
Company, Limited \\
Teijin Pharma \\
Limited \\
Medtronic Japan \\
Co. Ltd. \\
Takeda \\
Pharmaceutical \\
Company Limited \\
\end{tabular} & & & & & & & \\
\hline
\end{tabular}




\begin{tabular}{|c|c|c|c|c|c|c|c|c|c|c|c|c|c|c|}
\hline \multirow{2}{*}{ Author } & \multicolumn{9}{|c|}{ Member's own declaration items } & \multicolumn{3}{|c|}{$\begin{array}{l}\text { COI of the marital partner, first- } \\
\text { degree family members, or those } \\
\text { who share income and property }\end{array}$} & \multicolumn{2}{|c|}{ 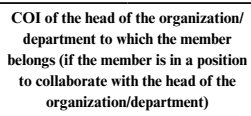 } \\
\hline & \begin{tabular}{c|} 
Employer/ \\
leadership \\
position \\
(private \\
company)
\end{tabular} & Stakeholder & $\begin{array}{c}\text { Patent } \\
\text { royalty }\end{array}$ & Honorarium & $\begin{array}{l}\text { Payment for } \\
\text { manuscripts }\end{array}$ & Research grant & $\begin{array}{c}\text { Scholarship } \\
\text { (educational) grant }\end{array}$ & Endowed chair & $\begin{array}{c}\text { Other } \\
\text { rewards }\end{array}$ & $\begin{array}{c}\text { Employer/ } \\
\text { leadership } \\
\text { position } \\
\text { (private } \\
\text { company) }\end{array}$ & Stakeholder & $\begin{array}{l}\text { Patent } \\
\text { royalty }\end{array}$ & Research grant & $\begin{array}{c}\text { Scholarship } \\
\text { (educational) } \\
\text { grant }\end{array}$ \\
\hline $\begin{array}{l}\text { Members: } \\
\text { Yoshihiko Saito }\end{array}$ & & & & $\begin{array}{l}\text { Novartis Pharma } \\
\text { K.K. } \\
\text { Daiichi Sankyo } \\
\text { Company, Limited } \\
\text { Otsuka } \\
\text { Pharmaceutical } \\
\text { Co., Ltd. } \\
\text { Mitsubishi Tanabe } \\
\text { Pharma } \\
\text { Corporation } \\
\text { Piizer Japan Inc. }\end{array}$ & & $\begin{array}{l}\text { Roche Diagnostics } \\
\text { K.K. } \\
\text { Amgen K.K. } \\
\text { Novartis Pharma } \\
\text { K.K. } \\
\text { TERUMO } \\
\text { CRURPORATION } \\
\text { Kowa } \\
\text { Pharmaceutical } \\
\text { Co., Ltd. } \\
\text { Daiichi Sankyo } \\
\text { Company, Limited }\end{array}$ & 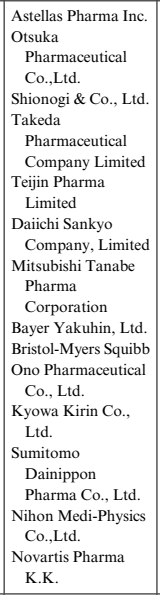 & & & & & & & \\
\hline $\begin{array}{l}\text { Members: } \\
\text { Yasushi Sakata }\end{array}$ & & & & \begin{tabular}{l|} 
AstraZeneca K.K. \\
Novartis Pharma \\
K.K. \\
Bayer Yakuhin, Ltd. \\
Otsuka \\
Pharmaceutical \\
Co., LLd. \\
Daiichi Sankyo \\
Company, Limited \\
Mitsubishi Tanabe \\
Pharma \\
Corporation \\
Nippon Boehringer \\
Ingelheim Co., Ltd. \\
Medtronic Japan \\
Co., Ltd.
\end{tabular} & & 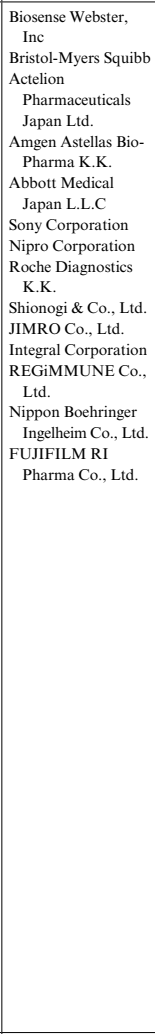 & 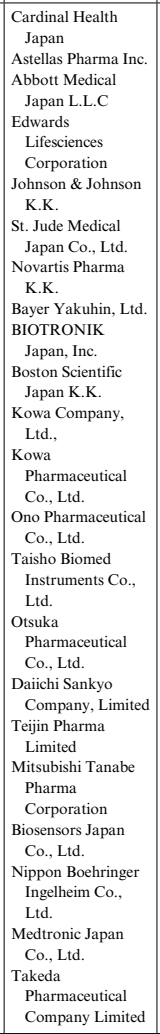 & & & & & & & \\
\hline $\begin{array}{l}\text { Members: } \\
\text { Wataru Shimizu }\end{array}$ & & & & $\begin{array}{l}\text { Bayer Yakuhin, Ltd. } \\
\text { Pfizer Japan Inc. } \\
\text { Bristol-Myers Squibb } \\
\text { Ono Pharmaceutical } \\
\text { Co., Ltd. } \\
\text { Daiich Sankyo } \\
\text { Company, Limited } \\
\text { Nippon Boehriger } \\
\text { Ingelheim Co., Ltd. }\end{array}$ & & $\begin{array}{l}\text { Daiichi Sankyo } \\
\text { Company, Limited } \\
\text { Nippon Boehringer } \\
\text { Ingelheim Co., Ltd. }\end{array}$ & \begin{tabular}{|l|} 
Abbott Medical \\
Japan L.LC. \\
Bristo-Myers Squibb \\
Ono Pharmaceutical \\
C...Ldd. \\
Daiichi Sankyo \\
Company, Limited \\
Nippon Boehringer \\
Ingeheim Co., \\
Ltd.
\end{tabular} & & & & & & & \\
\hline
\end{tabular}




\begin{tabular}{|c|c|c|c|c|c|c|c|c|c|c|c|c|c|c|}
\hline \multirow{2}{*}{ Author } & \multicolumn{9}{|c|}{ Member's own declaration items } & \multicolumn{3}{|c|}{$\begin{array}{l}\text { COI of the marital partner, first- } \\
\text { degree family members, or those } \\
\text { who share income and property }\end{array}$} & \multicolumn{2}{|c|}{$\begin{array}{l}\text { COI of the head of the organization/ } \\
\text { department to which the member } \\
\text { belongs (if the member is in a position } \\
\text { to collaborate with the head of the } \\
\text { organization/department) }\end{array}$} \\
\hline & \begin{tabular}{|c|} 
Employer/ \\
leadership \\
position \\
(private \\
company) \\
\end{tabular} & Stakeholder & \begin{tabular}{|l|}
$\begin{array}{l}\text { Patent } \\
\text { royalty }\end{array}$ \\
\end{tabular} & Honorarium & $\begin{array}{l}\text { Payment for } \\
\text { manuscripts }\end{array}$ & Research grant & $\begin{array}{c}\text { Scholarship } \\
\text { (educational) grant }\end{array}$ & Endowed chair & \begin{tabular}{c|} 
Other \\
rewards \\
\end{tabular} & \begin{tabular}{|c|} 
Employer/ \\
leadership \\
position \\
(private \\
company) \\
\end{tabular} & Stakeholder & $\begin{array}{l}\text { Patent } \\
\text { royalty }\end{array}$ & Research grant & $\begin{array}{c}\text { Scholarship } \\
\text { (educational) } \\
\text { grant }\end{array}$ \\
\hline $\begin{array}{l}\text { Members: } \\
\text { Kazuhiro } \\
\text { Yamamoto }\end{array}$ & & & & 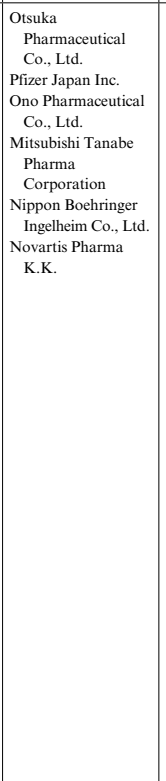 & & & 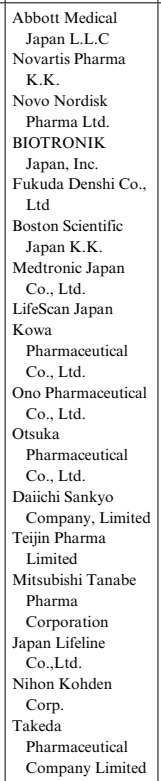 & & & & & & & \\
\hline $\begin{array}{l}\text { Collaborators: } \\
\text { Yasuko Bando }\end{array}$ & & & & 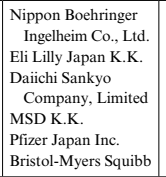 & & & & & & & & & & \\
\hline $\begin{array}{l}\text { Collaborators: } \\
\text { Yu-ki Iwasaki }\end{array}$ & & & & & & \begin{tabular}{|c|} 
Daiichi Sankyo \\
Company, Limited
\end{tabular} & & & & & & & & \\
\hline $\begin{array}{l}\text { Collaborators: } \\
\text { Shogo Oishi }\end{array}$ & & & & $\begin{array}{l}\text { Daiichi Sankyo } \\
\text { Company, Limited } \\
\text { Otsuka } \\
\text { Pharmaceutical } \\
\text { Co., Ltd. }\end{array}$ & & & & & & & & & & \\
\hline $\begin{array}{l}\text { Collaborators: } \\
\text { Atsushi Tanaka }\end{array}$ & & & & $\begin{array}{c}\text { Nippon Boehringer } \\
\text { Ingelheim Co., Ltd. }\end{array}$ & & $\begin{array}{l}\text { GlaxoSmithKline } \\
\text { K.K. }\end{array}$ & & & & & & & \begin{tabular}{|l|} 
Astellas Pharma \\
Inc. \\
Asahi Kasei \\
Corporation. \\
Teiji Pharma \\
Limited \\
Mitsubishi \\
Tanabe \\
Pharma \\
Corporation \\
Nippon \\
Boehringer \\
Ingelheim Co., \\
Ltd. \\
\end{tabular} & \begin{tabular}{|l} 
Teijin Pharma \\
Limited \\
Daiichi Sankyo \\
Company, \\
Limited \\
Bayer Yakuhin, \\
Ltd.
\end{tabular} \\
\hline \begin{tabular}{|l|} 
Independent \\
Assessment \\
Committee: \\
Takashi Akasaka
\end{tabular} & & & & \begin{tabular}{|l|} 
Abbott Vascular \\
Japan Co., Ltd. \\
Abbott Medical \\
Japan L.L.C \\
Nipro Corporation \\
Otsuka \\
Pharmaceutical \\
Co., Lte. \\
Daiichi Sanky \\
Company, Limited \\
Nihon Medi-Physics \\
Co.,Ltd. \\
\end{tabular} & $\begin{array}{l}\text { Bunkodo Co., } \\
\text { Ltd. }\end{array}$ & \begin{tabular}{|l|} 
Daiichi Sankyo \\
Company, Limited \\
Nihon Medi-Physics \\
Co.,Ltd.
\end{tabular} & \begin{tabular}{|c|}
$\begin{array}{c}\text { Abbott Vascular } \\
\text { Japan Co., Ltd. } \\
\text { Bayer Yakuhin, Ltd. }\end{array}$ \\
\end{tabular} & \begin{tabular}{|c|} 
Abbott Vascular \\
Japan Co., Ltd. \\
TERUMO \\
CORPORATION \\
Nipro \\
Corporation \\
\end{tabular} & & & & & & \\
\hline $\begin{array}{l}\text { Independent } \\
\text { Assessment } \\
\text { Committe: } \\
\text { Minoru Ono }\end{array}$ & & & & $\begin{array}{l}\text { Sun Medical } \\
\text { Technology } \\
\text { Research Corp. } \\
\text { Medtronic Japan } \\
\text { Co., Ltd. } \\
\text { Century Medical, Inc. } \\
\text { Nipro Corporation }\end{array}$ & & $\begin{array}{l}\text { Kono Seisakusho } \\
\text { Co., ttd. }\end{array}$ & \begin{tabular}{|l|} 
Astellas Pharma Inc. \\
Sun Medical \\
Technology \\
Research Corp. \\
NIKON \\
CORPORATION \\
Nissan Chemical \\
Corporation \\
\end{tabular} & & & & & & & \\
\hline
\end{tabular}




\begin{tabular}{|c|c|c|c|c|c|c|c|c|c|c|c|c|c|c|}
\hline \multirow{2}{*}{ Author } & \multicolumn{9}{|c|}{ Member's own declaration items } & \multicolumn{3}{|c|}{$\begin{array}{l}\text { COI of the marital partner, first- } \\
\text { degree family members, or those } \\
\text { who share income and property }\end{array}$} & \multicolumn{2}{|c|}{$\begin{array}{l}\text { COI of the head of the organization/ } \\
\text { department to which the member } \\
\text { belongs (if the member is in a position } \\
\text { to collaborate with the head of the } \\
\text { organization/department) }\end{array}$} \\
\hline & \begin{tabular}{c|} 
Employer/ \\
leadership \\
position \\
(private \\
company)
\end{tabular} & Stakeholder & $\begin{array}{l}\text { Patent } \\
\text { royalty }\end{array}$ & Honorarium & $\begin{array}{l}\text { Payment for } \\
\text { manuscripts }\end{array}$ & Research grant & $\begin{array}{c}\text { Scholarship } \\
\text { (educational) grant }\end{array}$ & Endowed chair & $\begin{array}{c}\text { Other } \\
\text { rewards }\end{array}$ & \begin{tabular}{|c|} 
Employer/ \\
leadership \\
position \\
(private \\
company)
\end{tabular} & Stakeholder & $\begin{array}{l}\text { Patent } \\
\text { royalty }\end{array}$ & Research grant & $\begin{array}{l}\text { Scholarship } \\
\text { (educational) } \\
\text { grant }\end{array}$ \\
\hline $\begin{array}{l}\text { Independent } \\
\text { Assessment } \\
\text { Committee: } \\
\text { Takeshi Kimura }\end{array}$ & & & & \begin{tabular}{|l|} 
Abbott Vascular \\
Japan Co., Ltd. \\
Sanofi K.K. \\
Bristol-Myers Squibb \\
Boston Scientific \\
Japan K.K. \\
Kowa Company, \\
Ltd., \\
Nippon Boehringer \\
Ingelheim Co., Ltd.
\end{tabular} & & $\begin{array}{l}\text { Edwards Lifesciences } \\
\text { Corporation } \\
\text { EP-CRSU Co., Ltd. } \\
\text { Pfizer Japan Inc. } \\
\text { Kowa Company, } \\
\text { Ltd., } \\
\text { Daiichi Sankyo } \\
\text { Company, Limited }\end{array}$ & \begin{tabular}{|l|} 
Astellas Pharma Inc. \\
MID,Inc. \\
Otsuka \\
Pharmaceutical \\
Co., Ltd. \\
Daiichi Sankyo \\
Company, Limited \\
Mitsubishi Tanabe \\
Pharma \\
Corporation \\
Nippon Boehringer \\
Ingelheim Co., \\
Ltd. \\
Takeda \\
Pharmaceutical \\
Company Limited \\
\end{tabular} & & & & & & & \\
\hline $\begin{array}{l}\text { Independent } \\
\text { Assessment } \\
\text { Committee: } \\
\text { Shun Kosaka }\end{array}$ & & & & \begin{tabular}{|l|} 
Bristol-Myers Squibb \\
Pfizer Japan Inc. \\
Bayer Yakuhin, Ltd. \\
AstraZeneca K.K. \\
\end{tabular} & & $\begin{array}{l}\text { Bristol-Myers Squibb } \\
\text { Daiichi Sankyo } \\
\text { Company, Limited }\end{array}$ & & & & & & & & \\
\hline $\begin{array}{l}\text { Independent } \\
\text { Assessment } \\
\text { Committee: } \\
\text { Masami Kosuge }\end{array}$ & & & & \begin{tabular}{|l} 
Daiichi Sankyo \\
Company, Limited
\end{tabular} & & & & & & & & & & $\begin{array}{l}\text { Abbott Vascular } \\
\text { Japan Co., } \\
\text { Ltd. } \\
\text { Abbott Medical } \\
\text { Japan L.L.C } \\
\text { Nipro } \\
\text { Corporation }\end{array}$ \\
\hline $\begin{array}{l}\text { Independent } \\
\text { Assessment } \\
\text { Committee: } \\
\text { Shin-ichi } \\
\text { Momomura }\end{array}$ & & & & $\begin{array}{l}\text { Otsuka } \\
\text { Pharmaceutical } \\
\text { Co., Ltd. } \\
\text { Nippon Boehringer } \\
\text { Ingelheim Co., Ltd. } \\
\text { Novartis Pharma } \\
\text { K.K. } \\
\text { Amgen K.K. } \\
\text { Ono Pharmaceutical } \\
\text { Co., Ltd. } \\
\text { AstraZeneca K.K. }\end{array}$ & & & & & & & & & & \\
\hline $\begin{array}{l}\text { No relevant } \mathrm{COI} \\
\text { Collaborators: } \mathrm{Y} \\
\text { Collaborators: Is } \\
\text { Collaborators: } \mathrm{H} \\
\text { Collaborators: } \mathrm{A}\end{array}$ & $\begin{array}{l}\text { the followin } \\
\text { aru Kinuge } \\
\text { Mizote, no } \\
\text { i Nakagaw: } \\
\text { Okada. not }\end{array}$ & $\begin{array}{l}\text { Ing authors. } \\
\text { zasa, none } \\
\text { ne } \\
\text { va, none } \\
\text { ne }\end{array}$ & & & & & & & & & & & & \\
\hline
\end{tabular}

